\title{
CORDEX-WRF v1.3: development of a module for the Weather Research and Forecasting (WRF) model to support the CORDEX community
}

\author{
Lluís Fita $^{1}$, Jan Polcher ${ }^{2}$, Theodore M. Giannaros ${ }^{3}$, Torge Lorenz ${ }^{4}$, Josipa Milovac ${ }^{5}$, Giannis Sofiadis ${ }^{6}$, \\ Eleni Katragkou ${ }^{6}$, and Sophie Bastin ${ }^{7}$ \\ ${ }^{1}$ Centro de Investigaciones del Mar y la Atmósfera (CIMA), CONICET-UBA, CNRS UMI-IFAECI, \\ C. A. Buenos Aires, Argentina \\ ${ }^{2}$ Laboratoire de Météorologie Dynamique (LMD), IPSL, CNRS, École Polytechnique, Palaisseau, France \\ ${ }^{3}$ National Observatory of Athens (NOA) - Institute for Environmental Research and \\ Sustainable Development (IERSD), Penteli, Greece \\ ${ }^{4}$ NORCE Norwegian Research Centre, Bjerknes Centre for Climate Research, Bergen, Norway \\ ${ }^{5}$ Institute of Physics and Meteorology, University of Hohenheim, Stuttgart, Germany \\ ${ }^{6}$ Department of Meteorology and Climatology, School of Geology, Aristotle University \\ of Thessaloniki (AUTH), Thessaloniki, Greece \\ ${ }^{7}$ Laboratoire Atmosphères, Milieux, Observations Spatiales (LATMOS)/IPSL, UVSQ Université Paris-Saclay, \\ Sorbonne Université, CNRS, Guyancourt, France \\ Correspondence: Lluís Fita (lluis.fita@ cima.fcen.uba.ar)
}

Received: 24 September 2018 - Discussion started: 1 November 2018

Revised: 1 March 2019 - Accepted: 5 March 2019 - Published: 22 March 2019

\begin{abstract}
The Coordinated Regional Climate Downscaling Experiment (CORDEX) is a scientific effort of the World Climate Research Program (WRCP) for the coordination of regional climate initiatives. In order to accept an experiment, CORDEX provides experiment guidelines, specifications of regional domains, and data access and archiving. CORDEX experiments are important to study climate at the regional scale, and at the same time, they also have a very prominent role in providing regional climate data of high quality. Data requirements are intended to cover all the possible needs of stakeholders and scientists working on climate change mitigation and adaptation policies in various scientific communities. The required data and diagnostics are grouped into different levels of frequency and priority, and some of them even have to be provided as statistics (minimum, maximum, mean) over different time periods. Most commonly, scientists need to post-process the raw output of regional climate models, since the latter was not originally designed to meet the specific CORDEX data requirements. This postprocessing procedure includes the computation of diagnostics, statistics, and final homogenization of the data, which
\end{abstract}

is often computationally costly and time-consuming. Therefore, the development of specialized software and/or code is required. The current paper presents the development of a specialized module (version 1.3) for the Weather Research and Forecasting (WRF) model capable of outputting the required CORDEX variables. Additional diagnostic variables not required by CORDEX, but of potential interest to the regional climate modeling community, are also included in the module. "Generic" definitions of variables are adopted in order to overcome the model and/or physics parameterization dependence of certain diagnostics and variables, thus facilitating a robust comparison among simulations. The module is computationally optimized, and the output is divided into different priority levels following CORDEX specifications (Core, Tier 1, and additional) by selecting pre-compilation flags. This implementation of the module does not add a significant extra cost when running the model; for example, the addition of the Core variables slows the model time step by less than a $5 \%$. The use of the module reduces the requirements of disk storage by about a $50 \%$. The module performs 
neither additional statistics over different periods of time nor homogenization of the output data.

\section{Introduction}

Regional climate downscaling pursues the use of limited area models (LAMs) to perform climate studies and analysis (Giorgi and Mearns, 1991). It is based on the premise that, by using LAMs, modelers can simulate the climate over a region at higher resolution compared to global climate models (GCMs). Therefore, certain aspects of the climate system can be better represented due to the higher resolution and higher complexity of the parameterizations (inherent in LAMs) used to simulate physical processes, which cannot be explicitly resolved (e.g., shortwave and longwave radiation, turbulence, dynamics of water species). This methodology has been widely used for studying climate features, connections, and processes (Jaeger and Seneviratne, 2011; Knist et al., 2014; Kotlarski et al., 2017) and to produce climate data within the scope of continental, national, or regional climate change studies.

The Coordinated Regional Climate Downscaling Experiment (CORDEX; http://www.cordex.org/, last access: 18 March 2019) of the World Climate Research Program (WRCP) aims to organize different initiatives devoted to regional climate all around the globe following a similar experimental design (Giorgi et al., 2009; Giorgi and Gutowski, 2015). CORDEX, with the second phase currently under discussion, attempts to establish a series of criteria for dynamical downscaling experiments, which includes setting common domain specifications and horizontal resolutions in order to make sure that all the continental areas of the Earth are under study (e.g., in 2010 Africa was a priority and researchers worldwide volunteered to contribute with their own simulations). Furthermore, CORDEX sets a series of model configurations (e.g., GCM forcing, greenhouse gas (GHG) evolution) to ensure that model simulations are carried out under similar conditions and are therefore intercomparable. At the same time, CORDEX requires a list of variables necessary for the later use of model data in multimodel analysis and other climate-related research activities like climate change mitigation, adaptation, and stakeholder decision-making policies. In order to maximize and facilitate data access (mostly made available by the Earth System Grid Federation, ESGF; https://esgf.llnl.gov/, last access: 18 March 2019), these data also have to be provided following a series of homogenization criteria known as climate and forecast (CF) compliant (http://cfconventions.org/, last access: 18 March 2019), which come from the Coupled Model Intercomparison Project (CMIP) exercises. The list of variables required by CORDEX consists of standard model fields and some diagnostics in certain frequencies, as well as statistical aggregations such as minimum, maximum, or mean, for a given period. These variables are grouped into different priority levels (Core, Tier 1, and Tier 2), with Core being the mandatory list of variables (see Appendix A for more details).

The production of these datasets is not a simple task and usually represents a big issue for the modeling community. Regional climate experiments tend to produce large amounts of data, since scientists simulate long time periods at high resolutions. Modelers have to code software at least capable of (1) computing a series of diagnostics, (2) concatenating model output, (3) performing statistical temporal computations, and (4) producing data following CF-compliant (i.e., cmorization) criteria in NetCDF format (NetCDF stands for Network Common Data Form, a binary self-describing and machine-independent file format; https://www.unidata.ucar. edu/software/netcdf/, last access: 18 March 2019). Aside from being time-consuming due to complexity and process management, this codification also implies certain duplication of huge datasets and additional consumption of computational resources.

Several tools (e.g., NetCDF operators - NCOs, climate data operators - CDOs) exist to facilitate the manipulation of NetCDF files (extract, concatenate, average, join, etc.), and there are also other post-processing initiatives that have been made available, especially to the Weather Research and Forecasting (WRF; http://www. mmm.ucar.edu/wrf/users/, last access: 18 March 2019; Skamarock et al., 2008) community: WRF NetCDF Extract\&Join (wrfncxnj; http://www.meteo.unican.es/wiki/ cordexwrf/SoftwareTools/WrfncXnj, last access: 18 March 2019), wrfout_to_cf.ncl (http://foehn.colorado.edu/wrfout_ to_cf/, last access: 18 March 2019), METtools (https:// dtcenter.org/met/users/metoverview/index.php, last access: 18 March 2019), and Climate Model Output Rewriter (CMOR; https://cmor.llnl.gov/, last access: 18 March 2019).

WRF is a popular model for regional climate downscaling experiments. It is used worldwide in different CORDEX domains (Fu et al., 2005; Mearns et al., 2009; Nikulin et al., 2012; Domínguez et al., 2013; Vautard et al., 2013; Evans et al., 2014; Katragkou et al., 2015; Ruti et al., 2016). The model was initially designed for short-term simulations at high resolutions, but a series of modifications that have been introduced to the model code so far have enhanced its capabilities and made it appropriate for climate experiments (Fita et al., 2010). Since WRF does not directly provide most of the required variables for CORDEX and due to the complexity of the post-processing procedures, many existing WRF climate simulations are not publicly available to the community.

This new module comes to complement the modifications introduced in CLimate WRF (clWRF; http://www.meteo. unican.es/wiki/cordexwrf/SoftwareTools/ClWrf, last access: 18 March 2019; Fita et al., 2010). In clWRF climate statistical values (such as minimum, maximum, and mean values) of certain surface variables were introduced into the 
model. At the same time, the evolution of greenhouse gases $\left(\mathrm{CO}_{2}, \mathrm{~N}_{2} \mathrm{O}, \mathrm{CH}_{4}, \mathrm{CFC}-11, \mathrm{CFC}-12\right)$ can be selected from an ASCII file instead of being hard-coded. Before these modifications, WRF users could only retrieve statistical values by post-processing the standard output of the model (at a certain frequency). With the clWRF modifications (incorporated into the WRF source code since version 3.5) statistical values are directly computed during model integration. This new CORDEX module proposes one step further by incorporating a series of new variables and diagnostics that are important for climate studies and WRF users can currently only obtain by post-processing the standard model output. At the same time, additional variables have been added into the WRF capabilities of output at pressure levels. In the current module version if the "adaptive time-step" option is enabled in WRF, some diagnostics related to time-step selection (e.g., precipitation, sunshine duration, etc.) will not be calculated properly because there is no proper adaptation.

We present a series of modifications to the model code and a new module (version 1.3) that will enable climate researchers using WRF to get almost all the CORDEX variables directly in the model output. With the use of this module, production of the data for regional climate purposes will become easier and faster. These modifications directly provide the required fields and variables (Core and almost all Tier 1; see Appendix A for more details) during model integration and aim to avoid the post-processing of the WRF output up to a certain level. However, in this version, they do not cover all the previously mentioned aspects of the task, such as computation of statistics and the cmorization of the data.

New variables and diagnostics will be provided at the user-selected output frequency. The user still needs to postprocess the data in order to obtain the different statistics required by CORDEX at daily, monthly, and seasonal periods. The data cmorization can be defined as a series of processes that need to be applied to the model output in order to meet the standards provided under the CF guidelines (which follows the CMOR standard; https://pcmdi.github.io/cmor-site/, last access: 18 March 2019). These guidelines are designed to facilitate comparison between climate models, and they represent the standard for the Coupled Model Intercomparison Project (CMIP; https://cmip.llnl.gov/, last access: 18 March 2019). This standardization includes the file names, variable names, and metadata (units, standard name, and long name), specification of geographical projections, and time axis. In order to achieve a complete CF standardization of WRF output in complete agreement with the CF requirements, substantial changes to the WRF input/output (I/O) tools would be required. This would affect backward compatibility and it has been decided to pursue this in upcoming module updates. Therefore, the users of the CORDEX-WRF module will still need to perform part of the standardization. This includes joining and/or concatenating WRF files, making use of standard names and attributes of the variables and file names, and finally providing the right variable with the standard attributes to describe the time coordinate.

The module also aims to establish a series of homogenizations for certain diagnostics. These diagnostics can be computed following different methodologies, and consequently they may be model and/or even physical parameterization dependent. In order to avoid dependency on the model configuration (mainly sensitivity to the choice of the various available physical schemes), and to allow for a fair comparison between different simulations, a series of additional "generic" definitions of some diagnostics are presented when possible.

The modification of the WRF model code was initiated within the development of the regional climate simulation platform from the Institute Pierre Simone Laplace (IPSL) (https://sourcesup.renater.fr/wiki/morcemed/Home, last access: 18 March 2019) and the CORDEX Flagship Pilot Study (CORDEX-FPS), "Europe+Mediterranean; Convective phenomena at high resolution over Europe and the Mediterranean" (Coppola et al., 2018), in order to obtain the variables required for the CORDEX experiment (available at https://www.hymex.org/cordexfps-convection/wiki/doku. php?id=protocol, last access: 18 March 2019) and share the code among WRF users of the CORDEX-FPS experiment.

In this work the complete module is presented, its capabilities are demonstrated, and the results of several diagnostics are shown in order to illustrate the accuracy of the implementation. The initial section of the paper describes the modifications that have been introduced into the code, followed by a description of the variables required by CORDEX. The following section demonstrates the performance tests and gives a description of aspects that are currently missing, but will be added in the upcoming module versions. The paper finishes with a discussion and outlook.

\section{The CORDEX module}

Here we present the module and explain the modifications introduced. The steps necessary in order to compile and use the module are provided as well. For a complete and detailed description of the steps to follow, the reader is referred to the Wiki page of the module: http://wiki.cima.fcen.uba. ar/mediawiki/index.php/CDXWRF (last access: 18 March 2019). The most common README file provided with the module is labeled README. cordex. The module has been implemented following the standards of modularity, which facilitates the upgrading and introduction of new variables to it.

\subsection{WRF code main characteristics}

First, we provide a short description of the WRF code characteristics. The WRF model is written in Fortran 90. It is open access. It consists mainly of two parts: WPS (WRF Prepro- 
cessing System) for the preparation of the initial and boundary conditions and the model itself. The source of the code is not fully provided. A pre-compilation process is carried out in order to automatically write certain parts of the code according to a series of ASCII files, and activation of certain parts of the code rely on pre-compilation flags. With the pre-compilation flags users can determine optional aspects of the model related to technical aspects of the compilation and the use of certain components like the incorporation of the Community Land Model version 4 (Oleson et al., 2010; Lawrence et al., 2011). Large parts of the code that are automatically written are related to the input/output of the model. There are a series of ASCII files provided in the Registry folder of the model called registry. These files contain the characteristics of the variables, mainly the name of the variable during execution, the rank and dimensions of the variable, assigned output file, the name of the variable in the output file, description of the variable, and units. The WRF model keeps all the variables in a Fortran pointer-derived type (called grid). At the same time, the WRF model setup is managed though the use of a Fortran namelist statement that reads the ASCII file called namelist.input, which has different sections. WRF manages the output via different streams (usually up to 23) with the standard output (wrfout+ files) being the number 0 . The WRF model integrates the atmosphere using $\eta$ as a vertical variable (see more detail in Skamarock et al., 2008) defined in Eq. (1) (where $p_{\text {surf }}$ is surface pressure, $p_{\text {top }}$ is pressure at top, $p$ is hydrostatic pressure, $\eta=1$ at the surface, and $\eta=0$ at the top of the atmosphere). WRF uses three horizontal grids (two $\mathrm{C}$ grids staggered for winds) and two sets of vertical coordinates (one staggered known as the "full" $\eta$ levels, with the un-staggered as the "half"- $\eta$ levels).

$\eta=\frac{p-p_{\text {top }}}{p_{\text {surf }}-p_{\text {top }}}$

For further technical details of the model, the reader is referred to WRF technical notes (http: //www2.mmm.ucar.edu/wrf/users/docs/arw_v3.pdf, last access: 18 March 2019; Skamarock et al., 2008) and the user guide (http://www2.mmm.ucar.edu/wrf/users/docs/user_ guide_v4/contents.html, last access: 18 March 2019).

\subsection{Module implementation}

The module is accompanied by a new registry file called Registry/registry.cordex in which the variables and namelist parameters related to the module are defined. The specific setup of the module is managed in the WRF namelist in a new section called cordex. Aside from the modifications of the code of the WRF model, the complete module currently consists of two new modules:

- phys/module_diag_cordex.F, the main module that manages the calls to the variables and performs the necessary accumulations for the calculations of statistical values (e.g., mean, maximum, minimum); and

- phys/module_diagvar_cordex.F, the module that contains the calculations of all the CORDEX variables separated into individual and independent 1-D Fortran subroutines.

A list of detailed information on the modifications introduced is given below.

1. The main call of the CORDEX module (module_diag_cordex.F) has been added to phys/module_diagnostics_driver.F, which accounts for the management of diagnostics, and it has been modified in order to introduce the new pressure-interpolated variables.

2. An input line to the registry.cordex has been added into the general Registry/Registry.EM_COMMON.

3. The complementary pressure-interpolated variables have been introduced in the related registry Registry/registry.diags.

4. The complementary interpolated variables have been added in the module that performs the pressure interpolation (phys/module_diag_pld.F).

5. The initialization of the modified pressure interpolation has been added in dyn_em/start_em.F.

6. Modifications have been introduced in the main/depend.common and phys/Makefile files to get the module compiled.

7. Specific changes for the inclusion of the water budget variables have been introduced in the dyn_em/solve_em.F module in order to get the advection terms of all water species.

8. An ASCII file called README. cordex with the description and synthesized instructions for compilation and use is provided as well.

The model output is grouped into a single file (WRF's auxiliary history output or stream no. 9) with a proposed file name (auxhist9_outname namelist parameter in the \&history section): wrfcordex_d<domain>_<date>, regulated with the standard WRF namelist parameters of output frequency (auxhist9_interval), number of time steps per file (frames_per_auxhist9), and format (io_form_auxhist9). Additional CORDEX variables required at pressure levels have been included in the WRF auxiliary output file number 23 . These introduced CORDEX variables follow the file setup via the currently existing namelist section called diags \&. 


\subsection{Module use}

Before the execution of WRF some preprocessing steps are necessary by the user that encompass the compilation of the code and its specific setup to be used during the execution time of the model. These are described in the following subsections.

\section{Compilation}

Pre-compilation flags need to be defined by the user, depending on his or her requirements. It is necessary to keep in mind that this is done due to efficiency constrains (see below in Sect. 6), although it is not a common procedure in the standard use of WRF. Usually WRF has almost all options available from a single compilation, switching options via the namelist.

Using the pre-compilation flag CORDEXDIAG, the CORDEX Core variables will be produced. The Tier 1 and additional groups of variables can be selected via the additional pre-compilation flag CDXWRF $(C D X W R F=1$ for Tier 1 and $C D X W R F=2$ for Tier 2 and the additionals). The reader is referred to Appendix B for more details about the groups of CORDEX variables associated with each option. The registry file (registry . cordex) has to be manually modified accordingly to the selected pre-compilation flag (uncomment the associated lines).

In order to adapt this derived type to the preselected compilation, it is also necessary to modify the module's specific register file (register.cordex) according to the chosen value given to the additional pre-compilation CDXWRF flag (if used). This is done in a way to control the size of a gridderived type, which has a positive impact on the model performance (see below). For a complete and detailed description of these steps, the reader is referred to the Wiki page of the module at http://wiki.cima.fcen.uba.ar/mediawiki/index. php/CDXWRF.

According to the value given to the pre-compilation CDXWRF flag, a different amount of variables is written out to the wrfcdx output file (see more detail in Appendix B).

- Using CORDEXDIAG and without CDXWRF, all the CORDEX Core variables will be calculated.

- For CDXWRF=1, CORDEX Core+Tier 1 variables are clgvi, clhvi, zmla, and [cape/cin/zlfc/plfc/lidx] $\{\min /$ max/mean $\}$.

- $\mathrm{CDXWRF}=2$ is as $\mathrm{CDXWRF}=1$, plus additional 3 -D variables at the model $\eta$ level (ua, va, ws, ta, press, zg, hur, hus), 2-D variables (tfog, fogvisblty $\{\min / \max /$ mean $\}, \quad \operatorname{tds}\{\min / \max / \operatorname{mean}\}), \quad$ and the water budget variables (wbacdiabh, wbacpw, wbacpw $[\mathrm{c} / \mathrm{r} / \mathrm{s} / \mathrm{i} / \mathrm{g} / \mathrm{h}]$, wbacf, $\quad$ wbacf $[\mathrm{c} / \mathrm{r} / \mathrm{s} / \mathrm{i} / \mathrm{g} / \mathrm{h}]$, wbacz, $\quad$ wbacz $[\mathrm{c} / \mathrm{r} / \mathrm{s} / \mathrm{i} / \mathrm{g} / \mathrm{h}], \quad$ wbacdiabh $\{1 / \mathrm{m} / \mathrm{h}\}$, wbacpw $\{1 / \mathrm{m} / \mathrm{h}\}, \quad \quad$ wbacpw $\{1 / \mathrm{m} / \mathrm{h}\}[\mathrm{c} / \mathrm{r} / \mathrm{s} / \mathrm{i} / \mathrm{g} / \mathrm{h}]$, $\operatorname{wbacf}\{1 / \mathrm{m} / \mathrm{h}\}, \quad \quad \operatorname{wbacf}\{1 / \mathrm{m} / \mathrm{h}\}[\mathrm{c} / \mathrm{r} / \mathrm{s} / \mathrm{i} / \mathrm{g} / \mathrm{h}]$ $\operatorname{wbacz}\{1 / \mathrm{m} / \mathrm{h}\}$, $\operatorname{wbacz}\{1 / \mathrm{m} / \mathrm{h}\}[\mathrm{c} / \mathrm{r} / \mathrm{s} / \mathrm{i} / \mathrm{g} / \mathrm{h}])$.

Moreover, the code also accounts for instantaneous CORDEX variables provided as statistics (e.g., capemean, tdsmax, or all the water budget variables). In order to get them, the user must follow certain modifications of the code (and recompilation) in phys/module_diag_cordex.F, phys/module_diagnostics_driver.F, and in the registry file registry.cordex.

\subsection{Usage}

Modifications of the module include two main sets of variables: (1) new variables and diagnostics and (2) additional variables interpolated at pressure levels. These two sets of variables are provided in two separated files. A new auxiliary output file in the ninth stream provides all the new variables and diagnostics required by CORDEX. Additional pressureinterpolated variables are included in the 23rd stream. Each of these files has to be set up in the namelist in the same way as with the standard WRF output files.

A new section labeled cordex has to be added into the WRF's namelist, which allows users to choose or set up different options of the module. The description of all the available options is provided in Table 1. In this section the user is required to choose the implementation of the diagnostics to use, provide values to some parameters for certain diagnostics, and activate or deactivate some of the most computationally costly diagnostics. Default values for all the options are provided in order to facilitate the use of the module.

This module has been tested under different highperformance computing (HPC) environments and compilations. It has been compiled with two compilers: GFortran and IFORT. Different parallelization paradigms include serial, distributed memory, and hybrid (distributed and shared), as well as the parallelized version of the NetCDF libraries. The tests have been performed mainly using two-nested domains with the second one being at convection-permitting resolution (no cumulus scheme activated). Under all these circumstances the module worked as expected.

Since the current version (v1.3) of the module, a text message with the version of the module has been printed in the standard output at the first time step of the model run in order to facilitate the detection of the module version that is being used.

\section{CORDEX variables}

CORDEX requires a series of mandatory variables grouped into the Core level and additional variables grouped into Tier 1 and Tier 2 levels. Furthermore, CORDEX also requires statistical values of specific variables, besides the instanta- 
Table 1. Setup parameters of the module_diag_cordex module for the WRF namelist contained in the cordex section. See the sections on variables for more details on the meaning of each methodology. The methodologies preferred by CORDEX are marked by ${ }^{\mathrm{a}}$, and the ones without preference by CORDEX are marked by ${ }^{\mathrm{b}}$; in these cases, users can select the method according to their experience.

\begin{tabular}{|c|c|c|}
\hline Name and value & Description & Default value \\
\hline output_cordex $=0$ & CORDEX diagnostic deactivation & 0 \\
\hline output_cordex $=1$ & CORDEX diagnostic activation & 0 \\
\hline psl_diag $=1$ & $\begin{array}{l}\text { sea level pressure diagnostic following hydrostatic Shuell correction (Stackpole and } \\
\text { Cooley, 1970) }\end{array}$ & 3 \\
\hline psl_diag $=2$ & psl diagnostic following a target pressure (Benjamin and Miller, 1990) & 3 \\
\hline psl_diag $=3$ & psl diagnostic following ECMWF method (Yesad, 2015) & $3^{\mathrm{a}}$ \\
\hline psmooth $=5$ & $\begin{array}{l}\text { number of passes of neighbor filtering (mean of the grid point with its eight neigh- } \\
\text { bors) of psfc (only for psl_diag=2) }\end{array}$ & 5 \\
\hline ptarget $=70000$. & pressure $(\mathrm{Pa})$ target to be used by psl_diag $=2$ & 70000. \\
\hline wsgs_diag $=1$ & wind-gust diagnostic following Brasseur (2001) & $1^{\mathrm{b}}$ \\
\hline wsgs_diag $=2$ & wind gust following heavy precipitation method & 1 \\
\hline output_wb $=0$ & deactivation of the computation of water budget variables (Fita and Flaounas, 2018) & 0 \\
\hline output_wb = 1 & activation of the computation of water budget variables & 0 \\
\hline wsz100_diag $=1$ & wind extrapolation at $\mathrm{z} 100 \mathrm{~m} \_$wind using power-law method & $1^{\mathrm{b}}$ \\
\hline wsz100_diag $=2$ & wind extrapolation at z100m_wind using logarithmic-law method & 1 \\
\hline wsz100_diag = 3 & wind extrapolation at z100m_wind using Monin-Obukhov method & 1 \\
\hline $\mathrm{z} 100 \mathrm{~m} \_$wind $=100$. & height $(\mathrm{m})$ to extrapolate winds for wsz100_diag & 100 \\
\hline zmlagen_dqv $=0.1$ & $\begin{array}{l}\text { percentage of variation in mixing ratio to determine mixed-layer depth used in zm- } \\
\text { lagen computation (Nielsen-Gammon et al., 2008) }\end{array}$ & $0.1^{\mathrm{b}}$ \\
\hline zmlagen_dtheta $=1.5$ & $\begin{array}{l}\text { increment in K of potential temperature from its minimum within the MLD used in } \\
\text { zmlagen computation }\end{array}$ & $1.5^{\mathrm{b}}$ \\
\hline potevap_diag = 1 & potential evapotranspiration using bulk computation (Manabe, 1969) & $2^{b}$ \\
\hline potevap_diag $=2$ & potential evapotranspiration using Milly92 correction (Milly, 1992) & 2 \\
\hline convxtrm_diag $=0$ & deactivation of diagnostic of extremes from convection indices & 0 \\
\hline convxtrm_diag $=1$ & activation of diagnostic of extremes from convection indices & 0 \\
\hline fogvisibility_diag $=1$ & diagnostic of visibility inside fog (Kunkel, 1984) & $3^{\mathrm{b}}$ \\
\hline fogvisibility_diag $=2$ & Rapid update cycle (RUC) method (Smirnova et al., 2000) & 3 \\
\hline fogvisibility_diag $=3$ & FRAML $50 \%$ prob (Gultepe and Milbrandt, 2010) & 3 \\
\hline fogvars $=1$ & use 3-D variables (hur, closest level to surface) to diagnose fog & $1^{\mathrm{b}}$ \\
\hline fogvars $=2$ & use sfc variables (hurs) to diagnose fog (not available for fogvisibility_diag $=1$ ) & 1 \\
\hline
\end{tabular}

a Preferred by CORDEX. ${ }^{\text {b }}$ No preference is specified by CORDEX.

neous values. To meet the CORDEX specifications, regional climate models have to provide three kind of variables.

- Instantaneous: values obtained at each model integration time step. An instantaneous value represents the field at the given instant of time over the given space encompassed within the grid point.

- Statistics: values obtained as statistics of consecutive instantaneous values along a given period of time. The statistical computation could be minimum, maximum, mean, or accumulated values, as well as the flux. Thus, one statistical variable represents the temporal statistics of the field for a given period of time over the given space encompassed within the grid point. CORDEX guidelines also require different temporal aggregations: 3-hourly, daily, monthly, and seasonal.
- Fixed: values that do not have an evolution in time. These fields are fixed over the simulation.

The WRF I/O file managing system provides an infrastructure for more than 20 different output files (called streams) at the same time. Each file is independently managed, and therefore in the namelist a user has to set up mainly two different options for each output stream: the frequency of an output (frequency of writing out the variables to an output file in minutes, e.g., 30, 60) and the number of frames per file (e.g., for 3-hourly frequency eight frames per file will give a daily output). Variables can be written in multiple streams (selected via the registry + files). During the model integration, at the given time step corresponding to the defined output frequency, data will be written out to the output file. When a given file reaches the selected amount of frames, it is closed and a new one is opened. The file name usually follows the criteria of a given header name (e.g., wrf $\mathrm{cdx}$ for 
this module) and the current date of the simulation, which is also set up in the namelist.

The CORDEX-WRF module is designed to provide the variables using the ninth stream, without reducing any of the capabilities of the model. Following this criterion, the module uses the same structure and components of the model designed to manage its $\mathrm{I} / \mathrm{O}$. This means that the statistical values are directly provided using the internal values between output frequencies. This ensures that, for example, a minimum value would be exactly the minimum value that the model simulated between output times. These variables are re-initialized after each stream output time (see Fig. 1). The WRF model is used in a myriad of applications and regions, and thus it was decided that statistical values will be provided at the selected frequency of the ninth stream. This gives more flexibility, allowing a user to get, e.g., highfrequency outputs. However, this will require the user to perform a post-processed aggregation of the output files in order to provide the required CORDEX statistics at the 3-hourly, daily, monthly, and/or seasonal periods. Users are strongly encouraged to use the output frequencies for the ninth stream, which are easy to combine in order to retrieve the required CORDEX statistics. It is necessary to highlight the fact that the statistics for a given period contained in the ninth stream correspond just to the instant in time of writing the field into the file (e.g., at a $3 \mathrm{~h}$ output frequency the value inside the file at $[\mathrm{HH}]+3: 00: 00$ represents the statistics from $[\mathrm{HH}]: 00: 00$ to $[\mathrm{HH}]+2: 59: 59)$. The WRF I/O does not allow us to produce static or fixed fields, and therefore this group of variables is not provided by the module.

\subsection{Generic methodology}

The list of variables requested by the CORDEX experiment (see the tables in Appendix B) is intended to be useful for the climate change mitigation, adaptation, and decision-making communities. Note that CORDEX-FPS might require other variables or require some of them at a different frequency of output in comparison to a standard CORDEX requested list of variables. Taking into account the performance of the model, variables are computed at specific frequencies: (1) at all time steps when a statistical value (accumulation and/or flux, minimum, maximum, and/or mean) of the variable is required, (2) at the given time step when a variable that is used for the diagnostic is updated following the configuration from the namelist (e.g., cloud-derived variables and the frequency of activation of the radiation scheme), and (3) instantaneous values that are computed only at the time step when the output is written out (see Fig. 1 for more details).

The list of added variables to the existing direct level pressure-interpolated output is provided in Table 2 and gathered in the 23rd auxiliary WRF output file with the standard name wrfpres_d<domain>_<date> (in WRF's namelist notation). At the same time, in order to avoid overloading the execution of WRF, the section of the code with compute variables required at each time step [ $a$ and $s$ kind of variables]

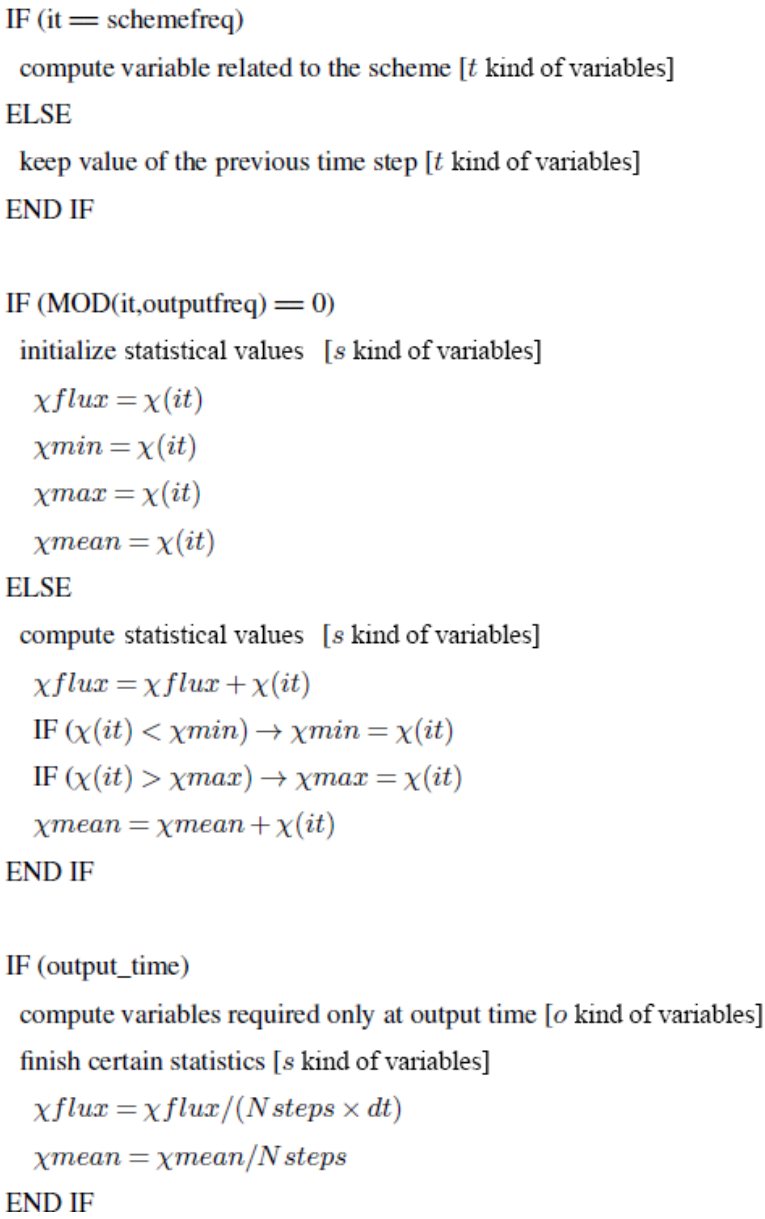

Figure 1. Calculation of diagnostics according to the time step for each kind of variable (see tables in Appendix B).

Table 2. Description of CORDEX additional pressure-interpolated variables provided with the module.

\begin{tabular}{llll}
\hline $\begin{array}{l}\text { CF } \\
\text { name }\end{array}$ & $\begin{array}{l}\text { WRF } \\
\text { name }\end{array}$ & Description & Units \\
\hline hus & HUS_PL & specific humidity & 1 \\
wa & W_PL & vertical wind speed & $\mathrm{m} \mathrm{s}^{-1}$ \\
ua & UER_PL & Earth-rotated wind $x$ component & $\mathrm{m} \mathrm{s}^{-1}$ \\
va & VER_PL & Earth-rotated wind $y$ component & $\mathrm{m} \mathrm{s}^{-1}$ \\
ws & WS_PL & wind speed & $\mathrm{m} \mathrm{s}^{-1}$ \\
\hline
\end{tabular}

the pressure interpolation has also been modified. Now the interpolation is only computed at the time step coincident with the output frequency (also selected in the namelist along with the characteristics of the pressure interpolation).

The different statistical values are initialized (as shown in Fig. 1) at the first time step after output time. More details on how certain diagnostic variables have been integrated and 
implemented in WRF are provided in the following sections. Furthermore, a series of plots accompanying different definitions of the diagnostic variables are presented as well. The intention of these figures is to illustrate the consistency of the implemented diagnostics. These preliminary outcomes are not for validation purposes, but rather to show that the diagnostic variables have been correctly introduced. A complete analysis in order to find the most accurate methodology for the calculation of a certain diagnostic would require devoted climate simulations and enough observations to validate them. Such a validation is out of the scope of this study. We do select "more appropriate" options based on the experience within the scientific community or according to the CORDEX specifications. These options are set as the "default" options within the namelist.

One should be aware that certain diagnostics use variables for their calculation that might only be available when specific physical schemes are selected. When this happens, zero values are returned. This undesired outcome is, when possible, fixed by using a generic definition of the diagnostics.

\subsection{Core variables}

These are the basic variables required by CORDEX. Most of them are standard fields and therefore tend to require simple calculations from the currently available variables from the WRF model. These variables are obtained by setting the precompilation flag CORDEXDIAG and will appear in two different files: 3-D variables at pressure levels (the WRF model internally interpolates them since it uses the $\eta$ coordinate in the vertical) that will appear in the output file with the 23rd stream (mainly called wrfpress) and the 2-D variables in the module's output file wrf cdx.

\subsubsection{3-D at pressure levels}

These are the additional variables that have been added into the WRF pressure-level integration module. Their values will be written in the 23rd output stream in addition to the ones currently available. All of them are instantaneous values.

\section{hus: humidity}

3-D atmospheric specific humidity (hus) ${ }^{1}$ and relative humidity (hur) are computed at the un-staggered model (half-) $\eta$ levels. Specific humidity is simply obtained from the water vapor mixing ratio using Eq. (2) (named QVAPOR in WRF). Relative humidity can be obtained following the ClausiusClapeyron formula and its approximation from the wellknown August-Roche-Magnus formula for saturated water vapor pressure $e_{\mathrm{S}}$ (Eqs. 3, 4, and 5).

$$
\text { hus }=\frac{\text { QVAPOR }}{\text { QVAPOR }+1}
$$

\footnotetext{
${ }^{1}$ From the AMS glossary at http://glossary.ametsoc.org/wiki/ Specific_humidity (last access: 18 March 2019).
}

$e_{\mathrm{S}}=6.1094 \times e^{\frac{17.625 \times \mathrm{tempC}}{\mathrm{tempC}+243.04}}$

$w_{\mathrm{s}}=\frac{0.622 \times e_{\mathrm{s}}}{\text { presshPa }-e_{\mathrm{s}}}$

hur $=\frac{\text { QVAPOR }}{w_{\mathrm{s}} \times 1000}$

Here, tempC is temperature in degrees Celsius $\left({ }^{\circ} \mathrm{C}\right)$, presshPa is pressure $(\mathrm{hPa}), e_{\mathrm{S}}$ is saturated water vapor pressure $(\mathrm{hPa})$, and $w_{\mathrm{s}}$ is the saturated mixing ratio $\left(\mathrm{kg} \mathrm{kg}^{-1}\right)$.

\section{press: air pressure}

The WRF model integrates the perturbation of the pressure field from a reference one. Thus, to obtain the full pressure at un-staggered model $\eta$ levels, the user is required to combine two different fields as shown in Eq. (6):

press $=P+\mathrm{PB}$,

where $\mathrm{PB}$ is WRF base pressure $(\mathrm{Pa})$, and $P$ is WRF perturbation pressure $(\mathrm{Pa})$.

\section{ta: air temperature}

This variable stands for the 3-D atmospheric temperature on un-staggered model $\eta$ levels. WRF model equations are based on the perturbation of potential temperature, and therefore a conversion to actual temperature is required, which is performed as indicated by Eq. (7):

$\mathrm{ta}=(T+300)\left(\frac{P+\mathrm{PB}}{p 0}\right)^{R / C_{p}}$,

where $T$ is WRF 3-D temperature output (as potential temperature perturbation from the base value, which in WRF equals $300 \mathrm{~K})$, and $p 0$ is the pressure reference $(100000 \mathrm{~Pa})$.

\section{ua/va: Earth-rotated wind components}

These variables stand for the 3-D atmospheric wind components following Earth coordinates on un-staggered model $\eta$ levels. WRF model equations use the Arakawa $\mathrm{C}$ horizontally staggered grid with wind components following the grid direction. In order to get actual winds following Earth geographical coordinates, a transformation shown in Eq. (8) is required:

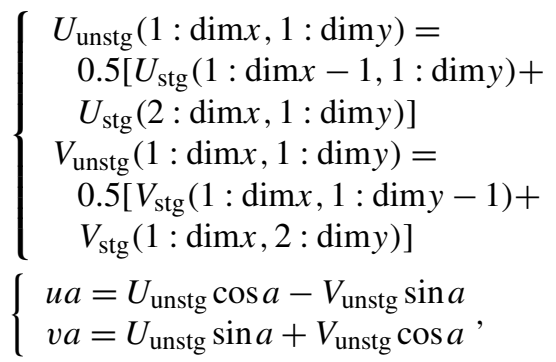

where $U_{\text {unstg }}$ is un-staggered WRF eastward wind $\left(\mathrm{m} \mathrm{s}^{-1}\right.$, $[1, \operatorname{dim} x]), V_{\text {unstg }}$ is un-staggered WRF northward wind 
$\left(\mathrm{m} \mathrm{s}^{-1},[1, \operatorname{dim} y]\right), U_{\text {stg }}$ is $x$-staggered WRF eastward wind $\left(\mathrm{m} \mathrm{s}^{-1},[1, \operatorname{dim} x+1]\right), V_{\text {stg }}$ is $y$-staggered WRF northward wind $\left(\mathrm{m} \mathrm{s}^{-1},[1, \operatorname{dim} y+1]\right), \cos a$ is the local cosine of map rotation (1), and $\sin a$ is the local sine of map rotation (1).

\section{zg: geopotential height}

As in the case of air pressure, the WRF model also integrates the perturbation of the geopotential field from a reference or base one. Thus, to obtain the full geopotential height on staggered model $\eta$ levels, the user is required to combine the two WRF fields, and it is also de-staggered as shown in Eq. (9):

$$
\begin{aligned}
& \mathrm{zg}_{\text {staggered }}=\mathrm{PH}+\mathrm{PHB} \\
& \mathrm{zg}(k)=0.5\left(\mathrm{zg}_{\text {staggered }}(k)+\mathrm{zg}_{\text {staggered }}(k+1)\right) \\
& \quad k=[1, \mathrm{~d} z],
\end{aligned}
$$

where PHB is WRF base geopotential height $\left(\mathrm{m}^{2} \mathrm{~s}^{-2}\right), \mathrm{PH}$ is WRF perturbation of the geopotential height $\left(\mathrm{m}^{2} \mathrm{~s}^{-2}\right)$, $\mathrm{zg}_{\text {staggered }}$ is staggered geopotential height $k=[1, \operatorname{dim} z+1]$, and $\mathrm{zg}$ is un-staggered geopotential height $k=[1, \operatorname{dim} z]$.

\subsubsection{Two-dimensional}

Here we provide a list of the added two-dimensional CORDEX variables. Some of them are diagnosed as a combination of three-dimensional variables, some are required as instantaneous values, and others as statistics. The fact that the module provides 2-D variables online using 3-D fields shows one more key advantage of the module related to disk space. Thanks to these online calculations when using the module, a user no longer needs to store large amounts of 3-D data from the model in order to post-process them. This reduces the requirements of disk space by a factor of around 2 .

\section{pr, pre, prl, prsh, prsn: precipitation fluxes}

The total precipitation flux (pr) is computed as the sum of all types of precipitation fields in the model accumulated along the ninth stream output frequency (9freq) divided by this period of time (9freq), as shown in Eq. (10):

$$
\begin{aligned}
& \mathrm{pr}= \\
& \frac{\sum_{\mathrm{it}}^{9{ }^{f r e q}}{ }^{2} \text { AINCV(it) }+ \text { RAINNCV(it) }+ \text { RAINSHV(it) }}{\text { Nsteps } \times \delta t},
\end{aligned}
$$

where RAINCV is instantaneous precipitation from the cumulus scheme $\left(\mathrm{kg} \mathrm{m}^{-2}\right)$, RAINNCV is instantaneous precipitation from the microphysics scheme $\left(\mathrm{kg} \mathrm{m}^{-2}\right)$, RAINSHV is instantaneous precipitation from the shallow-cumulus scheme $\left(\mathrm{kg} \mathrm{m}^{-2}\right)$, Nsteps is the number of time steps, and $\delta t$ is the time-step length (s) to achieve the ninth stream frequency output time $(9$ freq $=$ Nsteps $\times \delta t)$.

In this version, the computation of the accumulated values does not take into account configurations of the model with an adaptive time step. When an adaptive time step is used, we strongly discourage the use of these variables.

Each individual precipitation flux is also provided as follows.

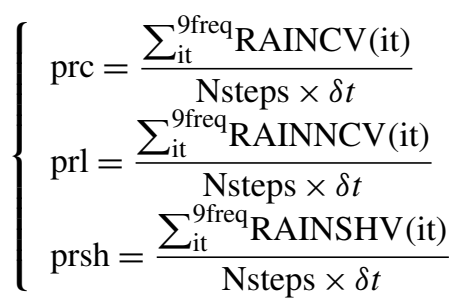

Solid precipitation flux (prsn) only accounts for frozen precipitation. Depending on the selected microphysics scheme chosen in the namelist, this variable might account for the precipitation of snow, graupel, and hail. It is computed as shown in Eq. (12):

$\operatorname{prsn}=\frac{\sum_{\mathrm{it}}^{9 \text { freq }} \text { prins }(\text { it }) \times \mathrm{SR}(\mathrm{it})}{\text { Nsteps } \times \delta t}$,

where prins is instantaneous total precipitation $\left(\mathrm{kg} \mathrm{m}^{-2}\right.$, previously obtained), and SR is the fraction of solid precipitation (\%, variable provided by WRF).

\section{Radiative flux}

Surface upwelling shortwave radiation flux (rsus, $\mathrm{W} \mathrm{g} \mathrm{m}^{-2}$ ) and surface upwelling longwave radiation flux (rlus,

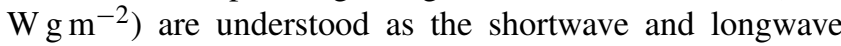
radiation from Earth's surface. They are directly provided by the radiation schemes CAM (Community Atmosphere Model) and RRTMG (Rapid Radiative Transfer Model) (sw_ra_scheme $=3,4$ ) as instantaneous variables swupb and slupb. When there is no use of such schemes, it is recommended to use the generic definition instead (rsusgen, rlusgen; see next section). Statistical retrieval for the surface fluxes follows the same methodology as for the precipitation fluxes.

Outgoing radiative fluxes at the top of the atmosphere are also provided as "rsut" for mean top-of-atmosphere (TOA) outgoing shortwave radiation (in $\mathrm{W} \mathrm{g} \mathrm{m}^{-2}$ ) and "rlut" for longwave. However, there is no generic implementation of these variables.

\section{sund: duration of sunshine}

This variable accounts for the sum of the time for which the direct solar irradiance (downwelling shortwave radiation, rsds) exceeds $120 \mathrm{~W} \mathrm{~m}^{-2}$ (WMO, 2010a); it is implemented following Eq. (13) and provided in seconds. In order to provide an example of the correct implementation of this diagnostic, preliminary results are shown in Fig. 2. The figure shows the "sund" values and compares them with the incoming solar radiation. It is shown how the "sund" values vary 

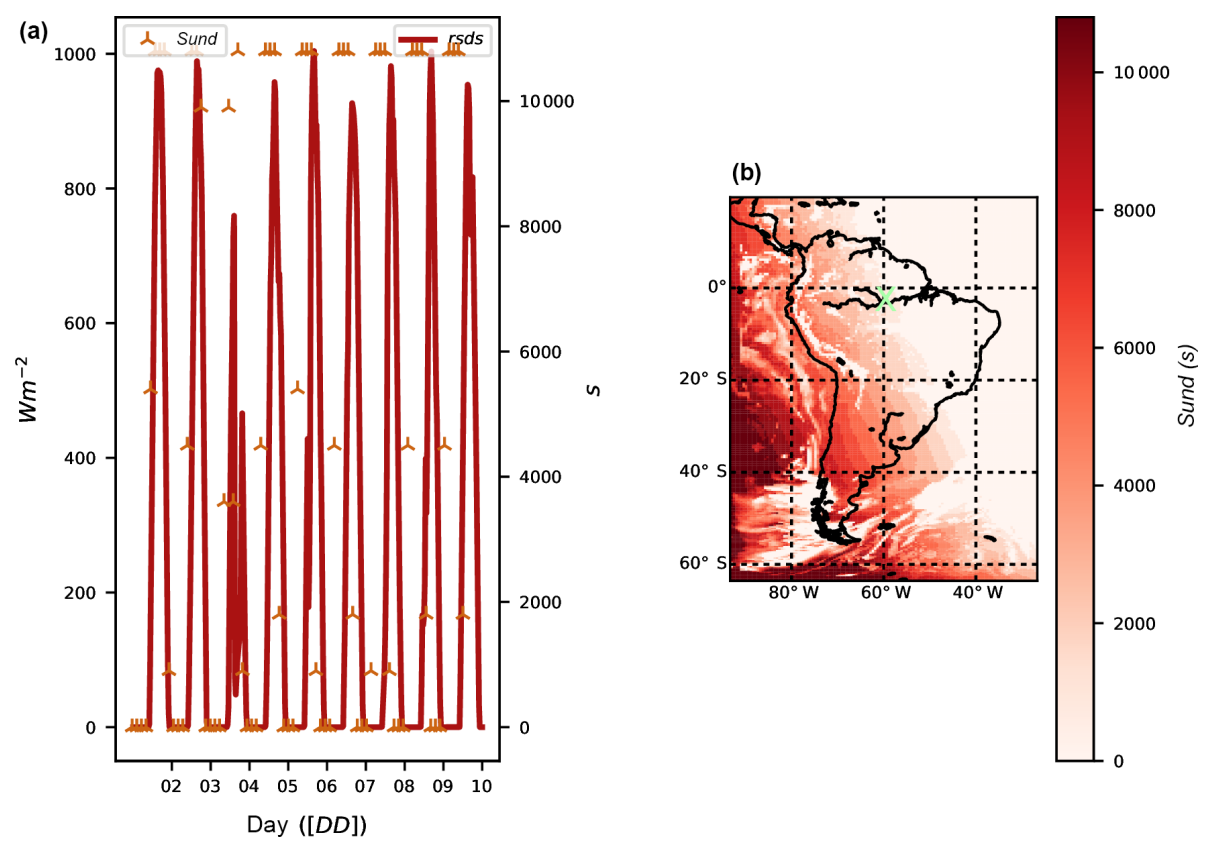

Figure 2. Temporal evolution at $62^{\circ} 4^{\prime} 38.00^{\prime \prime} \mathrm{S}, 4^{\circ} 58^{\prime} 55.51^{\prime \prime} \mathrm{W}$ (a) of shortwave downward radiation (rsds, red line, left $y$ axis) and sunshine duration for a 3-hourly 9freq (sund, stars, right $y$ axis). (b) Sunshine length map on 9 December 2012 at 15:00 UTC. X denotes the position of the temporal evolution.

accordingly to the moment of the day with zero values during night (panel a) or persistent totally cloud-covered regions (map in panel b):

$\operatorname{sund}=\sum_{\text {it }}^{9 \text { freq }} \delta t\left[\operatorname{SWDOWN}(\right.$ it $\left.) \geq 120 \mathrm{~W} \mathrm{~m}^{-2}\right]$,

where SWDOWN is downward shortwave radiation $\left(\mathrm{W} \mathrm{m}^{-2}\right)$, and $\delta t$ is time-step length (s).

\section{tauuv: surface downward wind stress}

Instantaneous surface downward wind stress at $10 \mathrm{~m}$ accounts for the force that winds exert on the Earth's surface. It is implemented following Eq. (14):

tauv $=\left(C_{\mathrm{D} \text { uas }^{2}}, C_{\mathrm{D}}\right.$ vas $\left.^{2}\right)$

where $C_{\mathrm{D}}$ is the drag coefficient (1), uas is Earth-rotated eastward $10 \mathrm{~m}$ surface wind $\left(\mathrm{m} \mathrm{s}^{-1}\right)$, and vas is Earth-rotated northward $10 \mathrm{~m}$ surface wind $\left(\mathrm{m} \mathrm{s}^{-1}\right)$. The drag coefficient is nonzero only for certain options of the surface-layer physics (sf_sfclay_physics parameter in the namelist): 1 (MM5-similarity) or 5 (MYNN surface layer). A generic formulation has been introduced when these schemes are not used.

\section{psl: sea level pressure}

This variable accounts for the instantaneous pressure extrapolated to the sea level. It represents the value of the pres- sure without the presence of orography. In order to provide a framework ready to implement different methodologies, three different methods have already been implemented. The choice of method can be controlled by a new namelist.input parameter labeled psl_diag in the cordex section. The implemented methods are the following:

- the hydrostatic Shuell method (Stackpole and Cooley, 1970) already implemented in the module phys/module_diag_afwa.F, assuming a constant lapse rate of $-6.5 \mathrm{~K} \mathrm{~km}^{-1}$, selected when in the WRF CORDEX namelist section setting the parameter [psl_diag $=1]$;

- the ptarget method (Benjamin and Miller, 1990) that uses smoothed surface pressure and a target upperlevel pressure, already implemented in the WRF postprocessing tool called p_interp.F90 [psl_diag $=2]$; and

- the ECMWF method (Yesad, 2015) taken from the Laboratoire de Météorologie Dynamique GCM (LMDZ; Hourdin et al., 2006) from the module pppmer.F90, following the methodology by Mats Hamrud and Philippe Courtier from ECMWF [psl_diag = 3].

According to the CORDEX specifications, the default method is the ECMWF method. When choosing the ptarget method (psl_diag = 2), the degree of smoothing of the surface using the surrounding nine-point average can 
also be chosen by selecting a number of smoothing passes (psmooth, default 5), and the upper pressure that has to be used as the target (ptarget, default $700 \mathrm{hPa}$ ).

Figure 3 shows the different outcomes when applying each method. There are some problems with the ptarget method in both psl estimates (mountain ranges can still be inferred) and borders for each parallel process (lines in figures showing differences among methods) when the spatial smoothing is applied. Lines showing the limits of the parallel processes appear because one cannot obtain the proper values from outside the correspondent tile of the domain associated with each individual parallel process.

\section{Cloud-derived variables}

Four cloud-derived variables are required by CORDEX: the total cloudiness (clt) and the cloudiness for each grid point at three different vertical layers aboveground (low: $p \geq$ $680 \mathrm{hPa}$, labeled cll; medium: $680<p \geq 400 \mathrm{hPa}$, clm; high: $p<400 \mathrm{hPa}$, clh). These cloud diagnostics are provided as mean values.

The module computes these variables taking the cloud fraction of a given grid cell and level as input. The cloud fraction in WRF is computed by the radiative scheme, and it is called at a frequency given by the radt parameter in the WRF namelist. Due to the large computational cost of the radiative scheme, radt is usually larger than the time step of the simulation. This determines when cloud fraction is also actualized to meet the evolved atmospheric conditions. Cloud fractions can be computed in the model using different methodologies. It would be possible to make available these methodologies as another choice in the namelist section and then compute the cloud fraction at each time step. However, in order to be consistent with the radiative cloud effects that the simulation is experiencing, this method was discarded. Thus, the cloud values provided by the module follow the same frequency of refreshing rate as the one set for radiation in the namelist level (radt value).

The most common implementation of clt found in other models (in particular most GCMs) assumes "random overlapping". Random overlapping assumes that adjacent cloud layers are from the same system and are hence overlapped at a maximum (Geleyn and Hollingsworth, 1979). In the module, the methodology from the GCM LMDZ was implemented. In this GCM, calculation of the total cloudiness and different layers' cloudiness is done inside the subroutine newmicro.f90. The method basically consists of a product of the consecutive nonzero values of cloud fraction as shown in Eq. (15):

zclear $=1$, zcloud $=0$, ZEPSEC $=1.0 \times 10^{-12}$

$\mathrm{iz}=$

1 to $\operatorname{dim} z\left\{\begin{array}{l}\text { zclear }=\text { zclear } \frac{1-\text { MAX[CLDFRAC }(\mathrm{iz}), \text { zcloud }]}{1-\text { MIN[zcloud, } 1 .- \text { ZEPSEC }]} \\ \text { clt }=1-\text { zclear } \\ \text { zcloud }=\text { CLDFRAC }(\mathrm{iz})\end{array}\right.$, where CLDFRAC is the cloud fraction (1) at each vertical level, zclear is the clear-sky value (1), zcloud is the cloudsky value (1), and ZEPSEC is a value for a very tiny number. The same methodology as in Eq. (15) is applied for the diagnostic of clh, clm, and cll but splitting by corresponding pressure layers. Figure 4 illustrates the result of the implementation and compares the results with the actual values of the cloud fraction (panels a and b), as well as the different cloud distributions (panels $\mathrm{c}$ to f).

\section{Wind-derived variables}

CORDEX requires two wind-derived diagnostics: the daily maximum near-surface wind speed of gusts (wsgsmax) and the daily maximum wind speed of gusts at $100 \mathrm{~m}$ aboveground (wsgsmax 100). These variables cannot be retrieved by post-processing the standard output since they require the combination of different variables (some of them are not available from the model output) and have to be produced as a maximum value. The module provides different ways to compute them under certain limitations.

wsgsmax: maximum near-surface wind speed of gusts. The wind gust accounts for the wind from upper levels that is projected to the surface due to instability within the planetary boundary layer. In the current version of the module two complementary methods of diagnosing the variable have been implemented (resultant winds are Earth-rotated). The choice between the two methods is done by the parameter labeled wsgs_diag (in cordex section), with the default value set to 1 . The implemented methods are the following (in italics).

- The Brasseur method [wsgs_diag = 1]. This is an implementation of wind gust considering turbulent kinetic energy (TKE) estimates and stability defined by virtual temperature $\left(\theta_{\mathrm{v}}\right)$ as indicated in Eq. (16) following Brasseur (2001). Implementation is adapted from a version already introduced in the CLimate WRF (clWRF; http://www.meteo.unican.es/wiki/ cordexwrf/SoftwareTools/ClWrf; Fita et al., 2010):

$$
\frac{1}{z_{\mathrm{p}}} \int_{0}^{z_{\mathrm{p}}} \operatorname{TKE}(z) \mathrm{d} z \geq \int_{0}^{z_{\mathrm{p}}} g \frac{\Delta \theta_{\mathrm{v}}(z)}{\Theta_{\mathrm{v}}(z)} \mathrm{d} z
$$

where TKE is turbulent kinetic energy $\left(\mathrm{m}^{2} \mathrm{~s}^{-2}\right)$, and $\theta_{\mathrm{v}}$ is virtual potential temperature $(\mathrm{K}) . z_{\mathrm{p}}$ is the height of the considered parcel $(\mathrm{m}$, maximum height that satisfies Eq. 16), and $\Delta \theta_{\mathrm{v}}(z)$ is the variation in $\theta_{\mathrm{v}}$ over a given layer $\left(\mathrm{K} \mathrm{m}^{-1}\right)$.

- The AFWA method [wsgs_diag = 2]. This is an implementation adopted from the WRF module module_diag_afwa.F that calculates the wind gust 
(a)
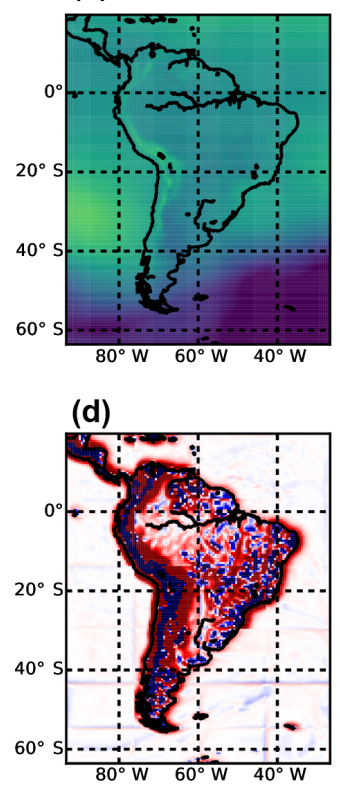

(b)

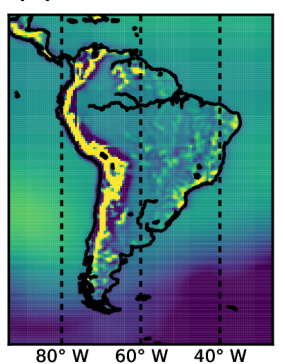

(e)

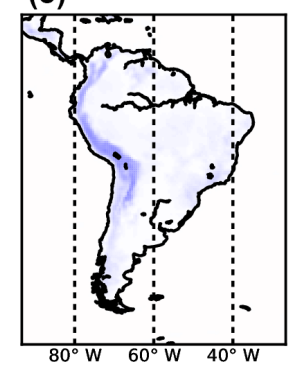

(c)

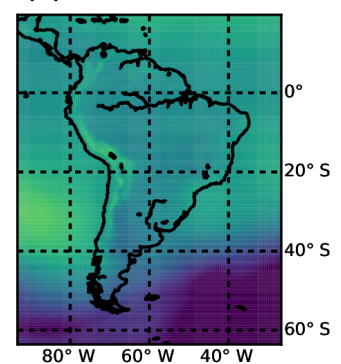

(f)

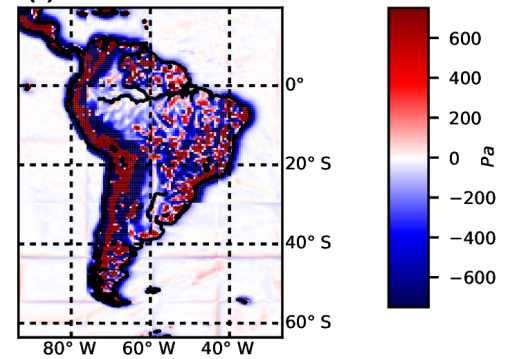

Figure 3. Sea level pressure estimates following the hydrostatic Shuell method at a given time step (psl ${ }^{\text {shuell }}$, a), ptarget (psl ${ }^{\text {ptarget }}$, b), and ECMWF (psl $\left.1^{\text {ecmwf }}, \mathbf{c}\right)$. Bottom panels show differences among methods psl ${ }^{\text {shuell }}-\mathrm{psl}^{\text {ptarget }}(\mathbf{d})$, psl ${ }^{\text {shuell }}-\mathrm{psl}^{\text {ecmwf }}(\mathbf{e})$, and psl $1^{\text {target }}-$ pslecter $^{\text {ecmof }}(\mathbf{f})$.
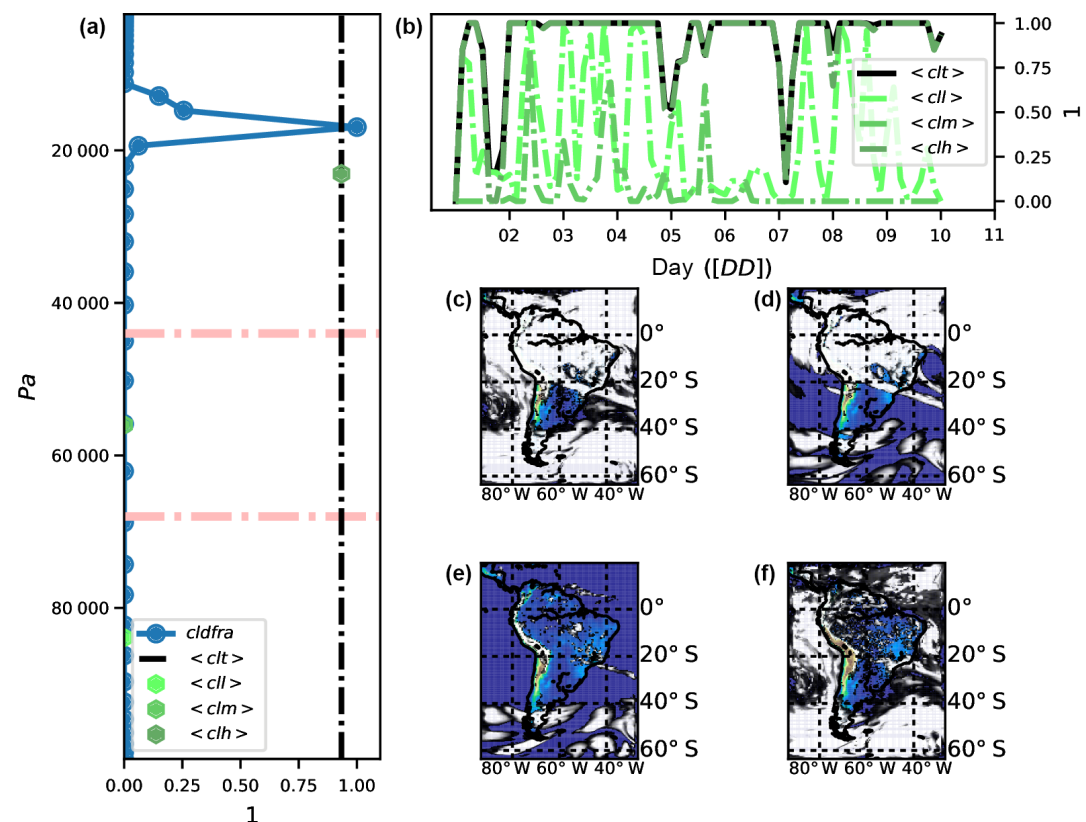

(e)
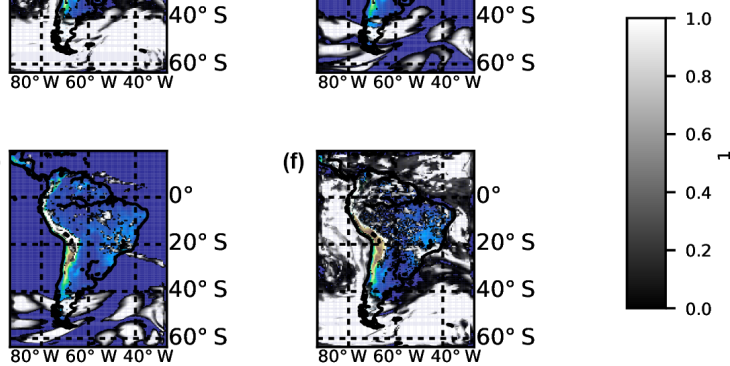

Figure 4. Vertical distribution of cloud fraction and the different cloud layers on 9 December 2012 at 15:00 UTC at 62 $4^{\prime} 38.00^{\prime \prime} \mathrm{S}$, $4^{\circ} 58^{\prime} 55.51^{\prime \prime} \mathrm{W}$ (a): cloud fraction (cldfra, full circles with line in blue), mean total cloud fraction (clt, vertical dashed line), mean lowlevel cloud fraction (cll $p \geq 680 \mathrm{hPa}$, dark green hexagon), mean mid-level cloud fraction (clm $680<p \geq 440 \mathrm{hPa}$, green hexagon), and mean high-level cloud fraction (clh $p<440 \mathrm{hPa}$, clear green hexagon). Temporal evolution of cloud layers at the given point (b). Map of clt with colored topography beneath to show cloud extent (c); map of clh (d), map of clm (e), and map of cll (f). 
that only occurs as a blending of upper-level winds, zagl (around $1 \mathrm{~km}$ aboveground; $\operatorname{zagl}\left(k_{1000}\right) \geq 1000 \mathrm{~m}$; see Eq. 17), when precipitation intensity per hour is above a given maximum value (prate $\mathrm{h}_{\mathrm{h}}^{\mathrm{mm}} \geq 50 \mathrm{~mm} \mathrm{~h}^{-1}$ ):

$$
\begin{aligned}
& \operatorname{va}_{1 \mathrm{~km}}=\operatorname{va}\left(k_{1000}-1\right) \\
& +\left[1000-\operatorname{zagl}\left(k_{1000}-1\right)\right] \frac{\mathrm{va}\left(k_{1000}\right)-\mathrm{va}\left(k_{1000}-1\right)}{\operatorname{zagl}\left(k_{1000}\right)} \\
& \gamma=\frac{150-\operatorname{prate}_{\mathrm{h}}^{\mathrm{mm}}}{100} \\
& \operatorname{va}_{\text {blend }}=\operatorname{vas} \gamma+\operatorname{va}_{1 \mathrm{~km}} \times(1-\gamma),
\end{aligned}
$$

where va is air wind $\left(\mathrm{m} \mathrm{s}^{-1}\right)$, zagl is height aboveground $(\mathrm{m})$, and $k_{1000}$ is the vertical level at which zagl is equal to or above $1000 \mathrm{~m}$; prate $\mathrm{mm}$ is the hourly precipitation rate $\left(\mathrm{mm} \mathrm{h}^{-1}\right)$, and vablend is blended wind $\left(\mathrm{m} \mathrm{s}^{-1}\right)$.

The two methods provide wind-gust estimation (WGE) from two different perspectives: mechanic and convective. In order to take into account both perspectives, additional variables are used: totwsgsmax (total maximum wind-gust speed at the surface), totugsmax (total maximum wind-gust eastward speed at the surface), totvgsmax (total maximum windgust northward speed at the surface), and totwsgspercen (percentage of time steps along 9freq in which a grid point got a wind gust in \%). Figure 5 shows the outcomes when applying each method. It is shown how wind gust is mainly originated by turbulence, with a minor impact of heavy precipitation events at the depicted time. Furthermore, in the bottom panels it is shown how wind gusts are highly frequent above the sea in comparison to the low frequency above continental flat areas (the Andes mountain range exhibits a high occurrence of wind gust).

wsgsmax100: daily maximum wind speed of gusts at $100 \mathrm{~m}$. The calculation of wind gusts at $100 \mathrm{~m}$ should follow a similar implementation as used for calculating the wsgsmax, but at $100 \mathrm{~m}$. An extrapolation of such turbulent phenomena would require a completely new set of equations that have not been established yet. However, it could be considered as a first approach to take the same wind gust as the one at the surface (when it is deflected from above $100 \mathrm{~m}$ ). The assumption would be that the wind gust at $100 \mathrm{~m}$ corresponds to the deflected wind on its "way" to the surface. Instead, as a way to complement this, the estimation of maximum wind speed at $100 \mathrm{~m}$ is provided. Provided wind components are also Earth-rotated. Three different methods have been implemented: two following assumed vertical wind profiles (after the PhD thesis of Jourdier, 2015) and a third one following Monin-Obukhov theory to estimate the wind components aboveground. These three methods are chosen by the namelist parameter labeled ws z100_diag. Its default value is 1 . The implemented methods are as follows.

- [wsz100_diag $=1$ ], following the power-law wind vertical distribution as depicted in Eq. (18) using the upper-level atmospheric wind speed below $\left(k_{100}^{<}\right)$ and above $\left(k_{100}^{>}\right)$the height aboveground of $100 \mathrm{~m}$ (zagl).

$$
\begin{aligned}
& \operatorname{va}_{100}=\operatorname{va}\left(k_{100}^{>}\right)\left(\frac{100 .}{\operatorname{zagl}\left(k_{100}^{>}\right)}\right)^{\alpha_{x, y}} \\
& \alpha_{x, y}=\frac{\ln \left(\operatorname{va}\left(k_{100}^{>}\right)\right)-\ln \left(\operatorname{va}\left(k_{100}^{<}\right)\right)}{\ln \left(\operatorname{zagl}\left(k_{100}^{>}\right)\right)-\ln \left(\operatorname{zagl}\left(k_{100}^{<}\right)\right)}
\end{aligned}
$$

- [wsz100_diag $=2$ ], following logarithmic-law wind vertical distribution, as depicted in Eq. (19), using upper-level atmospheric wind speed below $\left(k_{100}^{<}\right)$and above $\left(k_{100}^{>}\right)$the height aboveground of $100 \mathrm{~m}$ (zagl).

$$
\begin{aligned}
& \ln \left(z_{0}\right)= \\
& \frac{\operatorname{va}\left(k_{100}^{>}\right) \ln \left(\mathrm{zagl}\left(k_{100}^{<}\right)\right)-\mathrm{va}\left(k_{100}^{<}\right) \ln \left(\operatorname{zagl}\left(k_{100}^{>}\right)\right)}{\operatorname{va}\left(k_{100}^{>}\right)-\mathrm{va}\left(k_{100}^{<}\right)} \\
& \operatorname{va}_{100}=\operatorname{va}\left(k_{100}^{>}\right) \frac{\ln (100 .)-\ln \left(z_{0}\right)}{\ln \left(\operatorname{zagl}\left(k_{100}^{>}\right)\right)-\ln \left(z_{0}\right)}
\end{aligned}
$$

- [wsz100_diag = 3], following Monin-Obukhov theory. The user should keep in mind that this method is not useful for heights larger than a few decimeters $(z>80 \mathrm{~m})$. The wind at a given height is extrapolated following turbulent mechanisms. As shown in Eq. (20), the surface wind speed is used as a surrogate to estimate the $100 \mathrm{~m}$ wind direction $\left(\theta_{10}=\tan ^{-1}\right.$ (uas, vas), without considering Eckman pumping or other effects on wind direction). In this implementation $u^{*}$ in similarity theory is taken because the WRF estimates UST and Monin-Obukhov length $\left(\mathcal{L}_{\mathrm{O}}\right)$ as the WRF values for RMOL and roughness length $\left(z_{0}\right)$, with the WRF thermal time-varying roughness length ZNT:

$$
\begin{aligned}
& \text { wss }_{100}=\frac{\mathrm{UST}}{\kappa}\left(\ln \left(\frac{100}{z_{0}}\right)+\Psi_{M}\left(\frac{100}{\mathcal{L}_{\mathrm{O}}}\right)\right) \\
& \mathcal{L}_{\mathrm{O}}=\frac{-\mathrm{UST}^{3} T_{\mathrm{v}}}{\kappa g Q_{0}}(\text { Obukhov length) } \\
& \Psi_{M}\left(\frac{z}{\mathcal{L}_{\mathrm{O}}}\right)\left\{\begin{array}{l}
\frac{4.7 z}{\mathcal{L}_{\mathrm{O}}} ; \frac{z}{\mathcal{L}_{\mathrm{O}}}>0 \text { (stable) } \\
\ln \left[\left(\frac{1+X^{2}}{2}\right)\left(\frac{1+X}{2}\right)^{2}\right] \\
-2 \tan ^{-1}(X)+\frac{\pi}{2} ; \frac{z}{\mathcal{L}_{\mathrm{O}}}<0 \text { (unstable) }
\end{array}\right. \\
& X=\left(1-\frac{15 z}{\mathcal{L}_{\mathrm{O}}}\right)^{1 / 4} \\
& \theta_{10}=\operatorname{atan}\left(\frac{V 10}{U 10}\right) \boldsymbol{v a}_{100}=\left\{\begin{array}{l}
\text { ua } 100=\mathrm{wss}_{100} \cos \left(\theta_{10}\right) \\
\text { va }_{100}=\mathrm{wss}_{100} \sin \left(\theta_{10}\right)
\end{array},\right.
\end{aligned}
$$

where wss ${ }_{100}$ is wind speed at $100 \mathrm{~m}\left(\mathrm{~m} \mathrm{~s}^{-1}\right), \Psi_{M}$ is the stability function after Businger et al. (1971), UST is $u^{*}$ in similarity theory $\left(\mathrm{m} \mathrm{s}^{-1}\right), z_{0}$ is the roughness length (m), $U 10$ and $V 10$ represent $10 \mathrm{~m}$ wind speed $\left(\mathrm{m} \mathrm{s}^{-1}\right)$, 
$\theta_{10}$ is the $10 \mathrm{~m}$ wind speed direction (rad), ua 100 is the $100 \mathrm{~m}$ eastward wind speed $\left(\mathrm{m} \mathrm{s}^{-1}\right)$, and va 100 is the $100 \mathrm{~m}$ northward wind speed $\left(\mathrm{m} \mathrm{s}^{-1}\right)$. Note the absence of correction in wind direction due to Ekman pumping or other turbulence effects.

The user can also select the height at which the estimation is computed throughout the namelist parameter z100m_wind ( $100 \mathrm{~m}$ as the default value). Figure 6 shows different preliminary results using the three different approximations. It is illustrated (panel a) how wind gusts are larger than the $10 \mathrm{~m}$ diagnostic winds, and the difference is also larger when using the Monin-Obukhov method compared to the two other methods. Certain problems (too-small MoninObukhov length) are recognized when applying MoninObukhov for extrapolating wind at $100 \mathrm{~m}$, which is shown in panel (b), where wind gusts appear to be as strong as $80 \mathrm{~m} \mathrm{~s}^{-1}$. Therefore, users are advised to adopt this method with care.

\section{Vertically integrated variables}

The instantaneous vertically integrated amount of water vapor (prw), liquid condensed water species (clwvi), ice species (clivi), graupel (clgvi), and hail (clhvi) are the vertically integrated amounts of each species along the vertical column (density weighted) over each grid point. They are provided using the same implementation as those in the p_interp. F WRF tool for vertical interpolation. The general equation following WRF standard variables is

clvivar $=\frac{\mathrm{MU}+\mathrm{MUB}}{g} \sum_{\mathrm{iz}=1}^{e}$ vert $\mathrm{WRFVAR}[\mathrm{iz}](\mathrm{DNW}[\mathrm{iz}])$,

where clvivar is the column vertically integrated variable's CF-compliant name (prw, clwvi, clivi, clgvi, or clhvi), MU is the perturbation dry air mass in the column (Pa), MUB is the base-state dry air mass in the column $(\mathrm{Pa}), g$ is gravity $\left(\mathrm{m} \mathrm{s}^{-2}\right), e_{-}$vert represents the total number of vertical levels, WRFVAR is the water species mixing ratio at each sigma level $\left(\mathrm{kg} \mathrm{kg}^{-1}\right)$, and DNW is the difference between two consecutive full $\eta$ levels (-). Table 3 indicates the WRFVAR names associated with the clvivar names.

Note that clgvi and clhvi are part of the Tier 1 level and are only accessible if the pre-compilation variable CDXWRF is set to 1. See Sect. 2.3 for more detail. In order to provide an example of the correct computation of the diagnostics, results at a given grid point are shown in Fig. 7. It is shown that the total precipitable water (prw) correctly corresponds to the density-weighted vertical integration of the water content along the column of air.

\section{evspsblpot: potential evapotranspiration}

This variable represents the evaporative demand of the atmosphere. It is computed following the standard method already implemented in most GCMs. One of the first proposed methods was provided by Manabe (1969). Some corrections have been proposed to the initial methodology in order to overcome its deficiencies (see, e.g., Barella-Ortiz et al., 2013, for an intercomparison among different methods). It is provided as an averaged flux. Calculation of the potential evapotranspiration can be activated with the namelist input parameter potevap_diag (number 2 is the default option).

- The bulk method [potevap_diag = 1] corresponds to the original one proposed in Manabe (1969). It basically consists of a difference between a supposed saturated air at the surface temperature and the humidity of the atmosphere as depicted in Eq. (22):

$$
\begin{aligned}
& \mathrm{qc}=C_{\mathrm{D}} \sqrt{U 10^{2}+V 10^{2}} \\
& \text { evspsblpot }_{\text {bulk }}=\rho(1) \mathrm{qc}[\mathrm{ws}(\mathrm{ts})-\operatorname{QVAPOR}(1)],
\end{aligned}
$$

where ws(ts) is saturated air at ts $\left(\mathrm{kg} \mathrm{kg}^{-1}\right)$, qc is the surface drag coefficient $\left(\mathrm{m} \mathrm{s}^{-1}\right)$, TSK is surface temperature $(\mathrm{K})$, ws (ts) is saturated air by surface temperature $\left(\mathrm{kg} \mathrm{kg}^{-1}\right)$ based on the August-Roche-Magnus approximation, $U 10, V 10$ represent the $10 \mathrm{~m}$ wind components $\left(\mathrm{m} \mathrm{s}^{-1}\right)$, QVAPOR is the 3-D water vapor mixing ratio $\left(\mathrm{kg} \mathrm{kg}^{-1}\right)$, and $C_{\mathrm{D}}$ is the drag coefficient (-, only available from MM5 similarity and MYNN surface-layer schemes; otherwise, it is zero).

- The Milly92 method [potevap_diag = 2] makes a correction of the bulk diagnostic by introducing a Milly correction parameter $\xi$, which accounts for other atmosphere-related phenomena (Milly, 1992). It is explained in Eq. (23), and its implementation is similar to the one present in the ORCHIDEE model (Organising Carbon and Hydrology in Dynamic Ecosystems; http: //orchidee.ipsl.fr/, last access: 18 March 2019; de Rosnay et al., 2002). The implementation is retrieved from the modulesrc_sechiba/enerbil.f90:

$$
\begin{aligned}
& \beta=\frac{\text { sfcevap }}{\text { evspsblpot }_{\text {bulk }}} \\
& \partial_{T} \mathrm{ws}(T)=\frac{\mathrm{ws}[T(1)+0.5]-\mathrm{ws}[T(1)-0.5]}{2 \times 0.5} \\
& \xi= \\
& \frac{L \rho(1) \mathrm{qc} \partial_{T} \mathrm{ws}(T)(1-\beta)}{4 \mathrm{EMISSCtBoltzmannT}(1)^{3}+\rho(1) \mathrm{Cpqc}+L \rho(1) \mathrm{qc} \partial_{T} \mathrm{ws}(T) \beta} \\
& \text { evspsblpot }_{\text {Milly92 }}=\operatorname{evspsblpot}_{\text {bulk }} \frac{1}{1+\xi},
\end{aligned}
$$

where $\beta$ is the moisture availability function, sfcevap is QFX surface evaporation $\left(\mathrm{kg} \mathrm{m}^{-2} \mathrm{~s}^{-1}\right)$ from QFX, which is the surface moisture flux $\left(\mathrm{kg} \mathrm{m}^{-2} \mathrm{~s}^{-1}\right), L$ is the latent heat of vaporization, EMISS is emissivity (1), CtBoltzmann is the Stefan-Boltzmann constant, $\mathrm{Cp}$ is the specific heat of air, and $\partial_{T} \mathrm{ws}(T)$ is the derivative of saturated air at the temperature of the first atmospheric 


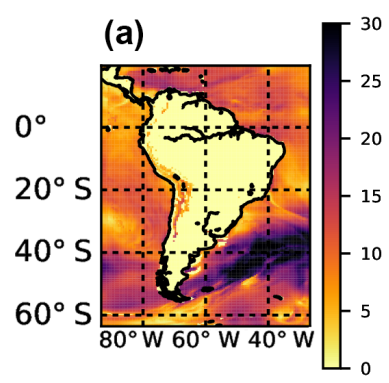

(d)

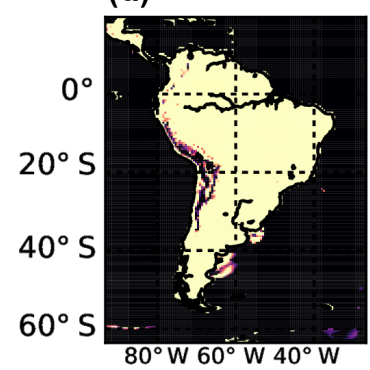

(b)

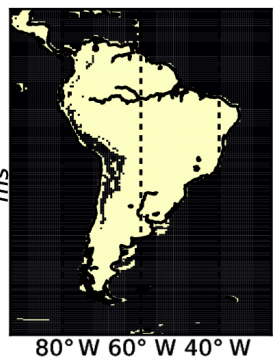

(e)

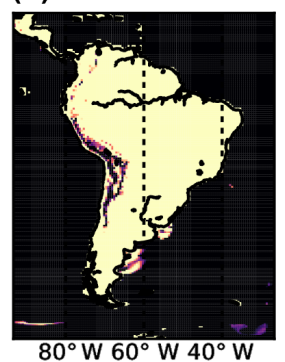

(c)

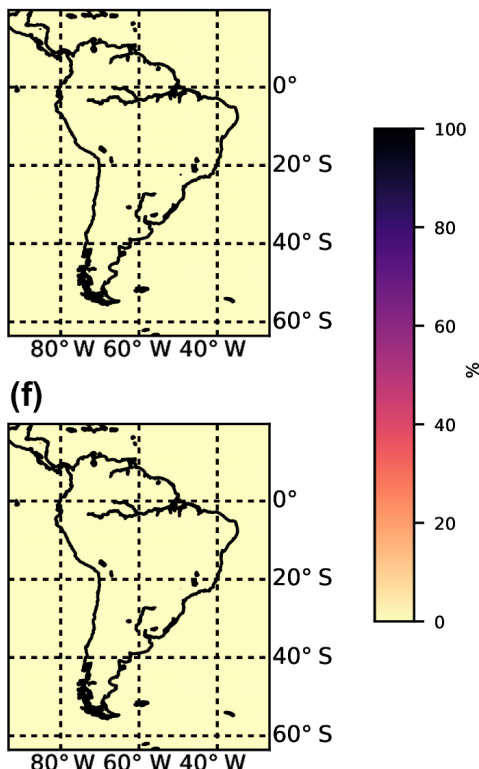

Figure 5. Near-surface wind-gust estimates on 9 December 2012 at 15:00 UTC. $3 \mathrm{~h}$ maximum total wind-gust strength (wsgsmax ${ }^{\text {tot }}$, a), percentage of wsgsmax ${ }^{\text {tot }}$ following the Brasseur method ( $\operatorname{wsgsmax}^{\mathrm{b} 01}, \mathbf{b}$ ), percentage following the AFWA heavy precipitation implementation (wsgsmax ${ }^{\text {hp }}, \mathbf{c}$ ), percentage of time steps for which a grid point got a total wind gust (d), percentage of time steps for which a grid point got wsgsmax ${ }^{\mathrm{b} 01}(\mathbf{e})$, and percentage due to wsgsmax ${ }^{\text {hp }}(\mathbf{f})$.

(a)

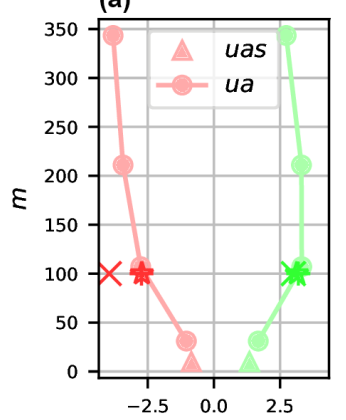

(b)

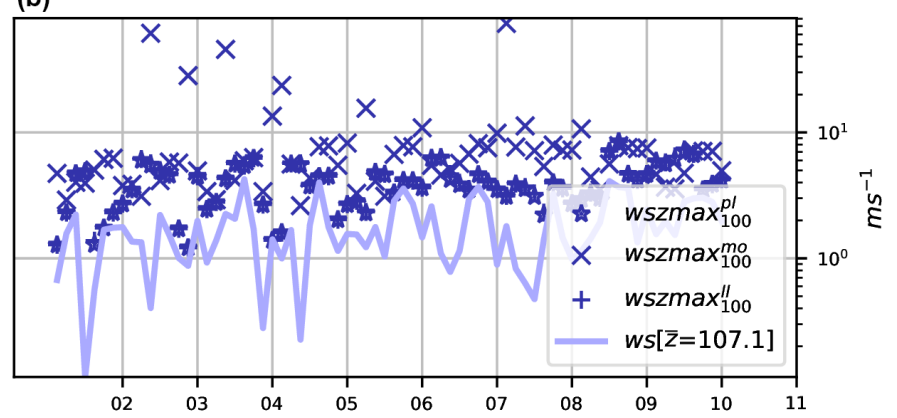

Day $([D D])$
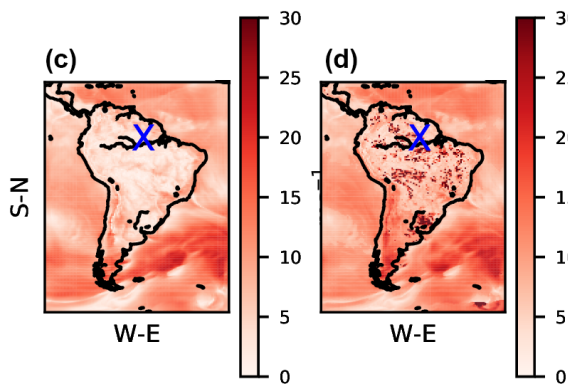

(e)
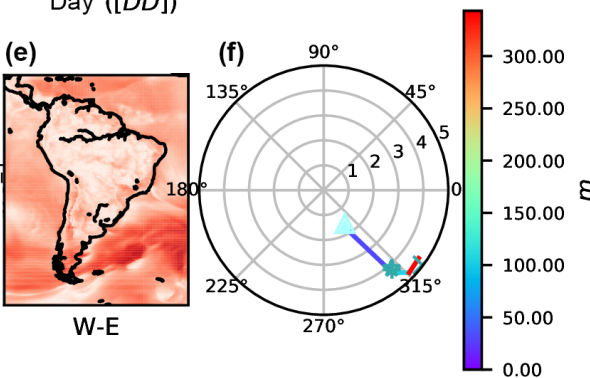

\section{$\varepsilon$}

Figure 6. $100 \mathrm{~m}$ wind estimates. Comparison between upper-level winds and estimation on 9 December 2012 at 15:00 UTC at 62 $2^{\circ} 4^{\prime} 38.00^{\prime \prime} \mathrm{S}$, $4^{\circ} 58^{\prime} 55.51^{\prime \prime}$ W. (a) $3 \mathrm{~h}$ maximum eastward wind (red) at $100 \mathrm{~m}$ by power law (uzmax ${ }^{\mathrm{pl}}$, star marker), Monin-Obukhov theory (uzmax ${ }^{\mathrm{mo}}$, cross), by logarithmic law (uzmax ${ }^{11}$, sum), $10 \mathrm{~m}$ wind value (uas, filled triangle), and upper-level winds (ua, filled circles with line), also for the northward component (green). Temporal evolution of wind speed (b) with all approximations and upper-level winds at the closest vertical level at $100 \mathrm{~m}$ (on a $\log y$ scale, $\bar{z}=107.1 \mathrm{~m}$ on average). Maps of three estimations: power law (c), Monin-Obukhov (d), and logarithmic law (e), with the blue cross showing the point of previous figures. Vertical distribution of winds at the given point in a wind-rose-like representation (f). 
Table 3. Mixing ratio associated with column-integrated variables.

\begin{tabular}{lll}
\hline Name & WRF species & Description \\
\hline prw & QVAPOR & water vapor mixing ratio \\
clwvi & QCLOUD+QRAIN & condensed water and rain mixing ratio \\
clivi & QICE+QSNOW+QGRAUPEL+QHAIL & ice, snow, graupel, and hail mixing ratio \\
clgvi & QGRAUPEL & graupel mixing ratio \\
clhvi & QHAIL & hail mixing ratio \\
\hline
\end{tabular}

layer $\left(\mathrm{kg} \mathrm{kg}^{-1}\right)$ using numerical first-order approximation.

See Fig. 8 for an example of the differences between the two implementations. It shows how important the correction introduced by Milly is and its strong effect on the diurnal cycle. Basically, the correction permits potential evapotranspiration during nighttime and reduces its strength at noon (18:00 UTC corresponds to 12:00 local time). There is a generic diagnostic to overcome boundary layer scheme dependency in the calculation of the drag coefficient (see the sections below on generic variables).

\subsection{Generic variables}

Some of the diagnostics required by CORDEX depend on the approximations, equations, methodologies, and observations used to compute them. This makes model intercomparison very difficult, since values might differ from one implementation to another. In order to overcome this problem, a series of variables is also provided in a generic form (when possible), meaning that they are obtained directly from standard variables. Thus, these generic forms of the diagnostics become "independent" of the model's implementation.

\section{cdgen: generic surface drag coefficient}

Computation of the instantaneous drag coefficient at the surface depends on the selected surface scheme. In order to avoid this scheme dependency, a generic calculation of the coefficient has been introduced as in Eq. (24) following Garratt (1992):

$C_{\mathrm{D}}^{\mathrm{gen}}=\left(\frac{\mathrm{UST}}{\mathrm{wss}}\right)^{2}$

with UST $u^{*}$ being friction velocity from the similarity theory $\left(\mathrm{m} \mathrm{s}^{-1}\right)$, and wss $=\sqrt{U 10^{2}+V 10^{2}}$ the $10 \mathrm{~m}$ wind speed $\left(\mathrm{m} \mathrm{s}^{-1}\right)$.

\section{tauuvgen: generic surface downward wind stress}

Generic surface downward wind stress at $10 \mathrm{~m}$ is calculated following Eq. (25), which uses the generic diagnostics of the drag coefficient:

tauvgen $=\left(C_{\mathrm{D}}^{\text {gen }}\right.$ uas $\left.^{2}, C_{\mathrm{D}}^{\text {gen }} \operatorname{vas}^{2}\right)$, where $C_{\mathrm{D}}^{\text {gen }}$ is the generic drag coefficient (-, see Eq. 24), uas is the Earth-rotated eastward $10 \mathrm{~m}$ wind component, and vas is the Earth-rotated northward $10 \mathrm{~m}$ wind component.

\section{rsusgen: surface upwelling shortwave radiation}

Surface upwelling shortwave radiation is the shortwave radiation directed from the surface. It is calculated in a generic way as the reflected shortwave radiation depending on the surface albedo as shown in Eq. (26):

rsus $=-$ ALBEDO $\times$ SWDOWN

where ALBEDO is albedo (1), and SWDOWN is downward shortwave radiation at the surface $\left(\mathrm{W} \mathrm{m}^{-2}\right)$.

\section{rlusgen: surface upwelling longwave radiation}

Surface upwelling longwave radiation is the longwave radiation coming from the surface. It is calculated in a generic way as the longwave radiation from a black body due to surface temperature following the Stefan-Boltzmann law as given in Eq. (27):

rlus $=$ CtBoltzmann $\times$ EMISS $\times \mathrm{TSK}^{4}$,

where CtBoltzmann is the Stefan-Boltzmann constant $\left(5.67051 \times 10^{-8} \mathrm{~W} \mathrm{~m}^{-2} \mathrm{~K}^{-4}\right)$, EMISS is surface emissivity (1), and TSK is skin temperature (K).

\section{evspsblpotgen: generic potential evapotranspiration}

This variable corresponds to the generic definition of potential evapotranspiration (evspsblpot). The same two methodologies as in the regular diagnostic have been implemented. The only difference is that, in this case, the generic estimation of the drag coefficient "cdgen" is used (see Eq. 24) instead of the one given by the model.

\subsection{Tier 1 variables}

These diagnostics are required by CORDEX, but they are not mandatory. They have also been included as a way to fulfill all the CORDEX requirements. These variables require the setting of the pre-compilation flag CDXWRF to 1 and performing some complementary modifications in the module's registry file registry.cordex. See Sect. 2.3 for more details. 

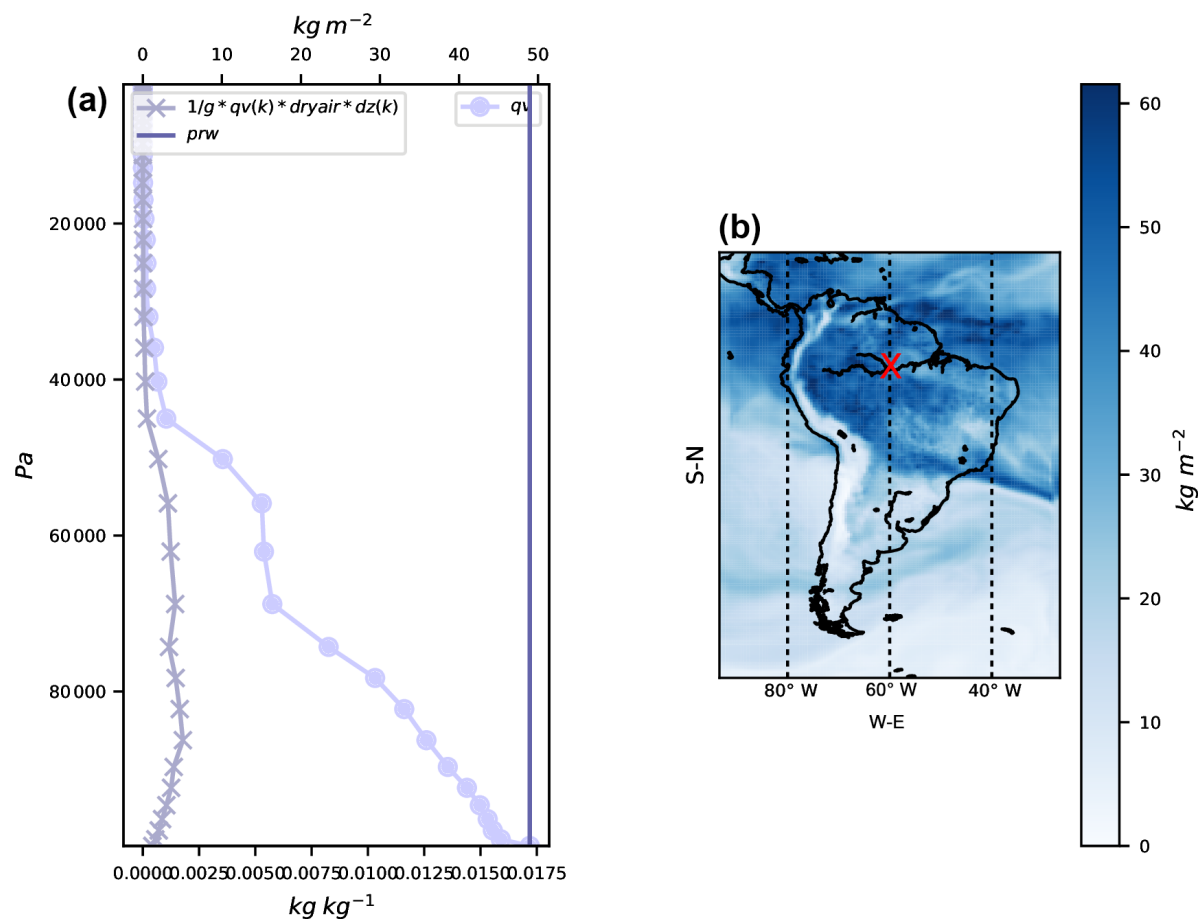

Figure 7. On 9 December 2012 at 15:00 UTC at $62^{\circ} 4^{\prime} 38.00^{\prime \prime} \mathrm{S}, 4^{\circ} 58^{\prime} 55.51^{\prime \prime} \mathrm{W}$ : (a) water path (prw, vertical straight line in millimeters top $x$ axis), vertical profile of water vapor (qv, line with full circles in $\mathrm{kg} \mathrm{kg}^{-1}$ bottom $x$ axis), and water path at each level (line with crosses). Map of water path (b) on 9 December 2012 at 15:00 UTC; red cross shows where the vertical accumulation is retrieved.

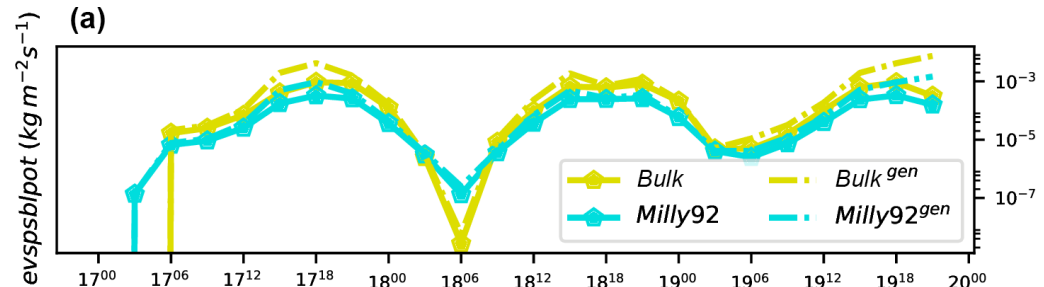

(b)

(d)

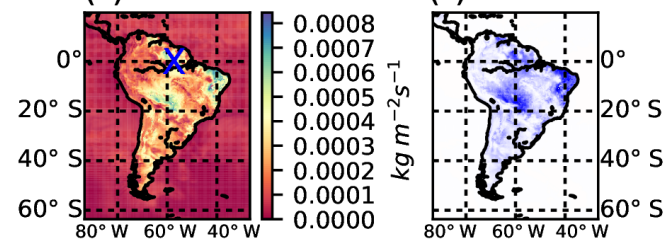

(e)

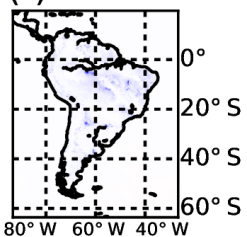

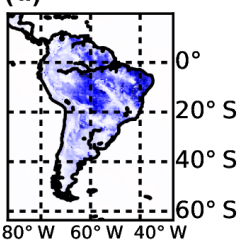

(f)

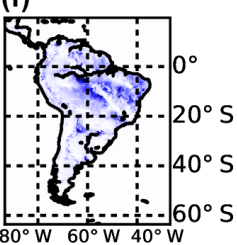

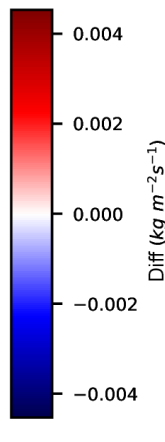

Figure 8. Evolution (a, in $y$ log scale) of potential evapotranspiration by bulk (yellow) and Milly92 (blue) generic (dashed lines) methods at $4^{\circ} 58^{\prime} 55.524^{\prime \prime} \mathrm{S}, 62^{\circ} 4^{\prime} 37.92^{\prime \prime} \mathrm{W}$ (blue cross in panel b). On 18 November 2015 15:00 UTC, potential evapotranspiration following Milly correction (b), differences between the two methods (c, evspblpot ${ }_{\text {Milly92 }}-$ evspblpot $\left._{\text {bulk }}\right)$, differences between the two generic methods $(\mathbf{d}$,

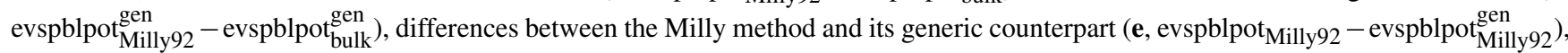
and differences between the bulk method and its generic counterpart (f, evspblpot ${ }_{\text {bulk }}-$ evspblpot $_{\text {bulk }}^{\text {gen }}$ ). 


\section{zmlagen: generic boundary layer height}

Instantaneous planetary boundary layer (PBL) height is a clear example of model dependence and even scheme dependence of how a diagnostic is computed. Each PBL scheme has its own assumptions, and "zmla" is computed in a scheme-dependent specific way.

In order to overcome the model and/or scheme dependence, we implemented a generic formulation for calculating the PBL height as was done in García-Díez et al. (2013) after Nielsen-Gammon et al. (2008). The method consists of defining the height of the PBL as the first level in the mixed layer (ML) where potential temperature exceeds the minimum potential ML temperature by more than $1.5 \mathrm{~K}$. It has been implemented using the definitions given below.

1. Mixed-layer depth (MLD) is defined as the model level $\left(k_{\mathrm{MLD}}\right)$ starting from the second model level at which the variation of the mixing ratio (QVAPOR $(k)$, normalized with its value at the first level) exceeds some predefined threshold value (QVAPOR(1)): $\frac{\left|\mathrm{QVAPOR}\left(k_{\mathrm{MLD}}\right)-\mathrm{QVAPOR}(1)\right|}{\text { VVAPOR }(1)}>\delta$ QVAPOR (here applied as $\delta$ QVAPOR $=0.1)$.

2. Within the MLD the value with the minimum potential temperature is taken as $\theta \min _{\mathrm{MLD}}=$ $\min \left[\theta(1), \ldots, \theta\left(k_{\mathrm{MLD}}\right)\right]$.

3. The level of the PBL height $\left(k_{\mathrm{zmla}}\right)$ is the level at which the maximum variation of potential temperature within the MLD exceeds some predefined threshold value: $\theta\left(k_{\mathrm{zmla}}\right)-\theta \min _{\mathrm{MLD}}>\delta \theta,($ here $\delta \theta=1.5 \mathrm{~K})$.

4. The PBL height (zmla) is obtained using the geopotential height $\mathrm{zg}$ at the calculated $k_{\mathrm{zmla}}$ level above the ground $(\mathrm{zagl}): \mathrm{zmla}=\operatorname{zagl}\left(k_{\mathrm{zmla}}\right)=\mathrm{zg}\left(k_{\mathrm{zmla}}\right) / g-$ HGT, with HGT being the surface elevation height above sea level.

No general rule has been applied to provide the correct value of $\delta$ qv used to determine MLD. It can be determined by the namelist parameters zmlagen_dqv for $\delta q v$ (default value 0.1 ) and zmlagen_dtheta for $\delta \theta$ (default value $1.5 \mathrm{~K})$. Comparison of this implementation with the zmla directly provided by WRF's Mellor-Yamada-Nakanishi-Niino Level 2.5 PBL scheme (MYNN2.5 Nakanishi and Niino, 2006) is shown in Fig. 9. In general the generic estimation produces a higher PBL (panel a) with lower values during night (panel b). Spatial distributions between the two diagnostics are similar.

\section{Convective diagnostics}

The diagnostics related to convective activity are convective available potential energy (CAPE), which accounts for all the energy that might be released convectively, convective inhibition (CIN), which accounts for processes that inhibit the convection, the height of the level of free convection (ZLFC), the pressure at the level of free convection (PLFC), and the lifted index (LI), which accounts for the temperature difference between the environmental temperature at some higher level in the troposphere and the temperature that a parcel would have if adiabatically lifted at that level. CORDEX requires these values as statistics between output times (9freq in this case).

Since v3.6 of WRF, these variables can already be calculated with the module module_diag_afwa.F via the Buoyancy function. In this version of the module, this is the only available implementation. These vertically integrated diagnostics have a high computational cost. In order to minimize it, they are only computed at the output time step by default. However, if a user requires them as statistics (such as capemin, capemax, capemean), then these diagnostics are computed at all time steps. This behavior of the module is regulated by the namelist parameter convxtrm_diag (the default value is 0 , meaning no computation) and by setting the pre-compilation flag CDXWRF to 1 and performing some complementary modifications in the module's registry file registry . cordex. See Sect. 2.3 for more detail.

\section{Additional variables}

Some variables not required by CORDEX but that may be interesting and useful to the community for a wide variety of purposes have also been added. These variables will be obtained if the pre-compilation flag CDXWRF is set to 2 and some additional modifications are made in the module's registry file registry . cordex. See Sect. 2.3 for more details.

\section{tds: dew point temperature}

The dew point temperature (cooler temperature at which air would saturate due to its current moisture content) is calculated following the August-Roche-Magnus approximation as shown in Eq. (28):

$$
\begin{aligned}
& \gamma=\log (\text { hurs })+\frac{b(T 2-273.15)}{(T 2-273.15)+c} \\
& \operatorname{tds}=\frac{c \gamma}{b-\gamma}+273.15
\end{aligned}
$$

where $T 2$ is $2 \mathrm{~m}$ temperature $(\mathrm{K})$, hurs is $2 \mathrm{~m}$ relative humidity (\%, previously computed), $b=17.625$, and $c=243.04$. This variable is provided as a statistic for the minimum, maximum, and mean in the output.

\section{Atmospheric water budget}

The water budget accounts for all the dynamics of the water in the atmosphere. This budget is divided into different terms (dynamical and source and/or sink) accounting for the total mass of water. It can be computed independently for each 

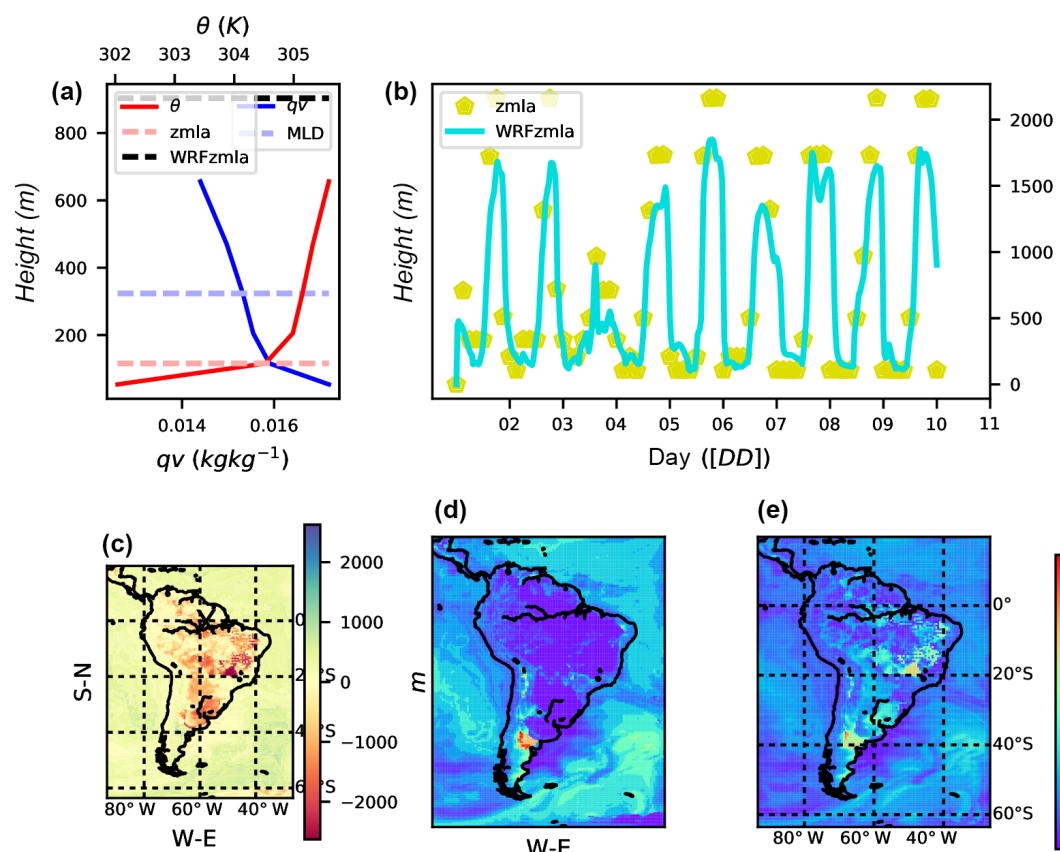

(d)

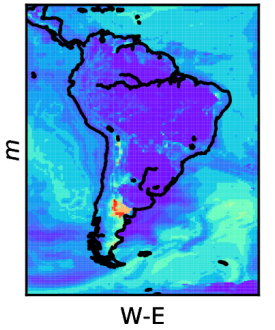

(e)

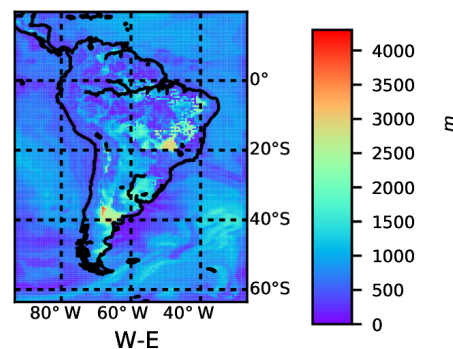

Figure 9. Vertical characteristics of the atmosphere on 9 December 2012 at 15:00 UTC at $62^{\circ} 4^{\prime} 38.00^{\prime \prime} \mathrm{S}, 4^{\circ} 58^{\prime} 55.51^{\prime \prime} \mathrm{W}$. (a) Potential temperature vertical profile $(\theta \mathrm{K}$, red line), vertical profile of mixing ratio (qv kg kg-1, blue line), mixed-layer depth (MLD, dashed horizontal line at $323.522 \mathrm{~m}$ ), derived boundary layer height (zmla, horizontal dashed line at 1007.122 m), and WRF-derived PBL scheme value $\left(\mathrm{WRF}_{\mathrm{zmla}}\right.$ at $\left.903.017 \mathrm{~m}\right)$. Comparison of temporal evolutions (b) between derived zmla (yellow stars) and WRF's PBL scheme (blue line). Map of differences between derived and WRF simulated (zmla - zmlawRF, c), zmla map (d), and zmlawRF (e).

water species. The equation for any given water species is as given in Eq. (29):

$$
\begin{aligned}
& \operatorname{TEN}_{q}=\mathrm{HOR}_{q}+\mathrm{VER}_{q}+\mathrm{MP}_{q} \\
& \frac{\partial q_{q}}{\partial t}=-V_{\mathrm{h}} \nabla q_{q}-w \frac{\partial q_{q}}{\partial z}+\mathrm{SO}_{q}-\mathrm{SI}_{q},
\end{aligned}
$$

where $q$ stands for one of the six water species (vapor, snow, ice, rain, liquid, graupel, or hail) concentrations $\left(\mathrm{kg} \mathrm{kg}^{-1}\right)$, $V_{\mathrm{h}}$ stands for horizontal wind speed $\left(\mathrm{m} \mathrm{s}^{-1}\right), w$ stands for the vertical wind speed $\left(\mathrm{m} \mathrm{s}^{-1}\right)$, and MP for the loss or gain of water due to cloud microphysical processes. The term on the left-hand side of the equation represents the water species tendency (TEN or "PW"), referring to the difference between $q$ at the model's previous time step and at the actual time step, divided by the time step. TEN equals the horizontal advection (HOR or $F$, first term on the right-hand side of the equation), the vertical advection (VER or $Z$, second term on the right-hand side), and the source (SO) or sink (SI) of atmospheric water due to MP. All terms are expressed in $\mathrm{kg} \mathrm{kg}^{-1} \mathrm{~s}^{-1}$. However, SO and SI cannot be provided because they are microphysics dependent and this makes it difficult to provide a generic formula for them.

In order to obtain the total column mass of water due to each term (in millimeters), an integration following Eq. (30) is applied to each term of Eq. (29) (similarly as in Eq. 21).

$$
-\frac{1}{g} \int_{p_{\text {sfc }}}^{p_{\text {top }}}<\text { term }>\mathrm{d} p
$$

Following the methodology of Huang et al. (2014) and Yang et al. (2011), Fita and Flaounas (2018) implemented a new module in WRF in order to allow for the computation of the water budget terms during model integration. This implementation is provided with the CORDEX module, but these variables are only provided as temporal accumulations (within 9freq) and vertical integrations in two forms: total column values and divided by the same layers as the cloud diagnostics (low, medium, high). The accumulation of diabatic heating from the microphysics scheme is provided as a proxy for the sink and/or source due to microphysics effects.

Preliminary results for all water species are shown in Figs. 10 and 11. Water vapor exhibits the largest values in both total tendency and horizontal advection. Dynamics of the other water species seems to be highly correlated with the presence of a storm system (lower right corner in the maps) or due to orthographic influences (the existence of the Andes mountain range can be inferred).

Figures 12 to 15 show temporal evolution and accumulated maps at a given time for all the water budget terms, decomposed for vapor (qv) and snow (qs). Accumulated maps 


\section{W.B. AC PW normalized by $\sigma$ on 2012-12-09 15}
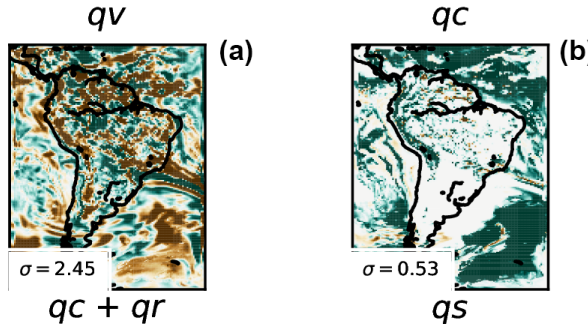

(b)

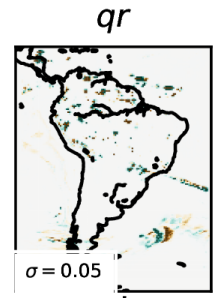

(c)

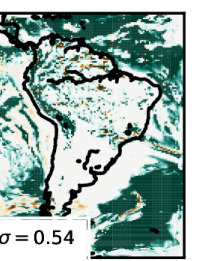

(d)

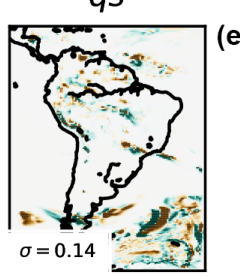

(e)

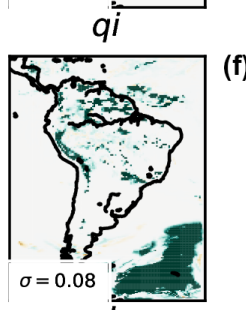

$q s+q s+q g$

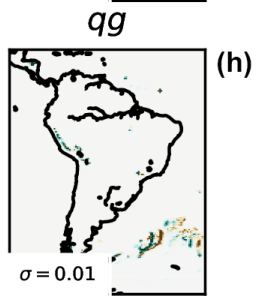

(h)
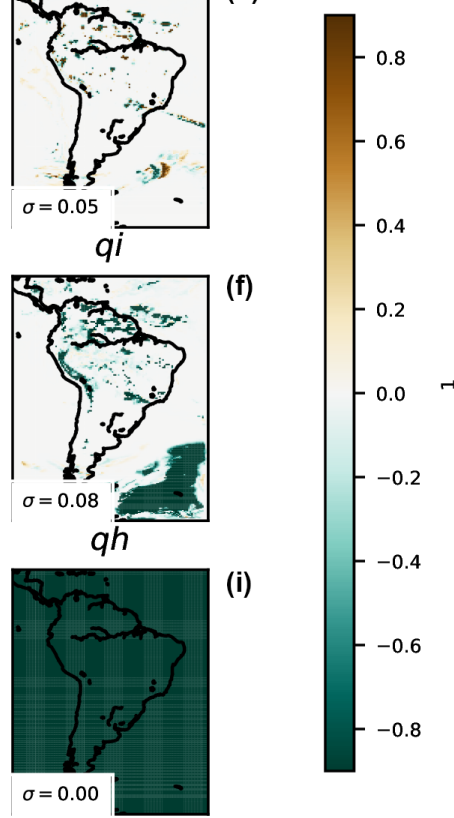

Figure 10. Normalized (with the spatial standard deviation of the mapped values, $\sigma$ ) water budget $3 \mathrm{~h}$ accumulated vertically integrated total tendency PW at a given time, for water vapor (qv, a), cloud (qc, b), rain (qr, c), water condensed species (qc+qr, d), snow (qs, e), ice (qi, f), water solid species (qs+qi+qg, $\mathbf{g}$ ), graupel (qg, h), and hail (qh, i). Numbers in the lower left corner of the panels correspond to the standard deviation ( $\sigma$ in millimeters) value used for the normalization.

W.B. AC F normalized by $\sigma$ on 2012-12-09 15

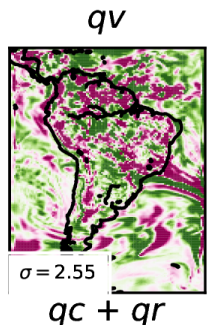

(a)

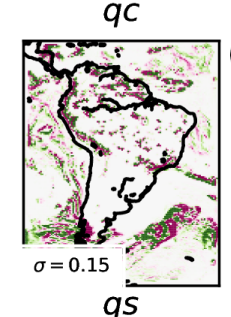

(b)

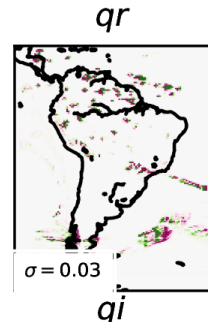

(c)
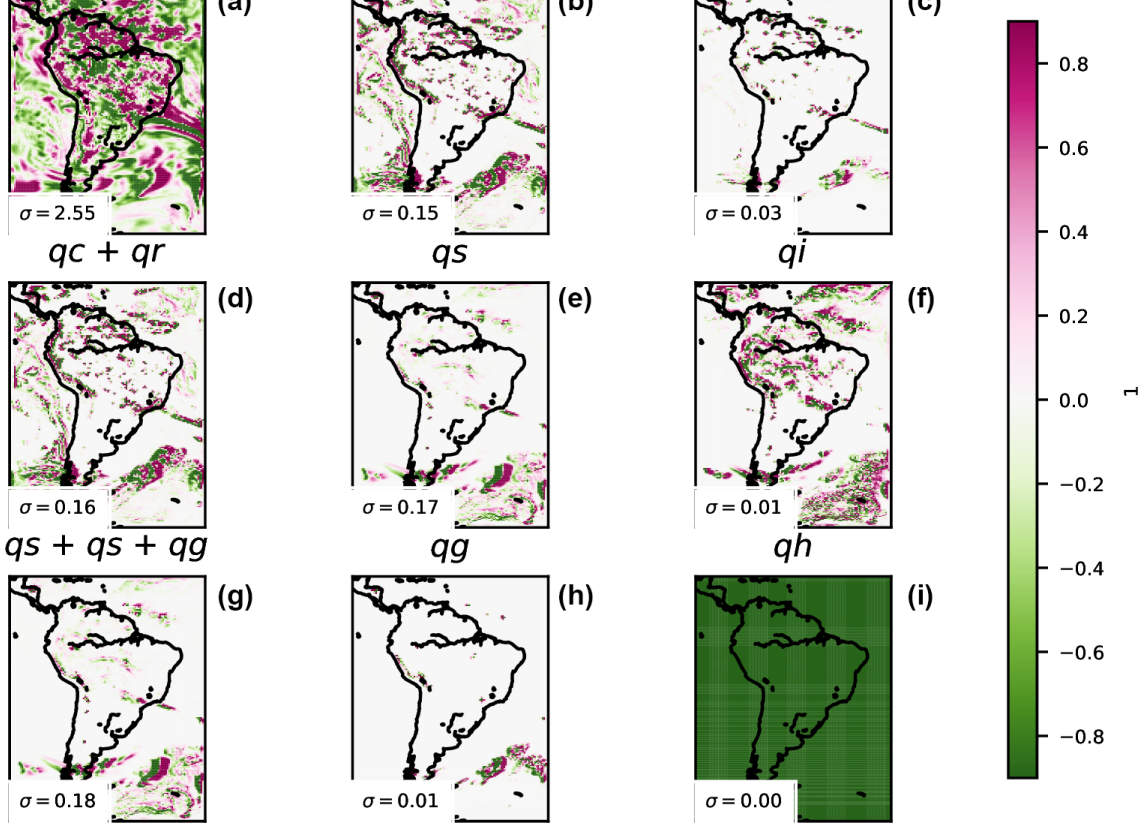

Figure 11. As in Fig. 10, but for water budget $3 \mathrm{~h}$ accumulated vertically integrated horizontal advection $F$ at a given time. 
Water budget terms at $-62^{\circ} 4^{\prime} 38.00^{\prime \prime},-4^{\circ} 58^{\prime} 55.51^{\prime \prime}(60,150)$
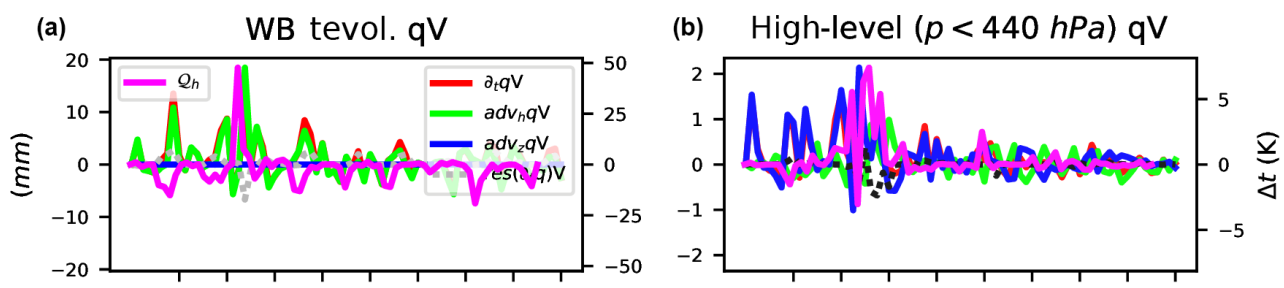

(c) Level decomp. of $\partial_{t} q \& \mathcal{Q}_{d}$

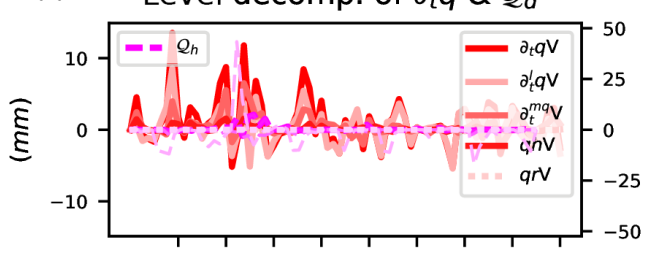

(d) Mid-level (680 $>p \geq 440 \mathrm{hPa}$ ) qV

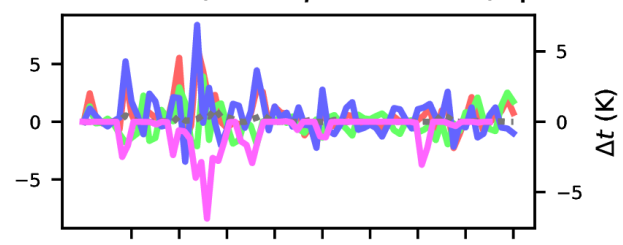

(e) Level decomp. of $a d v_{h} q \& a d v_{z} q$

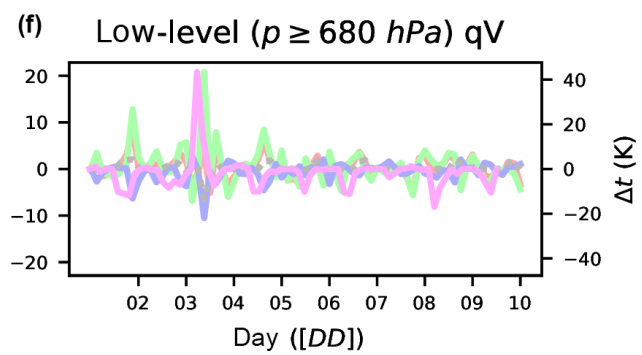

Figure 12. Water budget evolution at a given point for water vapor of vertically integrated water budget terms: total tendency PW ( $\partial_{\mathrm{t}} \mathrm{qv}$, red), horizontal advection $F\left(\operatorname{adv}_{\mathrm{h}} \mathrm{qv}\right.$, green), vertical advection $Z\left(\operatorname{adv}_{z} \mathrm{qv}\right.$, green), residual $\mathrm{PW}-F-Z$ (res $\left(\partial_{\mathrm{t}} \mathrm{qv}\right)$, gray dashed), and diabatic heating from microphysics $\left(\mathcal{Q}_{\mathrm{d}}\right.$, pink) (a). Only high-level vertically integrated values $(p<440 \mathrm{hPa}$, b), high-, mid-, and low-level (degree of color intensity) decomposition of $\partial_{\mathrm{t}} \mathrm{qv}$ (red) and $\mathcal{Q}_{\mathrm{d}}$ (pink) and their respective residuals as dashed lines (c). Only mid-level vertically integrated values $(680>p \leq 440 \mathrm{hPa}, \mathbf{d})$, high-, mid-, and low-level (degree of color intensity) decomposition of $\operatorname{adv}_{\mathrm{h}} \mathrm{qv}(\mathrm{green})$ and $\operatorname{adv}_{z} \mathrm{qv}$ (blue) and their respective residuals as dashed lines (e), and only low-level vertically integrated values $(p \geq 680 \mathrm{hPa}, \mathbf{f})$.

are grouped into vertical levels as is done with the clouds: $p \geq 68000 \mathrm{~Pa}, 40000 \leq p<68000 \mathrm{~Pa}, p<40000 \mathrm{~Pa}$. The largest amounts of the budget terms are mainly found in low (high) levels for water vapor (snow); temporal evolution at a given point shows the complexity of the water dynamics, with the terms compensating for each other. Figures 12 to 15 also show how the contribution to the total diabatic term is large at low levels over the ocean (showing the role of evaporation) and larger at high levels above the continent.

\section{fogvis: visibility inside fog}

Fog is one of the major causes of transportation disruption. The horizontal resolutions of state-of-the-art CORDEX activities like FPS_Alps $(3 \mathrm{~km})$ open the possibility to explore phenomena such as fog, which was impossible to analyze in previous reginal climate experiments. In order to contribute to the analysis of fog phenomena, three different methods to calculate visibility have been introduced. Visibility is used to determine the presence of fog at a given moment. In order to provide a quantity with the density of the fog, only the visibility during a fog event is kept. The three methods are as follows (in italics).
- K84 [visibility_diag = 1]. Visibility is computed using liquid water (QCLOUD) and ice (QICE) concentrations. Following Bergot et al. (2007), fog appears when there are liquid and/or ice water species at the lowest model level present. Visibility is computed using Eq. (31) as in Kunkel (1984):

fogvis $=\left\{\begin{array}{l}\text { visc }=0.027(\text { QCLOUD } \times 1000)^{-0.88} \\ \text { QCLOUD } \neq 0 \\ \text { visi }=0.024(\text { QICE } \times 1000)^{-1.0} \\ \text { QICE } \neq 0\end{array}\right.$

fogvis $=\min ($ visc, visi $)$,

where QCLOUD is the liquid water (cloud) mixing ratio $\left(\mathrm{kg} \mathrm{kg}^{-1}\right)$, and QICE is the ice mixing ratio $\left(\mathrm{kg} \mathrm{kg}^{-1}\right)$. Visibility values are in kilometers.

- RUC [visibility_diag = 2]. Visibility is computed using relative humidity (hur) as implemented in the RUC model (see Eq. 32 from Smirnova et al., 2000):

fogvis $=60.0 \exp \left[\frac{-2.5(\text { hur } \times 100-15)}{80}\right]$, 
Water budget terms on 2012-12-09 15:00 UTC

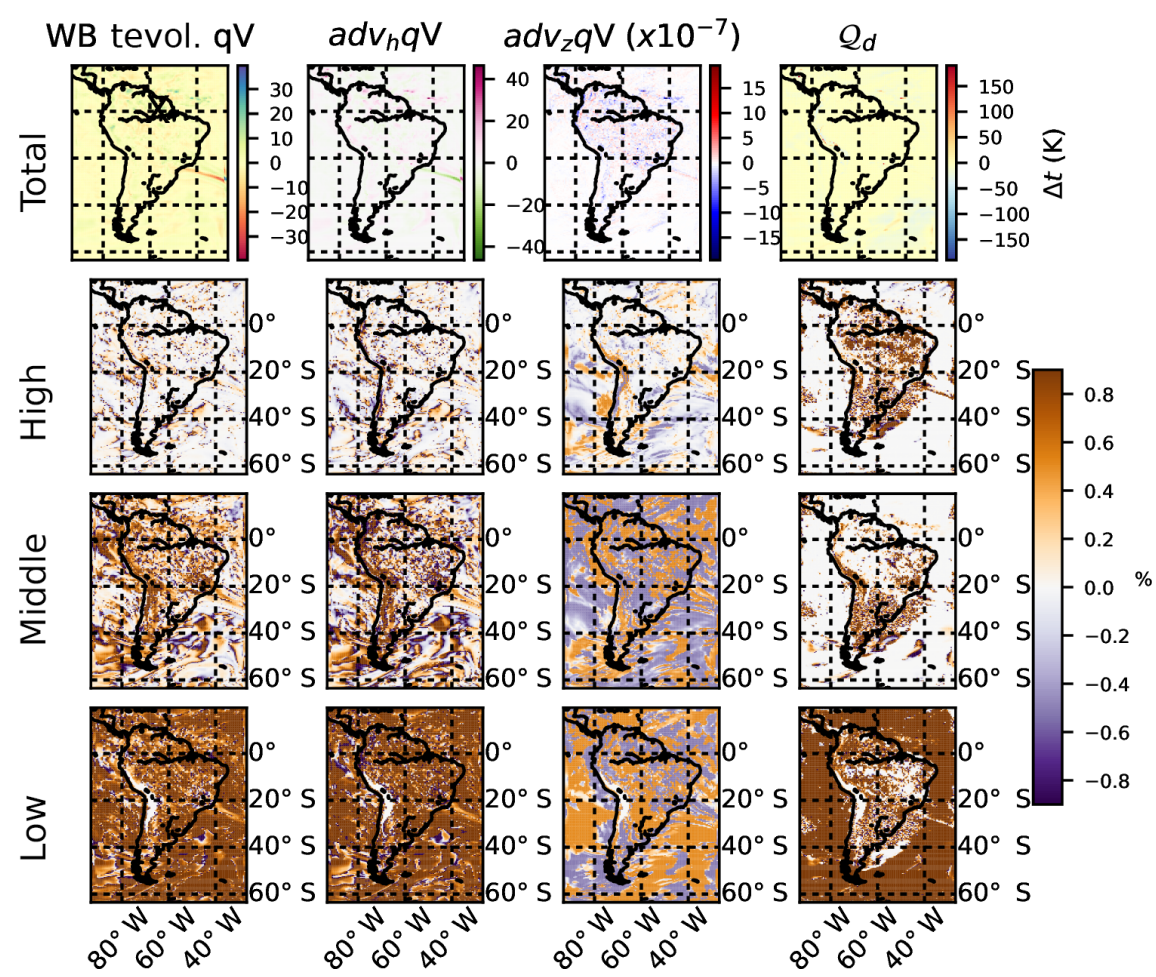

Figure 13. Water vapor budget maps of each component and diabatic heating from microphysics at a given time and the percentage contribution at each different vertically integrated layer with respect to the total. Total tendency PW ( $\partial_{\mathrm{t}} \mathrm{qv}$, first column), horizontal advection $F$ $\left(\operatorname{adv}_{\mathrm{h}} \mathrm{qv}\right.$, second column), vertical advection $Z\left(\operatorname{adv}_{z} \mathrm{qv}\right.$, third column), and diabatic heating from microphysics $\left(\mathcal{Q}_{\mathrm{d}}\right.$, fourth column). Percentage contribution of high-level ( $p<440 \mathrm{hPa}$ ) integration to the total (second row), percentage for mid-level $(680>p \geq 440 \mathrm{hPa})$ integration to the total (third row), and percentage of low-level ( $p \geq 680 \mathrm{hPa}$ ) integration (bottom row).

where hur is relative humidity (1, previously computed) and can be from the $2 \mathrm{~m}$ diagnostics or the first model layer. Visibility values are in kilometers.

- FRAM-L[visibility_diag = 3] (default). Visibility is computed using relative humidity (hur) after Gultepe and Milbrandt (2010, see their Eq. 33). In this work, a probabilistic approach is proposed to compute the visibility in three different bins: $95 \%, 50 \%$, and $5 \%$ probability to get certain visibility (for hurs $>30 \%$ ). As a matter of compromise in the module, the calculation with $50 \%$ probability has been chosen as the preferred one. Therefore, this method provides the visibility that may occur with $50 \%$ probability:

$$
\begin{aligned}
& \text { fogvis }^{\text {prob }}= \\
& \begin{cases}95 \% & -9.68 \times 10^{-14} \mathrm{RH}^{7.19}+52.20 \\
50 \% & -5.19 \times 10^{-10} \mathrm{RH}^{5.44}+40.10 \\
5 \% & -0.000114 \mathrm{RH}^{2.70}+27.45\end{cases}
\end{aligned}
$$

where $\mathrm{RH}$ is relative humidity and can be from $2 \mathrm{~m}$ diagnostics [hurs, in CF-notation] or the first model layer [hur(1)]. Visibility values are in kilometers.
The provided values of visibility during a fog event are the minimum, maximum, and mean values within output time steps (9freq) when fog occurred. Different choices are controlled through namelist variables: visibility_diag determines the method used to compute visibility, and fogvars determines the source of the relative humidity to be used as input in the visibility method. Users can choose between the relative humidity from the first model layer (hur) fogvars $=1$ (default value) or from the $2 \mathrm{~m}$ diagnostics (hurs) fogvars $=2$. Some preliminary results for an extreme fog episode in central Argentina are provided in Fig. 16. Results strongly differ among fog implementations. The best agreement with a satellite-visible channel picture for a given time of the event is obtained when the default setting is used (FRAM-L method with hur values as input).

It is known that certain methods for calculating visibility rely on numerical adjustments to observational data taken under certain circumstances and at specific places (e.g., for FRAM-L, adjusted values come from observations from a Canadian airport). It would be desirable to provide a more generic "all places and purposes" approach (if possible). It is recommended to use this variable with care. 
Water budget terms at $-62^{\circ} 4^{\prime} 38.00^{\prime \prime},-4^{\circ} 58^{\prime} 55.51^{\prime \prime}(60,150)$

(a)
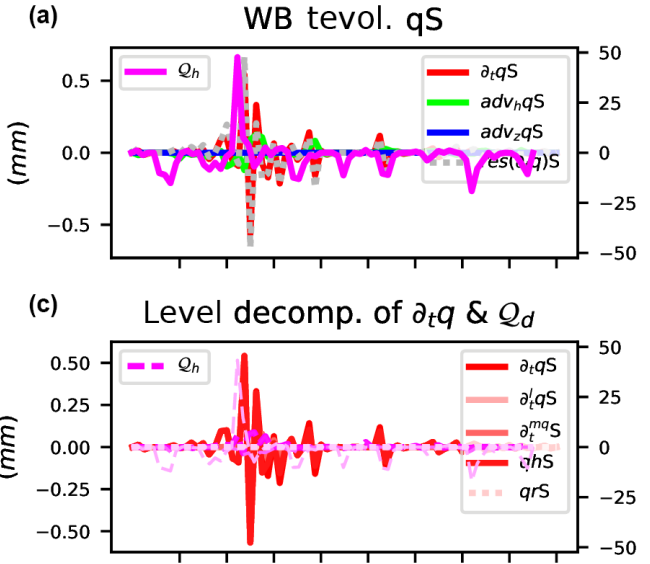

(e) Level decomp. of $a d v_{h} q \& a d v_{z} q$

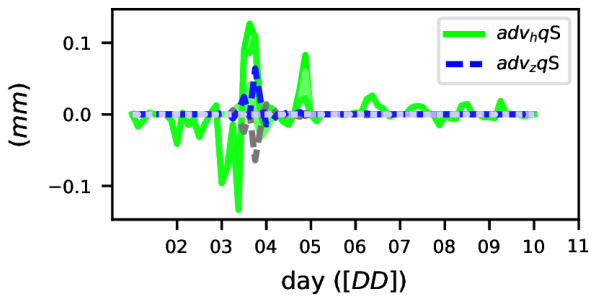

(b) High-level $(p<440 \mathrm{hPa}) \mathrm{qS}$

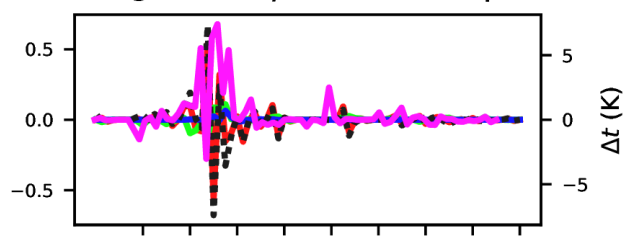

(d) Mid-level (680 $>p \geq 440 h P a)$ qS

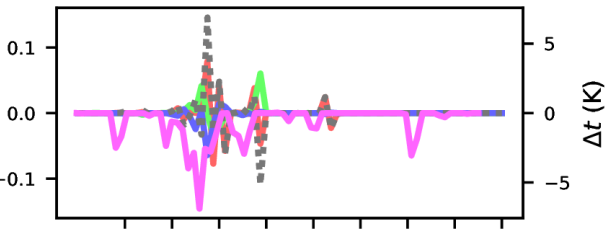

(f) Low-level ( $p \geq 680 \mathrm{hPa}) \mathrm{qS}$

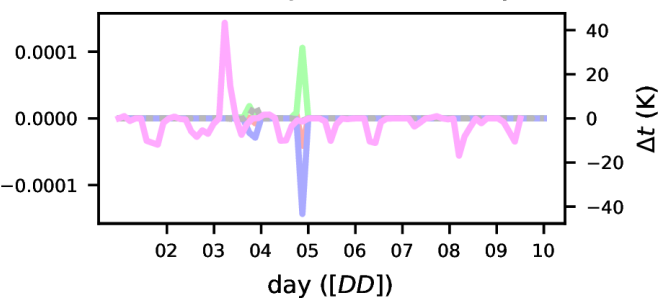

Figure 14. The same as in Fig. 12, but for snow.

Water budget terms on 2012-12-09 15:00 UTC
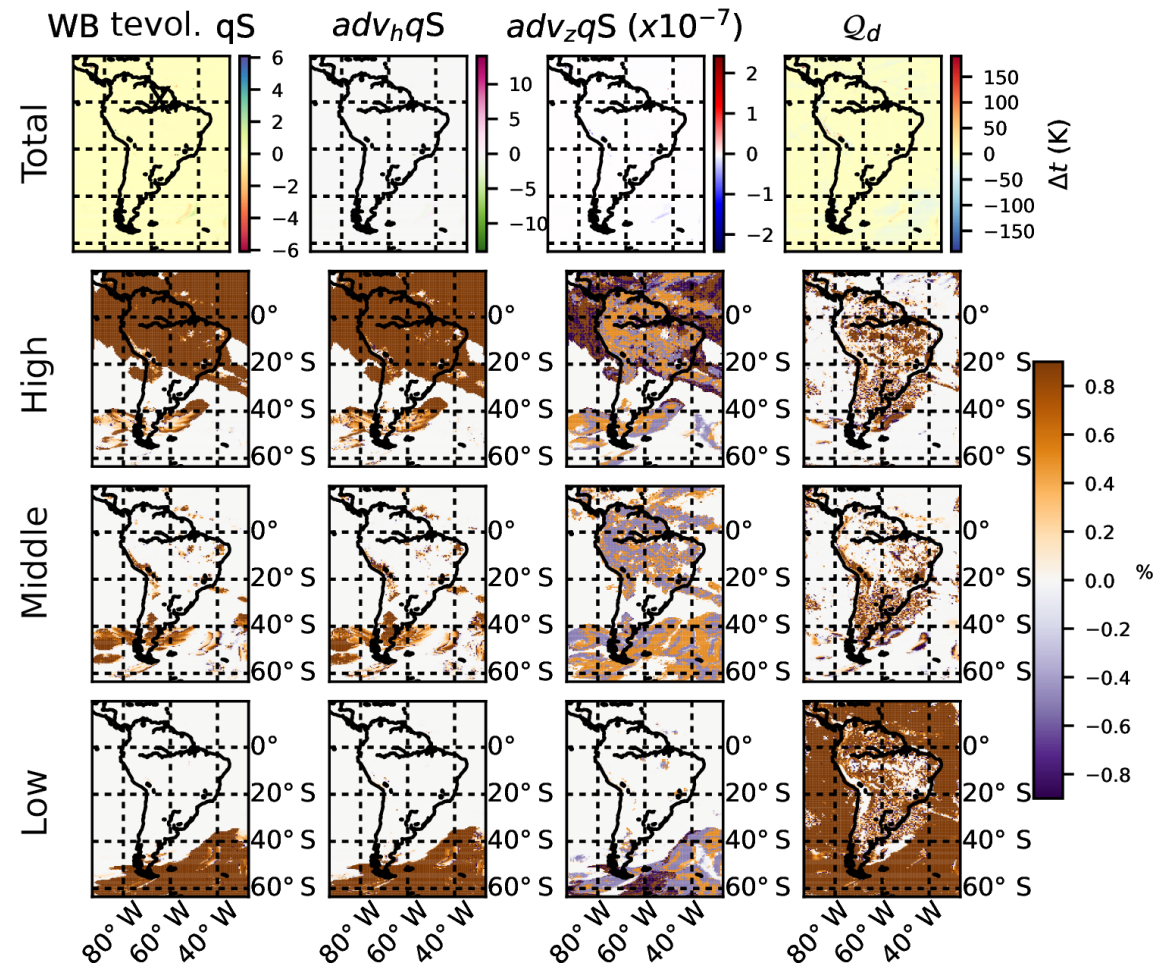

Figure 15. The same as in Fig. 13, but for snow. 
(a)

(b)

(c)
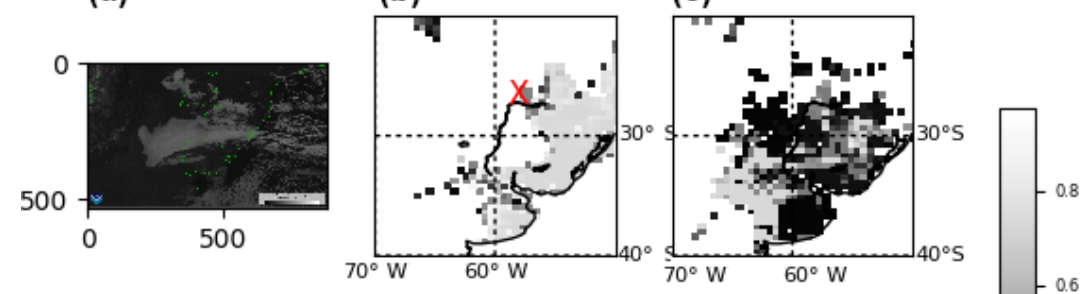

(d)

(e)

(f)

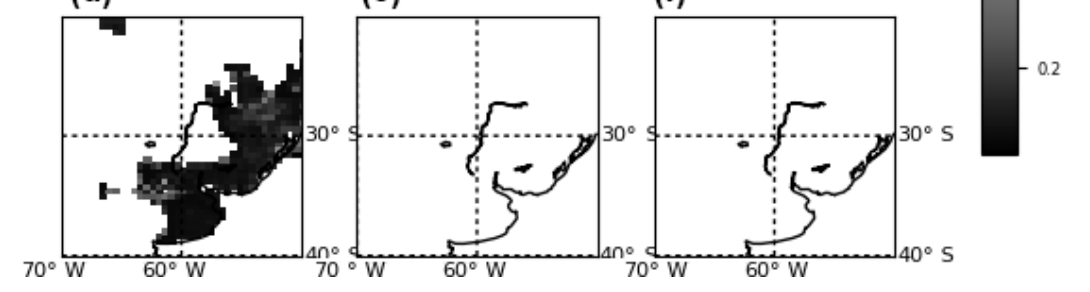

Figure 16. On 30 June 2007 at 12:00 UTC, comparison of the different configurations of the diagnostics of mean fog visibility (in $1 \mathrm{~h}$ ) to the satellite image from GOES-12 (a) at the same time in the visible channel (courtesy of NOAA-CLASS), default vis3vars1 (fogvisibility=3, fogvars $=1 ; \mathbf{b})$, vis3vars2 (c), vis1vars1 (d), vis2vars1 (e), and vis2vars2 (f).

\section{tfog: time of presence of fog}

Fog can be diagnosed when the visibility is lower than $1 \mathrm{~km}$ (WMO, 2010b), and tfog accounts for the period during which the grid point has visibility lower than $1 \mathrm{~km}$ during 9freq (see Eq. 34):

$\mathrm{tfog}=\sum_{\text {it }}^{\text {9freq }} \delta t,[\operatorname{vis}(\mathrm{it}) \leq 1 \mathrm{~km}]$

where vis is visibility $(\mathrm{km})$ below $1 \mathrm{~km}$ and $\delta t$ is the model time step (s).

\section{Optimization}

Regional climate dynamical downscaling experiments like the ones under the scope of CORDEX require long continuous simulations that consume larger amounts of HPC resources for a long period of time. Therefore, a series of tests were carried out in order to investigate the impact on the time of integration when the module is activated. The first version of the module (v1.0) was known to introduce about a $40 \%$ decrease in time-step speed of integration (highly dependent on HPC, model configuration, and domain specifications). In order to improve model performance when the module is activated, the module was upgraded to version 1.1. Since this new version, a series of optimizations of the code and precompilation flags have been activated (CDXWRF). Following this implementation (instead of via regular WRF namelist options), two main goals were achieved: (1) the amount of variables kept in memory during model execution was reduced and (2) the number of conditions (mainly avoiding IF statements) to be checked and calculations at each execution step of integration was reduced as well.

A domain as shown in Fig. 17 has been set up to perform short runs (5 days) to check the changes in performance of the WRF model when the module is activated in its different possible configurations. In order to avoid nonhomogeneous communication among the cluster nodes (which would affect the analysis), all the simulations were executed on a single node and with the WRF model compiled with Intel and GNU Fortran compilers. Tests are performed at the HPC Fram (https://www.sigma2.no/Fram, last access: 18 March 2019) from the Norwegian academic HPC infrastructure. Fram is based on Lenovo NeXtScale $n \times 360$, constituted by the CPU types Intel E5-2683v4 2.1 GHz and Intel E7-4850v4 $2.1 \mathrm{GHz}$.

The execution time is calculated as the mean elapsed time used during the 5-day model integration. The elapsed time necessary for each simulation step is available from the standard output of the model run (rsl.error.0000 WRF ASCII file). In this file, WRF users can get the elapsed time for all the time steps of the model and domains of simulation. Different peaks of slower time steps (see in Fig. 18) coincide with input/output file operations, differences between day and night regimes, and when different physical schemes (mainly the radiative scheme) are activated at a given frequency (e.g., radt). For a simulation covering 5 days with a time step of $15 \mathrm{~s}$, one obtains 28800 time steps. The sample of 28800 time steps is considered to be large enough to be representative for the mean time step of the whole simulation. 


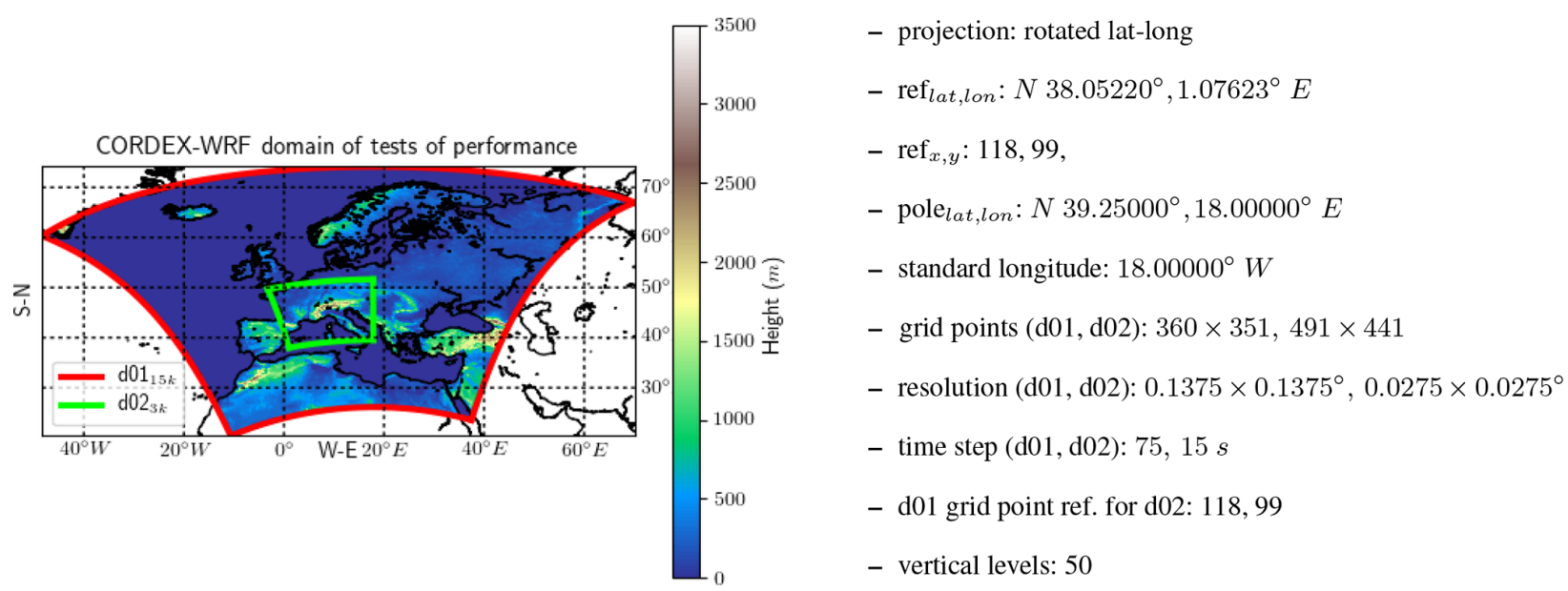

Figure 17. Two-nested domain WRF3.8.1 configuration in which different performance tests were carried out.

(a)

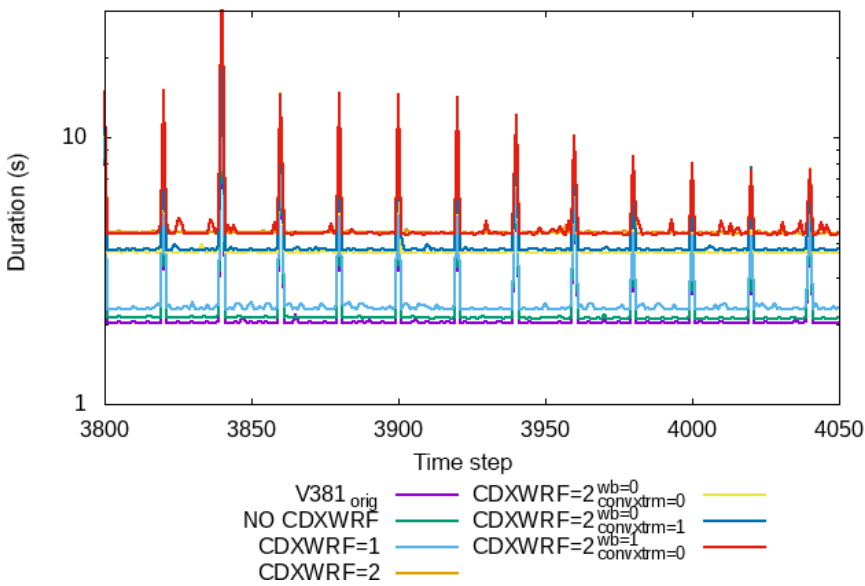

(b)

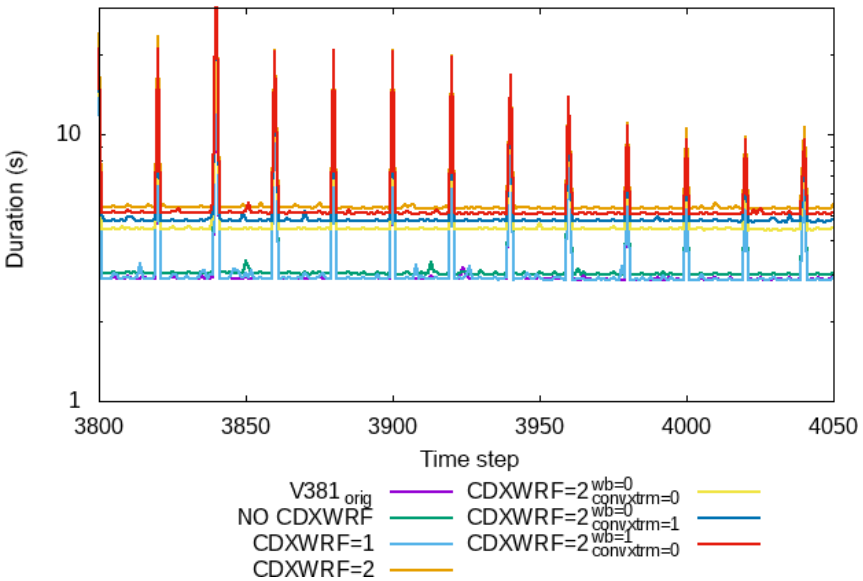

Figure 18. Elapsed times for each individual time-step integration on nested domain d02 (time steps from number 3800, simulating date 1 January 2014 15:35:00 UTC, to 4050 for 1 January 2014 16:37:30 UTC). Model was run with different module configurations. See text for more details. Larger time steps are related to activation of the shortwave and longwave radiation scheme (every 5 min). For WRF compilation using IFORT (a) and GCC compilers (b).

Table 4 describes the different configurations and namelist options used in this performance test. The first simulation (labeled v381orig), which is used as a reference, is the simulation with the original version of the model (here version 3.8.1) without the module. The other simulations are activation of the module (setting CORDEXDIAG) without setting the pre-compilation parameter CDXWRF (labeled NOCDXWRF), with pre-compilation parameter $C D X W R F=1$ (CDXWRF1), with pre-compilation parameter $\mathrm{CDXWRF}=2$, and computing all extra calculations (CDXWRF2). Finally, three more simulations (with $C D X W R F=2$ ) are made: without any extra calculation (CDXWRF2_00), without calculation of extra water budget terms (CDXWRF2_01), and without extremes from convection indices (CDXWRF2_10). Results might present some inconsistencies due to the fact that certain computations of diagnostics depend on the stability at each grid point, which might vary from run to run and depending on the workload of the HPC.

Results show that all the simulations (except CDXWRF1 with GCC) in which the module has been activated are slower than the simulation with the original version of the code (v381orig, $\langle t>=2.4248$ [IFORT], 3.5174[GCC] s). Simulation with version 1.3 of the module without pre-compilation flag CDXWRF (NOCDXWRF, $<t>=2.5058,3.6486 \mathrm{~s}$ ) is the second fastest. Simulation becomes slower when all the extra calculations are performed (CDXWRF2 $<t>=4.8296,5.9958 \mathrm{~s}$ ). The heaviest part of the module is related to the water budget computation (wb_diag=1), since when comparing to the simulation without extra calculations (CDXWRF2_00, $<t>=4.2038,5.0736 \mathrm{~s})$ there is an increase of only about 1 , or $9 \%\left(<t_{\text {step }}>\right.$ CDXWRF2_01 $/<t_{\text {step }}>$ CDXWRF2_00, 
Table 4. Mean elapsed time step of 5-day simulation and difference in time with respect to the original version of the code (v381orig) for different model configurations. See text for more details.

\begin{tabular}{llrr|rr}
\hline & & \multicolumn{2}{c|}{ IFORT } & \multicolumn{2}{c}{ GCC } \\
\cline { 3 - 6 } Label & Description & $<t_{\text {step }}>(\mathrm{s})$ & diff. $(\%)$ & $<t_{\text {step }}>(\mathrm{s})$ & diff. $(\%)$ \\
\hline v381orig & original WRF 3.8.1 & 2.4248 & - & 3.5174 & - \\
NOCDXWRF & without CDXWRF & 2.5058 & 3.34 & 3.6486 & 3.73 \\
CDXWRF1 & CDXWRF=1 & 2.6938 & 11.09 & 3.5070 & -0.27 \\
CDXWRF2 & CDXWRF=2 & 4.8296 & 99.17 & 5.9958 & 70.46 \\
CDXWRF2_00 & CDXWRF=2 wb_diag=0 \& convxtrm_diag=0 & 4.2038 & 73.37 & 5.0736 & 44.24 \\
CDXWRF2_01 & CDXWRF=2 wb_diag=0 \& convxtrm_diag=1 & 4.2388 & 74.81 & 5.4120 & 53.86 \\
CDXWRF2_10 & CDXWRF=2 wb_diag=1 \& convxtrm_diag=0 & 4.8510 & 100.06 & 5.7534 & 63.57 \\
\hline
\end{tabular}

$<t_{\text {step }}>$ CDXWRF2_01 $/<t_{\text {step }}>$ GCDXWRF2_00 $)$ GC mean time step when only statistics for extreme convective indices are activated (CDXWRF2_01, $<t>=4.2388,5.4120 \mathrm{~s})$ and 27, or $19 \% \quad(<$ $t_{\text {step }}>$ CDXWRF2_10 $/<t_{\text {step }}>$ CDXWRF2_00 $\left.\left.\right|_{\text {IFORT,GCC }}\right)$, when only the water budget terms are included (CDXWRF2_10, $<t>=4.8510,5.7534 \mathrm{~s})$. Reduction of the time step for CDXWRF1 with GCC must be related to a moment during which HPC Fram experiences a period of very low working load.

These results are not conclusive (optimization of the module should be tested in other HPC resources, domains, and compilers), but they provide a first insight on how the number of variables included during integration (in the derived grid) has an important effect on model performance by reducing or increasing the required amount of memory. CDXWRF1 and CDXWRF2_00 perform the same amount of computations of diagnostics, but the mean time step in CDXWRF2_00 is almost doubled (because in the CDXWRF2_00 case all the additional variables are defined but not diagnosed).

\section{Summary and outlook}

A series of modifications have been introduced into the WRF model in order to make it more suitable for CORDEX experiments. These modifications include the creation of a new module for the model and the modification of certain sections of the code. With the module implementation, users have the option to retrieve directly from the WRF output all the Core and almost all the Tier 1 CORDEX variables. Moreover, a series of additional variables not required by CORDEX, which may be of high interest to the regional climate modeling community, have been included. Additionally, a series of "generic" variables are provided that are independent of the model setup, which should allow for more robust intercomparisons.

A WRF user participating in a CORDEX regional climate experiment will strongly benefit when activating the module presented here, since it avoids most of the complex and time-consuming post-processing efforts necessary to obtain diagnostics required by CORDEX. Furthermore, the module makes use of the WRF online interpolation to pressure levels of certain three-dimensional variables, which is an expensive computational task. In addition, statistical values (like minimum fluxes or accumulation) are computed using the actual values obtained during the model integration. Since the use of the module avoids the post-processing of the model output, there is no need to keep large amounts of additional fields, which drastically reduces the requirements of disk storage (roughly $50 \%$ less disk storage).

In order to reduce the impact of the module during model integration, the setup of the module is managed before the compilation of the model via pre-compilation flags. This reduces the requirements of memory since the calculation of only required variables is activated. Different tests showed that the model performance is significantly improved when the code and the variables are constrained to the required ones (and not all of those available) and managed via precompilation flags (and via conditional statements from the model namelist as is usually done in the WRF model).

The module also establishes a first attempt to provide and implement generic definitions of certain diagnostics directly from regular model fields. This specific effort is intended to provide diagnostics that would not depend on the model configuration and/or the model itself, which will make intercomparisons between models more accurate, generic, and trustworthy. If there is also a certain coordination (e.g., within the CORDEX community) of the definition of these diagnostics, climate studies will benefit. Common definitions of diagnostics in a coordinated way across different modeling platforms will ensure the robustness of model intercomparisons.

There are certain variables from CORDEX Tier 1 protocol, which are not yet introduced but required. These are (1) snowmelt, (2) the daily maximum wind speed of gusts at $100 \mathrm{~m}$ (wsgsmax100), which is not yet introduced because of a lack of an appropriate method, and (3) intracloud, ground, and total lightning flashes (ic_lightning, cg_lightning, tot_lightning), even though a lightning scheme is already implemented in WRF. However, this implementa- 
tion is not appropriate for small domain patches used during parallelization. It has been found (Lluís Fita and Milagros Álvarez, CIMA personal communication, 2018) that lightning flash rates become patchy when the size of the parallel domain partitions are smaller than the actual extent of the cell. Lightning methods (Price and Rind, 1992; Wong et al., 2013) require encompassing the whole convective cell to analyze the updraft within the cell. When patches do not cover the whole cell, different values from the same cell at each parallel fraction of the domain are provided, from which spatial inconsistencies arise.

The module provides almost all the required CORDEX variables. However, users still need to perform some postprocessing of the output data in order to meet CORDEX standards, mainly the following:

- computation of the required different statistical values as daily, monthly and seasonal extremes (minimum, maximum, accumulations, means); and

- cmorization of the output understood as one file per variable, the right metadata and attributes, and general CF-compliant standard specifications.

There are some additional features that would make the module more useful for the climate regional community, which are also required by the CORDEX specifications. However, in order to prioritize the production of a basic, fully working, and useful version of the module as soon as possible, the following aspects are planned for future iterations and updates.

1. Flexibility enhancement is needed in terms of the capacity to provide a more flexible module that is easy to maintain and update with new requirements from CORDEX or WRF model updates.

2. Introduce new variables with a special focus on the implementation of more generic variable definitions

3. CF-compliant and cmorization output is needed because WRF output does not fully follow CF conventions. Thus, a huge coding effort is needed to provide fully CF-compliant output directly from it. Users still need to process the output of the model in order to provide data following all the CORDEX guidelines. Due to uncovered steps of the CF standard, a user of the WRF model still needs to concatenate files, change the names and attributes of variables, calculate temporal statistics over different periods (daily, monthly, seasonal), and provide the right time variables in order to fully reach the CF standard followed by CORDEX. However, these steps are computationally lighter and easier to perform in comparison to the computation of the different diagnostics and the vertical pressure interpolation already introduced in the module.
The incompatibility between WRF output and CF conventions can be overcome with the use of a complementary dedicated I/O library. This has been done, for example, on the RegIPSL platform (https://sourcesup.renater. fr/wiki/morcemed/Home, which uses WRF as an atmospheric model), which uses XIOS (http://forge.ipsl.jussieu. fr/ioserver, last access: 18 March 2019) libraries to manage the $\mathrm{I} / \mathrm{O}$.

The module is currently being implemented in the repository of the code in a dedicated branch. Once the module is fully implemented in the latest version of the model, and some additional tests are conducted, it might be possible that the model developing team decides to include it in the main source of the code.

Code availability. The discussed version of the module (1.3) in the present article for four different WRF versions is available through the following digital object identifiers (DOIs).

- WRF-CORDEX module version 1.3 for WRFV3.7.1: https://doi.org/10.5281/zenodo.1469639 (Fita et al., 2018a)

- WRF-CORDEX module version 1.3 for WRFV3.8.1: https://doi.org/10.5281/zenodo.1469645 (Fita et al., 2018b)

- WRF-CORDEX module version 1.3 for WRFV3.9.1.1: https://doi.org/10.5281/zenodo.1469647 (Fita et al., 2018c)

- WRF-CORDEX module version 1.3 for WRFV4.0: https://doi.org/10.5281/zenodo.1469651 (Fita et al., 2018d)

It is strongly recommended to make contact with lluis.fita@cima.fcen.uba.ar. This would facilitate the creation of a community of users of the module and make it easier to share updates and improvements with users.

A Wiki page has been set up in order to provide detailed instructions on how to manage the module and to give information about upcoming module versions and improvements. The page will be regularly updated and can be found at http://wiki.cima.fcen.uba. ar/mediawiki/index.php/CDXWRF (last access: 18 March 2019). 


\section{Appendix A: Requested CORDEX variables}

A generic list of requested variables by CORDEX is provided here. The reader is advised that there is not a single list of CORDEX requirement variables. It might depend on the experiment. However, with the aim of providing a generic list of variables, the CORDEX requirements are presented in Table A1. The source of the table is the ESGF servers at https://www.earthsystemcog.org/doc/detail/1065/ (last access: 18 March 2019). The same variables might appear at different levels (Core, Tier 1, Tier 2) as a function of the requested frequency and/or if they should be provided as statistical values between output frequency or instantaneous values, as well as depending on the experiment (FPS_Alps experiment requested additional variables provided in Table A2).

\section{Appendix B: CORDEX variables in WRF}

\section{B1 Core variables}

The variables given in Table B1 are always provided when the module is activated with the use of the pre-compilation flag CORDEXDIAG. These variables appear in the auxiliary output file number 9 . It is recommended to set the name of this file as wrfcdx_d<domain>_<date>. Note that some variables might not be produced according to chosen namelist options.

\section{B2 Tier 1}

The variables given in Table B2 are provided if the preprocessing variable CDXWRF is set to 1 . These variables also appear in the auxiliary output file number 9 . Note that some variables might not be produced according to chosen namelist options.

\section{B3 Additional}

The variables from Table B3 are provided if the preprocessing variable CDXWRF is set to 2 . These variables also appear in the auxiliary output file number 9 . Note that some variables might not be produced according to chosen namelist options.

\section{B4 Instantaneous}

The variables given in Table B4 are provided if some modifications are made in the WRF code. These variables represent instantaneous values for a certain number of variables that are internally used. These variables also appear in the auxiliary output file number 9 . Note that some variables might not be produced according to chosen namelist options. 
Table A1. CORDEX requested variables (from https://www.earthsystemcog.org/doc/detail/1065/). Ovarn: variable output name, L: level of requirement (c, Core; 1, Tier 1; 2, Tier 2), activation: option to get the variable from WRF (wrfout, standard WRF output; clwrf, after clWRF modifications; cdxdiag, basic CORDEXDIAG compilation; cdxwrf1, CORDEXDIAG activating pre-compilation flag cdxwrf=1; cdxwrf2, CORDEXDIAG activating pre-compilation flag cdxwrf=2; not available, not retrievable in this version of the module), ${ }^{*}$ indicates when a variable has a dependency on the chosen scheme.

\begin{tabular}{|c|c|c|c|c|c|}
\hline No. & Ovarn & Units & $\mathrm{L}$ & Variable comment & Activation \\
\hline 1 & tas & $\mathrm{K}$ & $\mathrm{c}$ & $2 \mathrm{~m}$ air temperature & wrfout \\
\hline 2 & tasmax & $\mathrm{K}$ & $\mathrm{c}$ & Daily maximum $2 \mathrm{~m}$ air temperature & clwrf \\
\hline 3 & tasmin & $\mathrm{K}$ & $\mathrm{c}$ & Daily minimum $2 \mathrm{~m}$ air temperature & clwrf \\
\hline 4 & $\mathrm{pr}$ & $\mathrm{kg} \mathrm{m}^{-2} \mathrm{~s}^{-1}$ & $\mathrm{c}$ & Precipitation & cdxdiag \\
\hline 5 & ps & $\mathrm{Pa}$ & 1 & Surface pressure & cdxdiag \\
\hline 6 & psl & $\mathrm{Pa}$ & c & Mean sea level pressure & cdxdiag \\
\hline 7 & huss & 1 & $\mathrm{c}$ & $2 \mathrm{~m}$ specific humidity & cdxdiag \\
\hline 8 & sfcWind & $\mathrm{ms}^{-1}$ & $\mathrm{c}$ & $10 \mathrm{~m}$ wind speed & cdxdiag \\
\hline 9 & sfcWindmax & $\mathrm{ms}^{-1}$ & c & Daily maximum $10 \mathrm{~m}$ wind speed & clwrf \\
\hline 10 & $\mathrm{clt}^{*}$ & $\%$ & $\mathrm{c}$ & Total cloud cover & cdxdiag \\
\hline 11 & sund & $\mathrm{s}$ & $\mathrm{c}$ & Sunshine hours & cdxdiag \\
\hline 12 & rsds* & $\mathrm{W} \mathrm{m}^{-2}$ & $\mathrm{c}$ & Surface downwelling shortwave radiation & cdxdiag \\
\hline 13 & rlds* & $\mathrm{W} \mathrm{m}^{-2}$ & $\mathrm{c}$ & Surface downwelling longwave radiation & cdxdiag \\
\hline 14 & hfls* & $\mathrm{W} \mathrm{m}^{-2}$ & $\mathrm{c}$ & Surface latent heat flux & cdxdiag \\
\hline 15 & hfss* & $\mathrm{W} \mathrm{m}^{-2}$ & $\mathrm{c}$ & Surface sensible heat flux & cdxdiag \\
\hline 16 & rsus* & $\mathrm{W} \mathrm{m}^{-2}$ & $\mathrm{c}$ & Surface upwelling shortwave radiation & cdxdiag \\
\hline 17 & rlus* & $\mathrm{W} \mathrm{m}^{-2}$ & $\mathrm{c}$ & Surface upwelling longwave radiation & cdxdiag \\
\hline 18 & evspsbl* & $\mathrm{kg} \mathrm{m}^{-2} \mathrm{~s}^{-1}$ & $\mathrm{c}$ & Surface evaporation & cdxdiag \\
\hline 19 & evspsblpot & $\mathrm{kg} \mathrm{m}^{-2} \mathrm{~s}^{-1}$ & 1 & Potential evapotranspiration & cdxdiag \\
\hline 20 & mrfso & $\mathrm{kg} \mathrm{m}^{-2}$ & $\mathrm{c}$ & Soil frozen water content & not available \\
\hline 21 & mrros & $\mathrm{kg} \mathrm{m}^{-2} \mathrm{~s}^{-1}$ & $\mathrm{c}$ & Surface runoff & cdxdiag \\
\hline 22 & mrro & $\mathrm{kg} \mathrm{m}^{-2} \mathrm{~s}^{-1}$ & $\mathrm{c}$ & Total runoff & cdxdiag \\
\hline 23 & mrso & $\mathrm{kg} \mathrm{m}^{-2}$ & c & Total soil moisture content & cdxdiag \\
\hline 24 & snw & $\mathrm{kg} \mathrm{m}^{-2}$ & $\mathrm{c}$ & Snow amount & cdxdiag \\
\hline 25 & snm & $\mathrm{kg} \mathrm{m}^{-2} \mathrm{~s}^{-1}$ & $\mathrm{c}$ & Snowmelt & not available \\
\hline 26 & prhmax & $\mathrm{kg} \mathrm{m}^{-2} \mathrm{~s}^{-1}$ & 1 & Maximum $1 \mathrm{~h}$ precipitation rate within $24 \mathrm{~h}$ period & not available \\
\hline 27 & prc & $\mathrm{kg} \mathrm{m}^{-2} \mathrm{~s}^{-1}$ & 1 & Convective precipitation & cdxdiag \\
\hline 28 & rlut* & $\mathrm{W} \mathrm{m}^{-2}$ & $\mathrm{c}$ & TOA outgoing longwave radiation & cdxdiag \\
\hline 29 & $\mathrm{rsdt}^{*}$ & $\mathrm{~W} \mathrm{~m}^{-2}$ & $\mathrm{c}$ & TOA incident shortwave radiation & cdxdiag \\
\hline 30 & rsut* & $\mathrm{W} \mathrm{m}^{-2}$ & $\mathrm{c}$ & TOA outgoing shortwave radiation & cdxdiag \\
\hline 31 & uas & $\mathrm{ms}^{-1}$ & $\mathrm{c}$ & Eastward $10 \mathrm{~m}$ wind speed & cdxdiag \\
\hline 32 & vas & $\mathrm{m} \mathrm{s}^{-1}$ & $\mathrm{c}$ & Northward $10 \mathrm{~m}$ wind speed & cdxdiag \\
\hline 33 & wsgsmax & $\mathrm{ms}^{-1}$ & 1 & Maximum $10 \mathrm{~m}$ gust wind speed & cdxdiag \\
\hline 34 & tauu & $\mathrm{Pa}$ & 1 & Surface downward eastward wind stress & cdxdiag \\
\hline 35 & tauv & $\mathrm{Pa}$ & 1 & Surface downward northward wind stress & cdxdiag \\
\hline 36 & ts & $\mathrm{K}$ & 1 & Surface (skin) temperature & cdxdiag \\
\hline 37 & $\mathrm{zmla}^{*}$ & $\mathrm{~m}$ & 1 & Atmospheric boundary layer thickness & wrfout \\
\hline 38 & prw & $\mathrm{kg} \mathrm{m}^{-2}$ & 1 & Column water vapor & cdxdiag \\
\hline 39 & clwvi & $\mathrm{kg} \mathrm{m}^{-2}$ & 1 & Column condensed (liquid + ice) water content & cdxdiag \\
\hline 40 & clivi & $\mathrm{kg} \mathrm{m}^{-2}$ & 1 & Column ice water content & cdxdiag \\
\hline 41 & ua850 & $\mathrm{m} \mathrm{s}^{-1}$ & $\mathrm{c}$ & Zonal (eastward) wind at $850 \mathrm{hPa}$ & cdxdiag \\
\hline 42 & va850 & $\mathrm{m} \mathrm{s}^{-1}$ & $\mathrm{c}$ & Meridional (northward) wind at $850 \mathrm{hPa}$ & cdxdiag \\
\hline 43 & $\operatorname{ta} 850$ & $\mathrm{~K}$ & c & Temperature at $850 \mathrm{hPa}$ & cdxdiag \\
\hline 44 & hus850 & 1 & $\mathrm{c}$ & Specific humidity at $850 \mathrm{hPa}$ & cdxdiag \\
\hline 45 & ua500 & $\mathrm{ms}^{-1}$ & $\mathrm{c}$ & Zonal (eastward) wind at $500 \mathrm{hPa}$ & cdxdiag \\
\hline 46 & va500 & $\mathrm{ms}^{-1}$ & $\mathrm{c}$ & Meridional (northward) wind at $500 \mathrm{hPa}$ & cdxdiag \\
\hline 47 & zg500 & $\mathrm{m}$ & $\mathrm{c}$ & Geopotential height at $500 \mathrm{hPa}$ & cdxdiag \\
\hline 48 & $\operatorname{ta} 500$ & $\mathrm{~K}$ & $\mathrm{c}$ & Temperature at $500 \mathrm{hPa}$ & cdxdiag \\
\hline 49 & ua200 & $\mathrm{ms}^{-1}$ & $\mathrm{c}$ & Zonal (eastward) wind at $200 \mathrm{hPa}$ & cdxdiag \\
\hline 50 & va200 & $\mathrm{ms}^{-1}$ & $\mathrm{c}$ & Meridional (northward) wind at $200 \mathrm{hPa}$ & cdxdiag \\
\hline
\end{tabular}


Table A1. Continued.

\begin{tabular}{llllll}
\hline No. & Ovarn & Units & L & Variable comment & Activation \\
\hline 51 & ta200 & $\mathrm{K}$ & $\mathrm{c}$ & Temperature at $200 \mathrm{hPa}$ & cdxdiag \\
52 & zg200 & $\mathrm{m}$ & $\mathrm{c}$ & Geopotential height at $200 \mathrm{hPa}$ & cdxdiag \\
53 & clh* $^{*}$ & $\%$ & 1 & High clouds $(p<440 \mathrm{hPa})$ & cdxdiag \\
54 & clm $^{*}$ & $\%$ & 1 & Medium clouds $(680 \mathrm{hPa})$ & cdxdiag \\
55 & cll $^{*}$ & $\%$ & 1 & Low clouds $(p>680 \mathrm{hPa})$ & cdxdiag \\
56 & snc & $\%$ & $\mathrm{c}$ & Snow area fraction & cdxdiag \\
57 & snd & $\mathrm{m}$ & $\mathrm{c}$ & Snow depth & cdxdiag \\
58 & sic & $\%$ & $\mathrm{c}$ & Sea ice fraction & not available \\
59 & prsn & $\mathrm{kg} \mathrm{m}^{-2} \mathrm{~s}-1$ & 1 & Snowfall flux & cdxdiag \\
60 & areacella & $\mathrm{m} 2$ & $\mathrm{c}$ & Atmosphere grid-cell area & not available \\
61 & orog & $\mathrm{m}$ & $\mathrm{c}$ & Surface altitude & not available \\
62 & sftlf & $\%$ & $\mathrm{c}$ & Land area fraction & not available \\
63 & sftgif & $\%$ & $\mathrm{c}$ & Fraction of grid cell covered with glacier & not available \\
64 & mrsofc & $\mathrm{kg} \mathrm{m}^{-2}$ & $\mathrm{c}$ & Capacity of soil to store water & not available \\
65 & rootd & $\mathrm{m}$ & $\mathrm{c}$ & Maximum root depth & not available \\
\hline
\end{tabular}

* Scheme dependant.

Table A2. As in Table A1, but for the additional variables requested by the CORDEX FPS_Alps experiment.

\begin{tabular}{|c|c|c|c|c|c|}
\hline No. & Ovarn & Units & $\mathrm{L}$ & Variable comment & CDXWRF option \\
\hline 1 & ua1000 & $\mathrm{ms}^{-1}$ & c & Zonal (eastward) wind at $1000 \mathrm{hPa}$ & cdxdiag \\
\hline 2 & va1000 & $\mathrm{m} \mathrm{s}^{-1}$ & $\mathrm{c}$ & Meridional (northward) wind at $1000 \mathrm{hPa}$ & cdxdiag \\
\hline 3 & ta1000 & $\mathrm{K}$ & $\mathrm{c}$ & Temperature at $1000 \mathrm{hPa}$ & cdxdiag \\
\hline 4 & hus 1000 & 1 & $\mathrm{c}$ & Specific humidity at $1000 \mathrm{hPa}$ & cdxdiag \\
\hline 5 & zg1000 & $\mathrm{m}$ & $\mathrm{c}$ & Geopotential height at $1000 \mathrm{hPa}$ & cdxdiag \\
\hline 6 & wa1000 & $\mathrm{m} \mathrm{s}^{-1}$ & $\mathrm{c}$ & Vertical (upward) wind at $1000 \mathrm{hPa}$ & cdxdiag \\
\hline 7 & ua925 & $\mathrm{ms}^{-1}$ & $\mathrm{c}$ & Zonal (eastward) wind at $925 \mathrm{hPa}$ & cdxdiag \\
\hline 8 & va925 & $\mathrm{ms}^{-1}$ & $\mathrm{c}$ & Meridional (northward) wind at $925 \mathrm{hPa}$ & cdxdiag \\
\hline 9 & ta925 & $\mathrm{K}$ & $\mathrm{c}$ & Temperature at $925 \mathrm{hPa}$ & cdxdiag \\
\hline 10 & hus925 & 1 & $\mathrm{c}$ & Specific humidity at $925 \mathrm{hPa}$ & cdxdiag \\
\hline 11 & zg925 & $\mathrm{m}$ & $\mathrm{c}$ & Geopotential height at $925 \mathrm{hPa}$ & cdxdiag \\
\hline 12 & wa925 & $\mathrm{m} \mathrm{s}^{-1}$ & $\mathrm{c}$ & Vertical (upward) wind at $925 \mathrm{hPa}$ & cdxdiag \\
\hline 13 & ua700 & $\mathrm{ms}^{-1}$ & $\mathrm{c}$ & Zonal (eastward) wind at $700 \mathrm{hPa}$ & cdxdiag \\
\hline 14 & va700 & $\mathrm{ms}^{-1}$ & $\mathrm{c}$ & Meridional (northward) wind at $700 \mathrm{hPa}$ & cdxdiag \\
\hline 15 & ta700 & $\mathrm{K}$ & $\mathrm{c}$ & Temperature at $700 \mathrm{hPa}$ & cdxdiag \\
\hline 16 & hus700 & 1 & $\mathrm{c}$ & Specific humidity at $700 \mathrm{hPa}$ & cdxdiag \\
\hline 17 & $\operatorname{zg} 700$ & $\mathrm{~m}$ & $\mathrm{c}$ & Geopotential height at $700 \mathrm{hPa}$ & cdxdiag \\
\hline 18 & wa700 & $\mathrm{ms}^{-1}$ & $\mathrm{c}$ & Vertical (upward) wind at $700 \mathrm{hPa}$ & cdxdiag \\
\hline 19 & wa850 & $\mathrm{m} \mathrm{s}^{-1}$ & $\mathrm{c}$ & Vertical (upward) wind at $850 \mathrm{hPa}$ & cdxdiag \\
\hline 20 & wa500 & $\mathrm{ms}^{-1}$ & $\mathrm{c}$ & Vertical (upward) wind at $500 \mathrm{hPa}$ & cdxdiag \\
\hline 21 & wa200 & $\mathrm{ms}^{-1}$ & $\mathrm{c}$ & Vertical (upward) wind at $200 \mathrm{hPa}$ & cdxdiag \\
\hline 22 & wsgsmax $100 \mathrm{~m}$ & $\mathrm{~ms}^{-1}$ & 1 & Maximum wind speed of gust at $100 \mathrm{~m}$ & cdxdiag \\
\hline 23 & ic_lightning & counts & 1 & Intra-cloud lightning flashes & not available \\
\hline 24 & cg_lightning & counts & 1 & Cloud-ground lightning flashes & not available \\
\hline 25 & total_lightning & counts & 1 & Total number lightning flashes & not available \\
\hline 26 & clgvi & $\mathrm{kg} \mathrm{m}^{-2}$ & 1 & Vertical integral of mass content of graupel & cdxwrf=1 \\
\hline 27 & clhvi & $\mathrm{kg} \mathrm{m}^{-2}$ & 1 & Vertical integral of mass content of hail & cdxwrf $=1$ \\
\hline 28 & CAPE & $\mathrm{J} \mathrm{kg}^{-1}$ & 1 & 2-D maximum convective available potential energy & cdxwrf $=1$ \\
\hline 29 & CIN & $\mathrm{J} \mathrm{kg}^{-1}$ & 1 & 2-D maximum convective inhibition & cdxwrf $=1$ \\
\hline
\end{tabular}


Table B1. Description of CORDEX Core variables provided with the module. "Kind" specifies when the variable is computed; a: computed all time steps, o: only at output time, t: according to a frequency in the namelist, s: statistic value from internal integration values and initialized after each output time step.

\begin{tabular}{|c|c|c|c|c|}
\hline CF name & WRF name & Description & Units & Kind \\
\hline \multicolumn{5}{|l|}{ 2-D } \\
\hline Lon. & LON & Longitude & degrees_east & o \\
\hline Lat. & LAT & Latitude & degrees_north & o \\
\hline cltmean & CLTMEAN & Mean total cloudiness in CORDEX output & $\%$ & $\mathrm{t}$ \\
\hline cllmean & CLLMEAN & Mean low-level cloudiness ( $p \geq 68000 \mathrm{~Pa}$ ) in CORDEX output & $\%$ & $\mathrm{t}$ \\
\hline clmmean & CLMMEAN & $\begin{array}{l}\text { Mean mid-level cloudiness }(44000 \leq p< \\
68000 \mathrm{~Pa}) \text { in CORDEX output }\end{array}$ & $\%$ & $\mathrm{t}$ \\
\hline clhmean & CLHMEAN & $\begin{array}{l}\text { Mean high-level cloudiness }(p<44000 \mathrm{~Pa} \text { ) IN } \\
\text { CORDEX output }\end{array}$ & $\%$ & $\mathrm{t}$ \\
\hline mrso & MRSO & Total soil content & $\mathrm{kg} \mathrm{m}^{-2}$ & o \\
\hline prw & PRW & Water vapor path & $\mathrm{kg} \mathrm{m}^{-2}$ & o \\
\hline psl & PSL & Sea level pressure & $\mathrm{Pa}$ & o \\
\hline clwvi & CLWVI & Liquid water path & $\mathrm{kg} \mathrm{m}^{-2}$ & o \\
\hline clivi & CLIVI & Ice water path & $\mathrm{kg} \mathrm{m}^{-2}$ & o \\
\hline hurs $^{\mathrm{a}}$ & HURS & $2 \mathrm{~m}$ relative humidity & 1 & o \\
\hline huss & HUSS & $2 \mathrm{~m}$ specific humidity & 1 & o \\
\hline slw & SLW & Total soil liquid water content & $\mathrm{kg} \mathrm{m}^{-2}$ & o \\
\hline uas & UAS & $10 \mathrm{~m}$ eastward wind speed & $\mathrm{ms}^{-1}$ & o \\
\hline vas & VAS & $10 \mathrm{~m}$ northward wind speed & $\mathrm{ms}^{-1}$ & o \\
\hline wsgsmax & WSGSMAX & Maximum near-surface wind speed of gust & $\mathrm{ms}^{-1}$ & s \\
\hline usgsmax & USGSMAX & Eastward maximum near-surface wind speed of gust & $\mathrm{ms}^{-1}$ & $\mathrm{~s}$ \\
\hline vsgsmax & VSGSMAX & Northward maximum near-surface wind speed of gust & $\mathrm{ms}^{-1}$ & $\mathrm{~s}$ \\
\hline totwsgsmax & TOTWSGSMAX & Total (TKE + h. pr) Maximum near-surface wind speed of gust & $\mathrm{ms}^{-1}$ & s \\
\hline totugsmax & TOTUGSMAX & Total eastward maximum near-surface wind speed of gust & $\mathrm{m} \mathrm{s}^{-1}$ & $\mathrm{~s}$ \\
\hline totvgsmax & TOTVGSMAX & Total northward maximum near-surface wind speed of gust & $\mathrm{ms}^{-1}$ & s \\
\hline wsz100max & WSZ100MAX & Maximum $100 \mathrm{~m}$ nwind speed & $\mathrm{m} \mathrm{s}^{-1}$ & $\mathrm{~s}$ \\
\hline uz100max & UZ100MAX & Eastward maximum $100 \mathrm{~m}$ wind speed & $\mathrm{ms}^{-1}$ & $\mathrm{~s}$ \\
\hline vz100max & VZ100MAX & Northward maximum $100 \mathrm{~m}$ wind speed & $\mathrm{ms}^{-1}$ & $\mathrm{~s}$ \\
\hline sund & SUND & Sunshine length (ac. time SWDOWN $>120 \mathrm{~W} \mathrm{~m}^{-2}$ ) & second & $\mathrm{s}$ \\
\hline tauu & TAUU & Northward downward wind stress at $10 \mathrm{~m}$ & $\mathrm{~m}^{2} \mathrm{~s}^{-2}$ & o \\
\hline tauv & TAUV & Eastward downward wind stress at $10 \mathrm{~m}$ & $\mathrm{~m}^{2} \mathrm{~s}^{-2}$ & o \\
\hline tauugen & TAUUGEN & Generic eastward downward wind stress at $10 \mathrm{~m}$ & $\mathrm{~m}^{2} \mathrm{~s}^{-2}$ & o \\
\hline tauvgen & TAUVGEN & Generic northward downward wind stress at $10 \mathrm{~m}$ & $\mathrm{~m}^{2} \mathrm{~s}^{-2}$ & o \\
\hline rsds & RSDS & Mean surface downwelling shortwave radiation & $\mathrm{W} \mathrm{m}^{-2}$ & s \\
\hline rlds & RLDS & Mean surface downwelling longwave radiation & $\mathrm{W} \mathrm{m}^{-2}$ & $\mathrm{~s}$ \\
\hline hfls & HFLS & Mean surface upward latent heat flux & $\mathrm{W} \mathrm{m}^{-2}$ & s \\
\hline hfss & HFSS & Mean surface upward sensible heat flux & $\mathrm{W} \mathrm{m}^{-2}$ & s \\
\hline rsus & RSUS & Mean surface upwelling shortwave radiation & $\mathrm{W} \mathrm{m}^{-2}$ & $\mathrm{~s}$ \\
\hline rlus & RLUS & Mean surface upwelling longwave radiation & $\mathrm{W} \mathrm{m}^{-2}$ & $\mathrm{~s}$ \\
\hline rsusgen & RSUSGEN & Mean generic surface upwelling shortwave radiation & $\mathrm{W} \mathrm{m}^{-2}$ & $\mathrm{~s}$ \\
\hline rlusgen & RLUSGEN & Mean generic surface upwelling longwave radiation & $\mathrm{W} \mathrm{m}^{-2}$ & $\mathrm{~s}$ \\
\hline evspsbl & EVSPSBL & Mean evaporation & $\mathrm{kg} \mathrm{m}^{-2} \mathrm{~s}^{-1}$ & s \\
\hline evspsblpot & EVSPSBLPOT & Mean potential evapotranspiration & $\mathrm{kg} \mathrm{m}^{-2} \mathrm{~s}^{-1}$ & $\mathrm{~s}$ \\
\hline evspsblpotgen & EVSPSBLPOTGEN & Mean generic potential evapotranspiration & $\mathrm{kg} \mathrm{m}^{-2} \mathrm{~s}^{-1}$ & $\mathrm{~s}$ \\
\hline $\mathrm{cd}$ & CDCDX & Drag coefficient & - & o \\
\hline cdgen & cdgen & Generic drag coefficient & - & o \\
\hline snc & SNC & Mean snow area fraction & $\%$ & s \\
\hline snd & SND & Mean snow depth & $\mathrm{m}$ & $\mathrm{s}$ \\
\hline mrros $^{b}$ & MRROS & Mean surface runoff & $\mathrm{kg} \mathrm{m}^{-2} \mathrm{~s}^{-1}$ & s \\
\hline mrro $^{b}$ & MRRO & Mean total runoff & $\mathrm{kg} \mathrm{m}^{-2} \mathrm{~s}^{-1}$ & $\mathrm{~s}$ \\
\hline
\end{tabular}


Table B1. Continued.

\begin{tabular}{|c|c|c|c|c|}
\hline $\mathrm{CF}$ name & WRF name & Description & Units & Kind \\
\hline \multicolumn{5}{|l|}{ 2-D } \\
\hline $\mathrm{mrsol}^{\mathrm{b}}$ & MRSOL & Mean total water content of soil layer & $\mathrm{kg} \mathrm{m}^{-2}$ & $\mathrm{~s}$ \\
\hline $\mathrm{pr}$ & PR & Precipitation flux & $\mathrm{kg} \mathrm{m}^{-2} \mathrm{~s}^{-1}$ & $\mathrm{~s}$ \\
\hline prl & PRL & Large-scale precipitation flux & $\mathrm{kg} \mathrm{m}^{-2} \mathrm{~s}^{-1}$ & $\mathrm{~s}$ \\
\hline prc & PRC & Convective precipitation flux & $\mathrm{kg} \mathrm{m}^{-2} \mathrm{~s}^{-1}$ & $\mathrm{~s}$ \\
\hline prsh & PRSH & Shallow-cumulus precipitation flux & $\mathrm{kg} \mathrm{m}^{-2} \mathrm{~s}^{-1}$ & $\mathrm{~s}$ \\
\hline prsn & PRSN & Solid precipitation flux & $\mathrm{kg} \mathrm{m}^{-2} \mathrm{~s}^{-1}$ & $\mathrm{~s}$ \\
\hline snw & SNW & Accumulated snow precipitation & $\mathrm{kg} \mathrm{m}^{-2}$ & $\mathrm{~s}$ \\
\hline rsdt & RSDT & Mean top-of-atmosphere (TOA) incident shortwave radiation & $\mathrm{kg} \mathrm{m}^{-2}$ & $\mathrm{~s}$ \\
\hline rsut & RSUT & Mean TOA outgoing shortwave radiation & $\mathrm{kg} \mathrm{m}^{-2}$ & $\mathrm{~s}$ \\
\hline rlut & RLUT & Mean TOA outgoing Longwave radiation & $\mathrm{kg} \mathrm{m}^{-2}$ & $\mathrm{~s}$ \\
\hline ps & CDXPS & Surface pressure & $\mathrm{Pa}$ & o \\
\hline ts & CDXTS & Skin temperature & $\mathrm{K}$ & o \\
\hline
\end{tabular}

${ }^{a}$ Needed for other variables. ${ }^{b}$ Unmasked to sea points.

Table B2. As in Table B1, but for the description of CORDEX Tier 1 variables provided with the module.

\begin{tabular}{|c|c|c|c|c|}
\hline CF name & WRF name & Description & Units & Kind \\
\hline clgvi & CLGVI & Graupel water path & $\mathrm{kg} \mathrm{m}^{-2}$ & o \\
\hline clhvi & CLHVI & Hail water path & $\mathrm{kg} \mathrm{m}^{-2}$ & o \\
\hline zmlagen & ZMLAGEN & $\begin{array}{l}\text { Generic boundary layer height theta(zmlagen })> \\
\min (\text { theta[mix. layer] })+1.5 \mathrm{~K}\end{array}$ & $\mathrm{~m}$ & o \\
\hline capemin* & CAPEMIN & $\begin{array}{l}\text { Minimum convective available potential } \\
\text { energy }\end{array}$ & $\mathrm{J} \mathrm{kg}^{-1}$ & $\mathrm{~s}$ \\
\hline capemax* & CAPEMAX & $\begin{array}{l}\text { Maximum convective available potential } \\
\text { energy }\end{array}$ & $\mathrm{J} \mathrm{kg}^{-1}$ & $\mathrm{~s}$ \\
\hline capemean* & CAPEMEAN & $\begin{array}{l}\text { Mean convective available potential } \\
\text { energy }\end{array}$ & $\mathrm{J} \mathrm{kg}^{-1}$ & $\mathrm{~s}$ \\
\hline cinmin* & CINMIN & Minimum convective inhibition & $\mathrm{J} \mathrm{kg}^{-1}$ & $\mathrm{~s}$ \\
\hline $\operatorname{cinmax}^{*}$ & CINMAX & Maximum convective inhibition & $\mathrm{J} \mathrm{kg}^{-1}$ & $\mathrm{~s}$ \\
\hline cinmeann* & CINMEAN & Mean convective inhibition & $\mathrm{J} \mathrm{kg}^{-1}$ & $\mathrm{~s}$ \\
\hline lfcpmin* & LFCPMIN & Minimum pressure-level free convection & $\mathrm{Pa}$ & $\mathrm{s}$ \\
\hline lfcpmax* & LFCPMAX & Maximum pressure-level free convection & $\mathrm{Pa}$ & $\mathrm{s}$ \\
\hline lfcpmean* & LFCPMEAN & Mean pressure-level free convection & $\mathrm{Pa}$ & $\mathrm{s}$ \\
\hline lfczmin* & LFCZMIN & Minimum height-level free convection & $\mathrm{m}$ & $\mathrm{s}$ \\
\hline lfczmax* & LFCZMAX & Maximum height-level free convection & $\mathrm{m}$ & $\mathrm{s}$ \\
\hline lfczmean* & LFCZMEAN & Mean height-level free convection & $\mathrm{m}$ & $\mathrm{s}$ \\
\hline limin* & LIMIN & Minimum lifted index & 1 & $\mathrm{~s}$ \\
\hline $\operatorname{limax} *$ & LIMAX & Maximum lifted index & 1 & $\mathrm{~s}$ \\
\hline limean* & LIMEAN & Mean lifted index & 1 & $\mathrm{~s}$ \\
\hline
\end{tabular}

It will be computed if the namelist parameter convxtrm_diag is set to 1 . 
Table B3. As in Table B1, but for the description of additional variables provided with the module.

\begin{tabular}{|c|c|c|c|c|}
\hline CF name & WRF name & Description & Units & Kind \\
\hline tdsmin & TDSMIN & Minimum surface dew point temperature & $\mathrm{K}$ & $\mathrm{s}$ \\
\hline tdsmax & TDSMAX & Maximum surface dew point temperature & $\mathrm{K}$ & $\mathrm{s}$ \\
\hline tdsmean & TDSMEAN & Mean surface dew point temperature & $\mathrm{K}$ & $\mathrm{s}$ \\
\hline $\operatorname{tfog}$ & TFOG & Time of presence of fog & $\mathrm{s}$ & $\mathrm{s}$ \\
\hline fogvisbltymin & FOGVISBLTYMIN & Minimum of visibility inside fog & $\mathrm{km}$ & s \\
\hline fogvisbltymax & FOGVISBLTYMAX & Maximum of visibility inside fog & $\mathrm{km}$ & s \\
\hline fogvisbltymean & FOGVISBLTYMEAN & Mean of visibility inside fog & $\mathrm{km}$ & $\mathrm{s}$ \\
\hline \multicolumn{5}{|l|}{$3-\mathrm{D}$} \\
\hline hur $^{\mathrm{a}}$ & HUR & Air relative humidity & 1 & $\mathrm{a}$ \\
\hline hus & HUS & Air specific humidity & 1 & o \\
\hline $\mathrm{zg}^{\mathrm{a}}$ & $\mathrm{ZG}$ & Air geopotential height & $\mathrm{m}$ & $\mathrm{a}$ \\
\hline press $^{\mathrm{a}}$ & Press & Air pressure & $\mathrm{Pa}$ & a \\
\hline $\mathrm{ta}^{\mathrm{a}}$ & TA & Air temperature & $\mathrm{K}$ & $\mathrm{a}$ \\
\hline ua & UA & Earth-rotated air eastward wind speed & $\mathrm{ms}^{-1}$ & o \\
\hline va & VA & Earth-rotated air northward wind speed & $\mathrm{ms}^{-1}$ & o \\
\hline
\end{tabular}

\begin{tabular}{|c|c|c|c|c|}
\hline \multicolumn{5}{|c|}{ Water budget $^{\mathrm{b}}$} \\
\hline$Q_{\text {hac }}$ & WBACDIABH & $\begin{array}{l}\text { Water budget column integrated and time accumulation of diabatic } \\
\text { heating from microphysics }\end{array}$ & $\mathrm{K}$ & $\mathrm{s}$ \\
\hline$\partial_{\mathrm{t}} \mathrm{quac}$ & WBACPW & $\begin{array}{l}\text { Water budget column integrated and time accumulated for water } \\
\text { vapor content }\end{array}$ & $\mathrm{mm}$ & $\mathrm{s}$ \\
\hline$\partial_{\mathrm{t}} \mathrm{qcac}$ & WBACPWC & Water budget col. int. \& time accumulated for cloud content & $\mathrm{mm}$ & $\mathrm{s}$ \\
\hline$\partial_{\mathrm{t}} \mathrm{qrac}$ & WBACPWR & Water budget col. int. \& time accumulated for rain content & $\mathrm{mm}$ & $\mathrm{s}$ \\
\hline$\partial_{\mathrm{t}} \mathrm{qsac}$ & WBACPWS & Water budget col. int. \& time accumulated for snow content & $\mathrm{mm}$ & $\mathrm{s}$ \\
\hline$\partial_{\mathrm{t}} \mathrm{qiac}$ & WBACPWI & Water budget col. int. \& time accumulated for ice content & $\mathrm{mm}$ & $\mathrm{s}$ \\
\hline$\partial_{\mathrm{t}} \mathrm{qhac}$ & WBACPWH & Water budget col. int. \& time accumulated for hail content & $\mathrm{mm}$ & $\mathrm{s}$ \\
\hline$\partial_{\mathrm{t}} \mathrm{qgac}$ & WBACPWG & Water budget col. int. \& time accumulated for graupel content & $\mathrm{mm}$ & $\mathrm{s}$ \\
\hline $\operatorname{adv}_{\mathrm{h}} \mathrm{qvac}$ & WBACF & W.B. c-int. acc. hor. convergence of water vapor $(+$, conv.; - , div. $)$ & $\mathrm{mm}$ & $\mathrm{s}$ \\
\hline $\operatorname{adv}_{h} q c a c$ & WBACFC & W.B. c-int. acc. hor. convergence of cloud (+, conv.; - , div. $)$ & $\mathrm{mm}$ & $\mathrm{s}$ \\
\hline $\operatorname{adv}_{\mathrm{h}} \mathrm{qrac}$ & WBACFR & W.B. c-int. acc. hor. convergence of rain $(+$, conv.; - , div. $)$ & $\mathrm{mm}$ & $\mathrm{s}$ \\
\hline $\operatorname{adv}_{\mathrm{h} q \mathrm{sac}}$ & WBACFS & W.B. c-int. acc. hor. convergence of snow (+, conv.; - , div. $)$ & $\mathrm{mm}$ & $\mathrm{s}$ \\
\hline $\operatorname{adv}_{\mathrm{h}} q \mathrm{iac}$ & WBACFI & W.B. c-int. acc. hor. convergence of ice $(+$, conv.; - , div. $)$ & $\mathrm{mm}$ & $\mathrm{s}$ \\
\hline $\operatorname{adv}_{h} q h a c$ & WBACFH & W.B. c-int. acc. hor. convergence of hail (+, conv.; - , div. $)$ & $\mathrm{mm}$ & $\mathrm{s}$ \\
\hline $\operatorname{adv}_{h} q g a c$ & WBACFG & W.B. c-int. acc. hor. convergence of graupel (+, conv.;,- div. $)$ & $\mathrm{mm}$ & $\mathrm{s}$ \\
\hline $\operatorname{adv}_{z}$ qvac & WBACZ & $\begin{array}{l}\text { W.B. c-int. acc. ver. convergence of water vapor }(+ \text {, conv.; }- \text {, div. }) \text {, } \\
\text { always } 0\end{array}$ & $\mathrm{~mm}$ & $\mathrm{~s}$ \\
\hline $\operatorname{adv}_{z} q c a c$ & WBACZC & W.B. c-int. acc. ver. convergence of cloud (+, conv.; - , div.) & $\mathrm{mm}$ & $\mathrm{s}$ \\
\hline $\operatorname{adv}_{z} \mathrm{qrac}$ & WBACZR & W.B. c-int. acc. ver. convergence of rain $(+$, conv.; - , div. $)$ & $\mathrm{mm}$ & $\mathrm{s}$ \\
\hline $\operatorname{adv}_{z} q \operatorname{qsac}$ & WBACZS & W.B. c-int. acc. ver. convergence of snow ( + , conv.; - , div. $)$ & $\mathrm{mm}$ & $\mathrm{s}$ \\
\hline $\operatorname{adv}_{z} q i a c$ & WBACZI & W.B. c-int. acc. ver. convergence of ice $(+$, conv.; - , div. $)$ & $\mathrm{mm}$ & $\mathrm{s}$ \\
\hline $\operatorname{adv}_{z}$ qhac & WBACZH & W.B. c-int. acc. ver. convergence of hail (+, conv.; - , div. $)$ & $\mathrm{mm}$ & $\mathrm{s}$ \\
\hline $\operatorname{adv}_{z}$ qgac & WBACZG & W.B. c-int. acc. ver. convergence of graupel $(+$, conv.; - , div. $)$ & $\mathrm{mm}$ & $\mathrm{s}$ \\
\hline$Q_{\mathrm{h}}^{1} \mathrm{ac}$ & WBACDIABHL & W.B. low-level acc. of diabatic heating from MP & $\mathrm{K}$ & $\mathrm{s}$ \\
\hline$Q_{\mathrm{h}}^{\mathrm{m}} \mathrm{ac}$ & WBACDIABHM & W.B. mid-level acc. of diabatic heating from MP & $\mathrm{K}$ & $\mathrm{s}$ \\
\hline$Q_{\mathrm{h}}^{\mathrm{m}} \mathrm{ac}$ & WBACDIABHH & W.B. high-level acc. of diabatic heating from MP & $\mathrm{K}$ & $\mathrm{s}$ \\
\hline$\partial_{t}^{1}$ qvac & WBACPWLV & W.B. low-level ( $p \geq 68000 \mathrm{~Pa})$ acc. for $\mathrm{QV}$ & $\mathrm{mm}$ & $\mathrm{s}$ \\
\hline$\partial_{\mathrm{t}}^{\mathrm{m}} \mathrm{quac}$ & WBACPWMV & W.B. mid-level $(44000 \leq p<68000 \mathrm{~Pa})$ acc. for $\mathrm{QV}$ & $\mathrm{mm}$ & $\mathrm{s}$ \\
\hline$\partial_{\mathrm{t}}^{\mathrm{h}} \mathrm{qvac}$ & WBACPWHV & W.B. high-level ( $p<44000 \mathrm{~Pa})$ acc. for QV & $\mathrm{mm}$ & $\mathrm{s}$ \\
\hline $\operatorname{adv}_{h}^{1} q v a c$ & WBACFLV & W.B. low-lev. acc. hor. convergence of QV & $\mathrm{mm}$ & $\mathrm{s}$ \\
\hline $\operatorname{adv}_{\mathrm{h}}^{\mathrm{m}} \mathrm{qvac}$ & WBACFMV & W.B. mid-lev. acc. hor. convergence of QV & $\mathrm{mm}$ & $\mathrm{s}$ \\
\hline $\operatorname{adv}_{h}^{h}$ qvac & WBACFHV & W.B. high-lev. acc. hor. convergence of QV & $\mathrm{mm}$ & $\mathrm{s}$ \\
\hline $\operatorname{adv}_{z}^{1} q v a c$ & WBACZLV & W.B. low-level acc. ver. convergence of QV & $\mathrm{mm}$ & $\mathrm{s}$ \\
\hline $\operatorname{adv}_{z}^{\mathrm{m}} \mathrm{qvac}$ & WBACZMV & W.B. mid-level acc. ver. convergence of QV & $\mathrm{mm}$ & $\mathrm{s}$ \\
\hline $\operatorname{adv}_{z} \mathrm{quac}$ & WBACZHV & W.B. high-level acc. ver. convergence of QV & $\mathrm{mm}$ & $\mathrm{s}$ \\
\hline
\end{tabular}


Table B3. Continued.

\begin{tabular}{|c|c|c|c|c|}
\hline CF name & WRF name & Description & Units & Kind \\
\hline$\partial_{\mathrm{t}}^{\mathrm{l}} \mathrm{qcac}$ & WBACPWLC & W.B. low-level ( $p \geq 68000 \mathrm{~Pa}$ ) acc. for QC & $\mathrm{mm}$ & $\mathrm{s}$ \\
\hline$\partial_{\mathrm{t}}^{\mathrm{m}} \mathrm{qcac}$ & WBACPWMC & W.B. mid-level (44000 $\leq p<68000 \mathrm{~Pa})$ acc. for QC & $\mathrm{mm}$ & $\mathrm{s}$ \\
\hline$\partial_{\mathrm{t}}^{\mathrm{h}} \mathrm{qcac}$ & WBACPWHC & W.B. high-level ( $p<44000 \mathrm{~Pa})$ acc. for QC & $\mathrm{mm}$ & $\mathrm{s}$ \\
\hline $\operatorname{adv}_{h}^{1} q c a c$ & WBACFLC & W.B. low-lev. acc. hor. convergence of QC & $\mathrm{mm}$ & $\mathrm{s}$ \\
\hline $\operatorname{adv}_{\mathrm{h}}^{\mathrm{m}} \mathrm{qcac}$ & WBACFMC & W.B. mid-lev. acc. hor. convergence of QC & $\mathrm{mm}$ & $\mathrm{s}$ \\
\hline $\operatorname{adv}_{\mathrm{h}}^{\mathrm{h}} \mathrm{qcac}$ & WBACFHC & W.B. high-lev. acc. hor. convergence of QC & $\mathrm{mm}$ & $\mathrm{s}$ \\
\hline $\operatorname{adv}_{z}^{1} q \mathrm{qcac}$ & WBACZLC & W.B. low-level acc. ver. convergence of QC & $\mathrm{mm}$ & $\mathrm{s}$ \\
\hline $\mathrm{adv}_{z}^{\mathrm{m}} \mathrm{qcac}$ & WBACZMC & W.B. mid-level acc. ver. convergence of QC & $\mathrm{mm}$ & $\mathrm{s}$ \\
\hline $\mathrm{adv}_{z}^{\mathrm{h}} \mathrm{qcac}$ & WBACZHC & W.B. high-level acc. ver. convergence of QC & $\mathrm{mm}$ & $\mathrm{s}$ \\
\hline$\partial_{\mathrm{t}}^{\mathrm{l} q \mathrm{qrac}}$ & WBACPWLR & W.B. low-level ( $p \geq 68000 \mathrm{~Pa})$ acc. for $\mathrm{QR}$ & $\mathrm{mm}$ & $\mathrm{s}$ \\
\hline$\partial_{\mathrm{t}}^{\mathrm{m}} \mathrm{qrac}$ & WBACPWMR & W.B. mid-level (44000 $\leq p<68000 \mathrm{~Pa})$ acc. for $\mathrm{QR}$ & $\mathrm{mm}$ & $\mathrm{s}$ \\
\hline$\partial_{\mathrm{t}}^{\mathrm{h}} \mathrm{qrac}$ & WBACPWHR & W.B. high-level ( $p<44000 \mathrm{~Pa}$ ) acc. for QR & $\mathrm{mm}$ & $\mathrm{s}$ \\
\hline $\operatorname{adv}_{\mathrm{h}}^{1} \mathrm{qrac}$ & WBACFLR & W.B. low-lev. acc. hor. convergence of QR & $\mathrm{mm}$ & s \\
\hline $\operatorname{adv}_{\mathrm{h}}^{\mathrm{m}} \mathrm{qrac}$ & WBACFMR & W.B. mid-lev. acc. hor. convergence of $\mathrm{QR}$ & $\mathrm{mm}$ & $\mathrm{s}$ \\
\hline $\operatorname{adv}_{\mathrm{h}}^{\mathrm{h}} \mathrm{qrac}$ & WBACFHR & W.B. high-lev. acc. hor. convergence of $\mathrm{QR}$ & $\mathrm{mm}$ & $\mathrm{s}$ \\
\hline $\operatorname{adv}_{z}^{1} q r a c$ & WBACZLR & W.B. low-level acc. ver. convergence of QR & $\mathrm{mm}$ & $\mathrm{s}$ \\
\hline $\operatorname{adv}_{z}^{\mathrm{m}} \mathrm{qrac}$ & WBACZMR & W.B. mid-level acc. ver. convergence of QR & $\mathrm{mm}$ & $\mathrm{s}$ \\
\hline $\operatorname{adv}_{z}^{\breve{h}} \mathrm{qrac}$ & WBACZHR & W.B. high-level acc. ver. convergence of QR & $\mathrm{mm}$ & $\mathrm{s}$ \\
\hline$\partial_{\mathrm{t}}^{1} \mathrm{qsac}$ & WBACPWLS & W.B. low-level ( $p \geq 68000 \mathrm{~Pa})$ acc. for QS & $\mathrm{mm}$ & s \\
\hline$\partial_{\mathrm{t}}^{\mathrm{m}} \mathrm{qsac}$ & WBACPWMS & W.B. mid-level $(44000 \leq p<68000 \mathrm{~Pa})$ acc. for QS & $\mathrm{mm}$ & $\mathrm{s}$ \\
\hline$\partial_{\mathrm{t}}^{\mathrm{h}} \mathrm{qsac}$ & WBACPWHS & W.B. high-level ( $p<44000 \mathrm{~Pa})$ acc. for QS & $\mathrm{mm}$ & s \\
\hline $\operatorname{adv}_{h}^{1} q s a c$ & WBACFLS & W.B. low-lev. acc. hor. convergence of QS & $\mathrm{mm}$ & $\mathrm{s}$ \\
\hline $\operatorname{adv}_{\mathrm{h}}^{\mathrm{m}} \mathrm{qsac}$ & WBACFMS & W.B. mid-lev. acc. hor. convergence of QS & $\mathrm{mm}$ & $\mathrm{s}$ \\
\hline $\operatorname{adv}_{\mathrm{h}}^{\mathrm{h}} \mathrm{qsac}$ & WBACFHS & W.B. high-lev. acc. hor. convergence of QS & $\mathrm{mm}$ & s \\
\hline $\operatorname{adv}_{z}^{1} q s a c$ & WBACZLS & W.B. low-level acc. ver. convergence of QS & $\mathrm{mm}$ & $\mathrm{s}$ \\
\hline $\operatorname{adv}_{z}^{\mathrm{m}} \mathrm{qsac}$ & WBACZMS & W.B. mid-level acc. ver. convergence of QS & $\mathrm{mm}$ & $\mathrm{s}$ \\
\hline $\mathrm{adv}_{z}^{\mathrm{h}} \mathrm{qsac}$ & WBACZHS & W.B. high-level acc. ver. convergence of QS & $\mathrm{mm}$ & $\mathrm{s}$ \\
\hline$\partial_{\mathrm{t}}^{\mathrm{l} q i a c}$ & WBACPWLI & W.B. low-level ( $p \geq 68000 \mathrm{~Pa})$ acc. for QI & $\mathrm{mm}$ & $\mathrm{s}$ \\
\hline$\partial_{\mathrm{t}}^{\mathrm{m}} \mathrm{qiac}$ & WBACPWMI & W.B. mid-level (44000 $\leq p<68000 \mathrm{~Pa}$ ) acc. for $\mathrm{QI}$ & $\mathrm{mm}$ & $\mathrm{s}$ \\
\hline$\partial_{\mathrm{t}}^{\mathrm{h}} \mathrm{qiac}$ & WBACPWHI & W.B. high-level ( $p<44000 \mathrm{~Pa})$ acc. for QI & $\mathrm{mm}$ & $\mathrm{s}$ \\
\hline $\operatorname{adv}_{\mathrm{h}}^{1} q i a c$ & WBACFLI & W.B. low-lev. acc. hor. convergence of QI & $\mathrm{mm}$ & $\mathrm{s}$ \\
\hline $\operatorname{adv}_{\mathrm{h}}^{\mathrm{m}} \mathrm{qiac}$ & WBACFMI & W.B. mid-lev. acc. hor. convergence of QI & $\mathrm{mm}$ & $\mathrm{s}$ \\
\hline $\operatorname{adv}_{h}^{\mathrm{h}} \mathrm{qiac}$ & WBACFHI & W.B. high-lev. acc. hor. convergence of QI & $\mathrm{mm}$ & $\mathrm{s}$ \\
\hline $\operatorname{adv}_{z}^{1} q i a c$ & WBACZLI & W.B. low-level acc. ver. convergence of QI & $\mathrm{mm}$ & $\mathrm{s}$ \\
\hline $\operatorname{adv}_{z}^{\mathrm{m}} \mathrm{qiac}$ & WBACZMI & W.B. mid-level acc. ver. convergence of QI & $\mathrm{mm}$ & $\mathrm{s}$ \\
\hline $\operatorname{adv}_{z}^{\mathrm{h}} \mathrm{qiac}$ & WBACZHI & W.B. high-level acc. ver. convergence of QI & $\mathrm{mm}$ & $\mathrm{s}$ \\
\hline$\partial_{\text {t }}^{1} \mathrm{qgac}$ & WBACPWLG & W.B. low-level ( $p \geq 68000 \mathrm{~Pa})$ acc. for QG & $\mathrm{mm}$ & $\mathrm{s}$ \\
\hline$\partial_{\mathrm{t}}^{\mathrm{m}} \mathrm{qgac}$ & WBACPWMG & W.B. mid-level (44000 $\leq p<68000 \mathrm{~Pa}$ ) acc. for $\mathrm{QG}$ & $\mathrm{mm}$ & $\mathrm{s}$ \\
\hline$\partial_{\mathrm{t}}^{\mathrm{h}} \mathrm{qgac}$ & WBACPWHG & W.B. high-level ( $p<44000 \mathrm{~Pa}$ ) acc. for QG & $\mathrm{mm}$ & $\mathrm{s}$ \\
\hline $\operatorname{adv}_{h}^{1} q g a c$ & WBACFLG & W.B. low-lev. acc. hor. convergence of QG & $\mathrm{mm}$ & $\mathrm{s}$ \\
\hline $\operatorname{adv}_{\mathrm{h}}^{\mathrm{m}} \mathrm{qgac}$ & WBACFMG & W.B. mid-lev. acc. hor. convergence of QG & $\mathrm{mm}$ & $\mathrm{s}$ \\
\hline $\operatorname{adv}_{h}^{h} q g a c$ & WBACFHG & W.B. high-lev. acc. hor. convergence of QG & $\mathrm{mm}$ & $\mathrm{s}$ \\
\hline $\operatorname{adv}_{z}^{1}$ qgac & WBACZLG & W.B. low-level acc. ver. convergence of QG & $\mathrm{mm}$ & $\mathrm{s}$ \\
\hline $\operatorname{adv}_{z}^{\mathrm{m}} \mathrm{qgac}$ & WBACZMG & W.B. mid-level acc. ver. convergence of QG & $\mathrm{mm}$ & $\mathrm{s}$ \\
\hline $\operatorname{adv}_{z} \mathrm{qgac}$ & WBACZHG & W.B. high-level acc. ver. convergence of QG & $\mathrm{mm}$ & $\mathrm{s}$ \\
\hline$\partial_{\mathrm{t}}^{\mathrm{l} q h a c}$ & WBACPWLH & W.B. low-level ( $p \geq 68000 \mathrm{~Pa}$ ) acc. for $\mathrm{QH}$ & $\mathrm{mm}$ & $\mathrm{s}$ \\
\hline$\partial_{\mathrm{t}}^{\mathrm{m}} \mathrm{qhac}$ & WBACPWMH & W.B. mid-level $(44000 \leq p<68000 \mathrm{~Pa})$ acc. for $\mathrm{QH}$ & $\mathrm{mm}$ & $\mathrm{s}$ \\
\hline$\partial_{\mathrm{t}}^{\mathrm{h}} \mathrm{qhac}$ & WBACPWHH & W.B. high-level ( $p<44000 \mathrm{~Pa}$ ) acc. for $\mathrm{QH}$ & $\mathrm{mm}$ & $\mathrm{s}$ \\
\hline $\operatorname{adv}_{h}^{1} q h a c$ & WBACFLH & W.B. low-lev. acc. hor. convergence of QH & $\mathrm{mm}$ & $\mathrm{s}$ \\
\hline $\mathrm{adv}_{\mathrm{h}}^{\mathrm{m}} \mathrm{qhac}$ & WBACFMH & W.B. mid-lev. acc. hor. convergence of QH & $\mathrm{mm}$ & $\mathrm{s}$ \\
\hline $\operatorname{adv}_{\mathrm{h}}^{\mathrm{h}} \mathrm{qhac}$ & WBACFHH & W.B. high-lev. acc. hor. convergence of $\mathrm{QH}$ & $\mathrm{mm}$ & $\mathrm{s}$ \\
\hline $\operatorname{adv}_{z}^{1}$ qhac & WBACZLH & W.B. low-level acc. ver. convergence of QH & $\mathrm{mm}$ & $\mathrm{s}$ \\
\hline $\operatorname{adv}_{z}^{\mathrm{m}} \mathrm{qhac}$ & WBACZMH & W.B. mid-level acc. ver. convergence of $\mathrm{QH}$ & $\mathrm{mm}$ & s \\
\hline $\operatorname{adv}_{z}^{\mathrm{h}} \mathrm{qhac}$ & WBACZHH & W.B. high-level acc. ver. convergence of $\mathrm{QH}$ & $\mathrm{mm}$ & s \\
\hline
\end{tabular}

${ }^{a}$ Needed for other variables. ${ }^{b}$ Variables will be computed if the namelist parameter output_wb is set to 1 . 
Table B4. As in Table B1, but for the description of CORDEX "instantaneous" variables provided with the module.

\begin{tabular}{|c|c|c|c|c|}
\hline $\mathrm{CF}$ name & WRF name & description & units & kind \\
\hline clt & CLT & Total cloudiness & 1 & $\mathrm{t}$ \\
\hline cll & CLL & Low-level cloudiness $(p \geq 68000 \mathrm{~Pa})$ & 1 & $\mathrm{t}$ \\
\hline $\operatorname{clm}$ & CLM & Mid-level cloudiness $(44000 \leq p<68000 \mathrm{~Pa})$ & 1 & $\mathrm{t}$ \\
\hline $\mathrm{clh}$ & CLH & High-level cloudiness $(p<44000 \mathrm{~Pa})$ & 1 & $\mathrm{t}$ \\
\hline cape & CDXCAPE & Convective available potential energy & $\mathrm{J} \mathrm{kg}^{-1}$ & $\mathrm{a} / \mathrm{o}^{*}$ \\
\hline $\operatorname{cin}$ & $\mathrm{CIN}$ & Convective inhibition & $\mathrm{J} \mathrm{kg}^{-1}$ & $\mathrm{a} / \mathrm{o}^{*}$ \\
\hline lfcp & LFCP & Pressure-level free convection & $\mathrm{Pa}$ & $\mathrm{a} / \mathrm{o}^{*}$ \\
\hline lfcz & LFCZ & Height-level free convection & $\mathrm{m}$ & $\mathrm{a} / \mathrm{o}^{*}$ \\
\hline li & LI & Lifted index & 1 & $\mathrm{a} / \mathrm{o}^{*}$ \\
\hline wsgs & WSGS & Near-surface wind speed of gust & $\mathrm{m} \mathrm{s}^{-1}$ & a \\
\hline usgs & USGS & Eastward near-surface wind speed of gust & $\mathrm{m} \mathrm{s}^{-1}$ & a \\
\hline vsgs & VSGS & Northward near-surface wind speed of gust & $\mathrm{m} \mathrm{s}^{-1}$ & a \\
\hline wsgspercen & WSGSPERCEN & Percentage of time steps in which a grid point got a wind gust & $\%$ & s \\
\hline totwsgspercen & TOTWSGSPERCEN & Percentage of time steps in which a grid point got a total wind gust & $\%$ & s \\
\hline wsz100 & WSZ100 & $100 \mathrm{~m}$ wind speed & $\mathrm{ms}^{-1}$ & a \\
\hline uz100 & UZ100 & Eastward $100 \mathrm{~m}$ wind speed & $\mathrm{ms}^{-1}$ & a \\
\hline vz100 & VZ100 & Northward $100 \mathrm{~m}$ wind speed & $\mathrm{m} \mathrm{s}^{-1}$ & a \\
\hline fog & FOG & Whether there is fog (1: yes [vis $<1 \mathrm{~km}$ ]; 0 : not $)$ & - & a \\
\hline fogvisblty & FOGVISBLTY & Visibility inside fog & $\mathrm{km}$ & a \\
\hline $\operatorname{tds}$ & TDS & Surface dew point temperature & $\mathrm{K}$ & a \\
\hline \multicolumn{5}{|c|}{ 3-D water budget } \\
\hline qvttend & QVTTEND & Inter-time-step water vapor tendency & $\mathrm{kg} \mathrm{kg}^{-1} \mathrm{~s}^{-1}$ & a \\
\hline $\mathrm{qc}_{\mathrm{t}}$ tend & QCTTEND & Inter-time-step cloud tendency & $\mathrm{kg} \mathrm{kg}^{-1} \mathrm{~s}^{-1}$ & a \\
\hline $\mathrm{qr}_{\mathrm{t}}$ tend & QRTTEND & Inter-time-step rain tendency & $\mathrm{kg} \mathrm{kg}^{-1} \mathrm{~s}^{-1}$ & a \\
\hline $\mathrm{qs}_{\mathrm{t}}$ tend & QSTTEND & Inter-time-step snow tendency & $\mathrm{kg} \mathrm{kg}^{-1} \mathrm{~s}^{-1}$ & a \\
\hline $\mathrm{qi}_{\mathrm{t}}$ tend & QITTEND & Inter-time-step ice tendency & $\mathrm{kg} \mathrm{kg}^{-1} \mathrm{~s}^{-1}$ & a \\
\hline $\mathrm{qh}_{\mathrm{t}}$ tend & QHTTEND & Inter-time-step hail tendency & $\mathrm{kg} \mathrm{kg}^{-1} \mathrm{~s}^{-1}$ & a \\
\hline $\mathrm{qg}_{\mathrm{t}}$ tend & QGTTEND & Inter-time-step graupel tendency & $\mathrm{kg} \mathrm{kg}^{-1} \mathrm{~s}^{-1}$ & a \\
\hline $\mathrm{qv}_{\mathrm{h}} \mathrm{adv}$ & QV_HADV & Instantaneous QV horizontal advection & $\mathrm{kg} \mathrm{kg}^{-1}$ & a \\
\hline $\mathrm{qc}_{\mathrm{h}} \mathrm{adv}$ & QC_HADV & Instantaneous QC horizontal advection & $\mathrm{kg} \mathrm{kg}^{-1}$ & $\mathrm{a}$ \\
\hline $\mathrm{qr}_{\mathrm{h}} \mathrm{adv}$ & QR_HADV & Instantaneous QR horizontal advection & $\mathrm{kg} \mathrm{kg}^{-1}$ & a \\
\hline $\mathrm{qs}_{\mathrm{h}} \mathrm{adv}$ & QS_HADV & Instantaneous QS horizontal advection & $\mathrm{kg} \mathrm{kg}^{-1}$ & a \\
\hline$q i_{h} a d v$ & QI_HADV & Instantaneous QI horizontal advection & $\mathrm{kg} \mathrm{kg}^{-1}$ & $\mathrm{a}$ \\
\hline $\mathrm{qh}_{\mathrm{h}} \mathrm{adv}$ & QH_HADV & Instantaneous $\mathrm{QH}$ horizontal advection & $\mathrm{kg} \mathrm{kg}^{-1}$ & a \\
\hline qghadv & QG_HADV & Instantaneous QG horizontal advection & $\mathrm{kg} \mathrm{kg}^{-1}$ & a \\
\hline $\mathrm{qv}_{z} \mathrm{adv}$ & QV_ZADV & Instantaneous QV vertical advection & $\mathrm{kg} \mathrm{kg}^{-1}$ & a \\
\hline $\mathrm{qc}_{z} \mathrm{adv}$ & QC_ZADV & Instantaneous QC vertical advection & $\mathrm{kg} \mathrm{kg}^{-1}$ & a \\
\hline $\mathrm{qr}_{z} \mathrm{adv}$ & QR_ZADV & Instantaneous QR vertical advection & $\mathrm{kg} \mathrm{kg}^{-1}$ & a \\
\hline $\mathrm{qs}_{z} \mathrm{adv}$ & QS_ZADV & Instantaneous QS vertical advection & $\mathrm{kg} \mathrm{kg}^{-1}$ & a \\
\hline$q i_{z} \mathrm{adv}$ & QI_ZADV & Instantaneous QI vertical advection & $\mathrm{kg} \mathrm{kg}^{-1}$ & a \\
\hline $\mathrm{qh}_{z} \mathrm{adv}$ & QH_ZADV & Instantaneous QH vertical advection & $\mathrm{kg} \mathrm{kg}^{-1}$ & a \\
\hline $\mathrm{qg}_{z} \mathrm{adv}$ & QG_ZADV & Instantaneous QG vertical advection & $\mathrm{kg} \mathrm{kg}^{-1}$ & a \\
\hline
\end{tabular}

* Depending on namelist parameter convxtrm_diag 0:o, 1:a. 
Author contributions. All authors contributed to revising the paper. At the same time, the authors carried out different tasks in the study.

LF contributed to the study by developing the code of the module, implementing it in the different versions of WRF, and performing some model simulations in order to test the module and obtain the necessary data for the different figures. He was in charge of the text of the paper, created all the figures, and obtained the different DOIs. JP contributed by testing the outcomes of the module in parallel simulations and provided some advice on the implementation of diagnostics such as potential evapotranspiration. TMG contributed by revising the implementation of the first versions of the module. TL contributed by making the different simulations needed to test the performance of the module. JM contributed by detecting some flaws in the module through independent simulations. GS revised the definition of the variables in the module by checking their agreement with the CF conventions. EK and SB made important contributions to the text of the paper and other details in the development of the code for the module.

Competing interests. The authors declare that they have no conflict of interest.

Acknowledgements. All the coders of WRF, LMDZ, and ORCHIDEE models are acknowledged for their hard work on developing and maintaining the models. Maria Antònia Jiménez from the Universitat de les Illes Balears is acknowledged for her explanations on certain PBL calculations. Daniel Argüeso from UIB and Victoria Galligani, Juan Ruiz, and Mariano Sebastián from CIMA are also acknowledged for their commentaries. Anna Sörensson and Elsa Borrell are also acknowledged for their assistance. Implementation tests were performed at the CIMA HPC resources "hydra" cluster supported by the High Performance Computing National System (SNCAD) of Argentina. Lluís Fita thanks the CIMA IT support staff for their work. Eleni Katragkou and Giannis Sofiadis acknowledge the technical support and provision of resources from the Scientific Computing Center of AUTH (https://it.auth.gr/el, last access: 18 March 2019) and the GRNET National HPC infrastructure (https://hpc.grnet.gr/, last access: 18 March 2019). Josipa Milovac gratefully acknowledges support from the German Science Foundation (DFG) through project FOR 1695 and the supercomputing center HLRS in Stuttgart, Germany, for granting the computing time necessary for the test simulations. Torge Lorenz acknowledges support from the Research Council of Norway and its basic institute support of the strategic project on climate services. The simulations were performed on resources provided by UNINETT Sigma2 - the National Infrastructure for High Performance Computing and Data Storage in Norway. Figures were produced with Python (except performance tests drawn with GNUplot), and Lluís Fita thanks the development team of Matplotlib with which he developed and made available a suite in Python for NetCDF management and plotting purposes called PyNCplot (available from http://www.xn-llusfb5va.cat/python/PyNCplot, last access: 18 March 2019). The authors are grateful for the commentaries of the topical editor (Jatin Kala), which remarkably improved the paper.
Review statement. This paper was edited by Jatin Kala and reviewed by two anonymous referees.

\section{References}

Barella-Ortiz, A., Polcher, J., Tuzet, A., and Laval, K.: Potential evaporation estimation through an unstressed surface-energy balance and its sensitivity to climate change, Hydrol. Earth Syst. Sci., 17, 4625-4639, https://doi.org/10.5194/hess-17-4625-2013, 2013.

Benjamin, S. G. and Miller, P. A.: An Alternative Sea Level Pressure Reduction and a Statistical Comparison of Geostrophic Wind Estimates with Observed Surface Winds, Mon. Weather Rev., 118, 2099-2116, https://doi.org/10.1175/15200493(1990)118<2099:AASLPR>2.0.CO;2, 1990.

Bergot, T., Terradellas, E., Cuxart, J., Mira, A., Liechti, O., Mueller, M., and Nielsen, N. W.: Intercomparison of Single-Column Numerical Models for the Prediction of Radiation Fog, J. Appl. Meteorol. Clim., 46, 504-521, https://doi.org/10.1175/JAM2475.1, 2007.

Brasseur, O.: Development and Application of a Physical Approach to Estimating Wind Gusts, Mon Weather Rev., 129, 5-25, https://doi.org/10.1175/15200493(2001)129<0005:DAAOAP>2.0.CO;2, 2001.

Businger, J. A., Wyngaard, J. C., Izumi, Y., and Bradley, E. F.: Flux-Profile Relationships in the Atmospheric Surface Layer, J. Atmos. Sci., 28, 181-189, https://doi.org/10.1175/15200469(1971)028<0181:FPRITA >2.0.CO;2, 1971.

Coppola, E., Sobolowski, S., Pichelli, E., Raffaele, F., Ahrens, B., Anders, I., Ban, N., Bastin, S., Belda, M., Belusic, D., CaldasAlvarez, A., Cardoso, R. M., Davolio, S., Dobler, A., Fernández, J., Fita, L., Fumiere, Q., Giorgi, F., Goergen, K., Guettler, I., Halenka, T., Heinzeller, D., Hodnebrog, O., Jacob, D., Kartsios, S., Katragkou, E., Kendon, E., Khodayar, S., Kunstmann, H., Knist, S., Lavín, A., Lind, P., Lorenz, T., Maraun, D., Marelle, L., van Meijgaard, E., Milovac, J., Myhre, G., H.-J.Panitz, Piazza, M., Raffa, M., Raub, T., Rockel, B., Schär, C., Sieck, K., Soares, P. M. M., Somot, S., Srnec, L., Stocchi, P., Tölle, M., Truhetz, H., Vautard, R., de Vries, H., and Warrach-Sagi, K.: A first-of-itskind multi-model convection permitting ensemble for investigating convective phenomena over Europe and the Mediterranean, Clim. Dynam., e-print first, https://doi.org/10.1007/s00382-0184521-8, 2018.

de Rosnay, P., Polcher, J., Bruen, M., and Laval, K.: Impact of a physically based soil water flow and soilplant interaction representation for modeling large-scale land surface processes, J. Geophys. Res.-Atmos., 107, 4118, https://doi.org/10.1029/2001JD000634, 2002.

Domínguez, M., Romera, R., Sánchez, E., Fita, L., Fernández, J., Jiménez-Guerrero, P., Montávez, J. P., Cabos, W. D., Liguori, G., and Gaertner, M. A.: Present climate precipitation and temperature extremes over Spain from a set of high resolution RCMs, Clim. Res., 58, 149-164, https://doi.org/10.3354/cr01186, 2013.

Evans, J. P., Ji, F., Lee, C., Smith, P., Argüeso, D., and Fita, L.: Design of a regional climate modelling projection ensemble experiment - NARCliM, Geosci. Model Dev., 7, 621-629, https://doi.org/10.5194/gmd-7-621-2014, 2014. 
Fita, L. and Flaounas, E.: Medicanes as subtropical cyclones: the December 2005 case from the perspective of surface pressure tendency diagnostics and atmospheric water budget, Q. J. Roy. Meteor. Soc., 144, 1028-1044, https://doi.org/10.1002/qj.3273, qJ-17-0198.R2, 2018.

Fita, L., Fernández, J., and García-Díez, M.: CLWRF: WRF modifications for regional climate simulation under future scenarios, Proceedings of 11th WRF Users' Workshop, 22-24 June 2010, Boulder, Colorado, USA, 2010.

Fita, L., Polcher, J., and Giannaros, T. M.: WRFCORDEX module version 1.3 for WRFV3.7.1, https://doi.org/10.5281/zenodo.1469639, 2018a.

Fita, L., Polcher, J., and Giannaros, T. M.: WRFCORDEX module version 1.3 for WRFV3.8.1, https://doi.org/10.5281/zenodo.1469645, 2018b.

Fita, L., Polcher, J., and Giannaros, T. M.: WRFCORDEX module version 1.3 for WRFV3.9.1.1, https://doi.org/10.5281/zenodo.1469647, 2018c.

Fita, L., Polcher, J., and Giannaros, T. M.: WRFCORDEX module version 1.3 for WRFV4.0, https://doi.org/10.5281/zenodo.1469651, 2018d.

Fu, C., Wang, S., Xiong, Z., Gutowski, W. J., Lee, D. K., McGregor, J. L., Sato, Y., Kato, H., Kim, J. W., and Suh, M. S.: Regional climate model intercomparison project for Asia, B. Am. Meteorol. Soc., 86, 257-266, 2005.

García-Díez, M., Fernández, J., Fita, L., and Yagüe, C.: Seasonal dependence of WRF model biases and sensitivity to PBL schemes over Europe, Q. J. Roy. Meteor. Soc., 139, 501-514, https://doi.org/10.1002/qj.1976, 2013.

Garratt, J.: The Atmospheric Boundary Layer, Cambridge Univ. Press, Cambridge, UK, 1992.

Geleyn, J. F. and Hollingsworth, A.: An economical analytical method for the computation of the interaction between scattering and line absorption of radiation, Contrib. Atmos. Phys, 52, $1-16,1979$.

Giorgi, F. and Gutowski, W. J.: Regional Dynamical Downscaling and the CORDEX Initiative, Annu. Rev. Env. Resour., 40, 467-490, https://doi.org/10.1146/annurev-environ-102014021217, 2015.

Giorgi, F. and Mearns, L. O.: Approaches to the simulation of regional climate change: A review, Rev. Geophys., 29, 191-216, https://doi.org/10.1029/90RG02636, 1991.

Giorgi, F., Jones, C., and Asrar, G.: Addressing climate information needs at the regional level: the CORDEX framework, WMO Buletin, 58, 175-183, 2009.

Gultepe, I. and Milbrandt, J. A.: Probabilistic Parameterizations of Visibility Using Observations of Rain Precipitation Rate, Relative Humidity, and Visibility, J. Appl. Meteorol. Clim., 49, 3646, https://doi.org/10.1175/2009JAMC1927.1, 2010.

Hourdin, F., Musat, I., Bony, S., Braconnot, P., Codron, F., Dufresne, J.-L., Fairhead, L., Filiberti, M.-A., Friedlingstein, P., Grandpeix, J.-Y., Krinner, G., LeVan, P., Li, Z.-X., and Lott, F.: The LMDZ4 general circulation model: climate performance and sensitivity to parametrized physics with emphasis on tropical convection, Clim. Dynam., 27, 787-813, https://doi.org/10.1007/s00382-006-0158-0, 2006.

Huang, H.-L., Yang, M.-J., and Sui, C.-H.: Water Budget and Precipitation Efficiency of Typhoon Morakot (2009), J. Atmos. Sci., 71, 112-129, https://doi.org/10.1175/JAS-D-13-053.1, 2014.
Jaeger, E. B. and Seneviratne, S. I.: Impact of soil moistureatmosphere coupling on European climate extremes and trends in a regional climate model, Clim. Dynam., 36, 1919-1939, https://doi.org/10.1007/s00382-010-0780-8, 2011.

Jourdier, B.: Ressource éolienne en France métropolitaine: méthodes d'evaluation du potentiel, variabilité et tendances, Climatologie: École Doctorale Polytechnique, 2015. Français, Palaisseau, France, 1-229, 2015.

Katragkou, E., García-Díez, M., Vautard, R., Sobolowski, S., Zanis, P., Alexandri, G., Cardoso, R. M., Colette, A., Fernandez, J., Gobiet, A., Goergen, K., Karacostas, T., Knist, S., Mayer, S., Soares, P. M. M., Pytharoulis, I., Tegoulias, I., Tsikerdekis, A., and Jacob, D.: Regional climate hindcast simulations within EURO-CORDEX: evaluation of a WRF multi-physics ensemble, Geosci. Model Dev., 8, 603-618, https://doi.org/10.5194/gmd-8603-2015, 2015.

Knist, S., Goergen, K., Buonomo, E., Christensen, O. B., Colette, A., Cardoso, R. M., Fealy, R., Fernández, J., García-Díez, M., Jacob, D., Kartsios, S., Katragkou, E., Keuler, K., Mayer, S., Meijgaard, E., Nikulin, G., Soares, P. M. M., Sobolowski, S., Szepszo, G., Teichmann, C., Vautard, R., Warrach-Sagi, K., Wulfmeyer, V., and Simmer, C.: Land-atmosphere coupling in EURO-CORDEX evaluation experiments, J. Geophys. Res.Atmos., 122, 79-103, https://doi.org/10.1002/2016JD025476, 2014.

Kotlarski, S., Keuler, K., Christensen, O. B., Colette, A., Déqué, M., Gobiet, A., Goergen, K., Jacob, D., Lüthi, D., van Meijgaard, E., Nikulin, G., Schär, C., Teichmann, C., Vautard, R., Warrach-Sagi, K., and Wulfmeyer, V.: Regional climate modeling on European scales: a joint standard evaluation of the EUROCORDEX RCM ensemble, Geosci. Model Dev., 7, 1297-1333, https://doi.org/10.5194/gmd-7-1297-2014, 2014.

Kunkel, B. A.: Parameterization of Droplet Terminal Velocity and Extinction Coefficient in Fog Models, J. Clim. Appl. Meteorol., 23, 34-41, https://doi.org/10.1175/15200450(1984)023<0034:PODTVA>2.0.CO;2, 1984.

Lawrence, D. M., Oleson, K. W., Flanner, M. G., Thornton, P. E., Swenson, S. C., Lawrence, P. J., Zeng, X., Yang, Z.-L., Levis, S., Sakaguchi, K., Bonan, G. B., and Slater, A. G.: Parameterization improvements and functional and structural advances in Version 4 of the Community Land Model, J. Adv. Model. Earth Syst., 3, M03001, https://doi.org/10.1029/2011MS00045, 2011.

Manabe, S.: Climate and the ocean circulation, 1. the atmospheric circulation and the hydrology of the earth's surface, Mon. Weather Rev., 97, 739-774, https://doi.org/10.1175/15200493(1969)097<0739:CATOC>2.3.CO;2, 1969.

Mearns, L., Gutowski, W. J., Jones, R., Leung, R., McGinnis, S., Nunes, A., and Qian, Y.: A regional climate change assessment program for North America, EOS Transactions AGU, 90, 311312, https://doi.org/10.1029/2009EO360002, 2009.

Milly, P. C. D.: Potential Evaporation and Soil Moisture in General Circulation Models, J. Climate, 5, 209-226, https://doi.org/10.1175/15200442(1992)005<0209:PEASMI>2.0.CO;2, 1992.

Nakanishi, M. and Niino, H.: An Improved Mellor-Yamada Level3 Model: Its Numerical Stability and Application to a Regional Prediction of Advection Fog, Bound.-Lay. Meteorol., 119, 397407, https://doi.org/10.1007/s10546-005-9030-8, 2006. 
Nielsen-Gammon, J. W., Powell, C. L., Mahoney, M. J., Angevine, W. M., Senff, C., White, A., Berkowitz, C., Doran, C., and Knupp, K.: Multisensor Estimation of Mixing Heights over a Coastal City, J. Appl. Meteorol. Clim., 47, 27-43, https://doi.org/10.1175/2007JAMC1503.1, 2008.

Nikulin, G., Jones, C., Giorgi, F., Asrar, G., Büchner, M., CerezoMota, R., Christensen, O. B., Déqué, M., Fernández, J., Hänsler, A., van Meijgaard, E., Samuelsson, P., Sylla, M. B., and Sushama, L.: Precipitation Climatology in an Ensemble of CORDEX-Africa Regional Climate Simulations, J. Climate, 25, 6057-6078, https://doi.org/10.1175/JCLI-D-11-00375.12012.

Oleson, K. W., Lawrence, D. M., B, G., Flanner, M. G., Kluzek, E., J, P., Levis, S., Swenson, S. C., Thornton, E., Feddema, J., Heald, C. L., Lamarque, J.-F., Niu, G.-Y., Qian, T., Running, S., Sakaguchi, K., Yang, L., Zeng, X., Zeng, X., and Decker, M.: Technical Description of version 4.0 of the Community Land Model (CLM), NCAR Technical Note NCAR/TN-478+STR, https://doi.org/10.5065/D6FB50WZ, 2010.

Price, C. and Rind, D.: A simple lightning parameterization for calculating global lightning distributions, J. Geophys. Res.-Atmos., 97, 9919-9933, https://doi.org/10.1029/92JD00719, 1992.

Ruti, P. M., Somot, S., Giorgi, F., Dubois, C., Flaounas, E., Obermann, A., Dell'Aquila, A., Pisacane, G., Harzallah, A., Lombardi, E., Ahrens, B., Akhtar, N., Alias, A., Arsouze, T., Aznar, R., Bastin, S., Bartholy, J., Béranger, K., Beuvier, J., BouffiesCloché, S., Brauch, J., Cabos, W., Calmanti, S., Calvet, J.-C., Carillo, A., Conte, D., Coppola, E., Djurdjevic, V., Drobinski, P., Elizalde-Arellano, A., Gaertner, M., Galàn, P., Gallardo, C., Gualdi, S., Goncalves, M., Jorba, O., Jordà, G., L'Heveder, B., Lebeaupin-Brossier, C., Li, L., Liguori, G., Lionello, P., Maciàs, D., Nabat, P., Önol, B., Raikovic, B., Ramage, K., Sevault, F., Sannino, G., Struglia, M. V., Sanna, A., Torma, C., and Vervatis, V.: Med-CORDEX Initiative for Mediterranean Climate Studies, B. Am. Meteorol. Soc., 97, 1187-1208, https://doi.org/10.1175/BAMS-D-14-00176.1, 2016.

Skamarock, W. C., Klemp, J. B., Dudhia, J., Gill, D. O., Duda, D. M. B. M. G., Huang, X.-Y., Wang, W., and Powers, J. G.: A Description of the Advanced Research WRF Version 3, NCAR TECHNICAL NOTE, 475, NCAR/TN475+STR, Boulder, Colorado, USA, 2008.
Smirnova, T. G., Benjamin, S. G., and Brown, J. M.: Case study verification of RUC/MAPS fog and visibility forecasts, Preprints, 9 th Conference on Aviation, Range, and Aerospace Meteorlogy, AMS, Orlando, FL, USA, 11-16 September 2000, 2.3, 31-36, 2000 .

Stackpole, J. and Cooley, D. S.: Revised method of $1000 \mathrm{mb}$ height computations in the PE model, Technical Procedures Bulletin. U.S. Dept. of Commerce, National Oceanic and Atmospheric Administration, National Weather Service, NOAA Library, Silver Spring, MD, USA, 57, 6, 1970.

Vautard, R., Gobiet, A., Jacob, D., Belda, M., Colette, A., Déqué, M., Fernández, J., García-Díez, M., Goergen, K., Güttler, I., Halenka, T., Karacostas, T., Katragkou, E., Keuler, K., Kotlarski, S., Mayer, S., van Meijgaard, E., Nikulin, G., Patarčić, M., Scinocca, J., Sobolowski, S., Suklitsch, M., Teichmann, C., Warrach-Sagi, K., Wulfmeyer, V., and Yiou, P.: The simulation of European heat waves from an ensemble of regional climate models within the EURO-CORDEX project, Clim. Dynam., 41, 2555-2575, https://doi.org/10.1007/s00382-013-1714-z, 2013.

WMO: Manual on the Global Observing System, WMO, Geneva, Switzerland, 544, 2010a.

WMO: Guide to Meteorological Instruments and Methods of Observation, Weather-Climate-Weather, Geneva, Switzerland, 1176, 2010b.

Wong, J., Barth, M. C., and Noone, D.: Evaluating a lightning parameterization based on cloud-top height for mesoscale numerical model simulations, Geosci. Model Dev., 6, 429-443, https://doi.org/10.5194/gmd-6-429-2013, 2013.

Yang, M. J., Braun, S. A., and Chen, D.-S.: Water Budget of Typhoon Nari (2001), Mon. Wather Rev., 139, 3809-3828, https://doi.org/10.1175/MWR-D-10-05090.1, 2011.

Yesad, K.: FULL-POS in the Cycle 41T1 of ARPEGE/IFS, Tech. Rep., Meteo-France, 45, available at: https://www.umr-cnrm. fr/gmapdoc/IMG/pdf/ykfpos43.pdf (last access: last access: 18 March 2019), 2015. 